\title{
Holistic Indoor Environmental Quality \& Energy Simulation: Generative Design Assessment Methodology for Heritage Building Retrofits
}

\author{
by \\ Adrian J. Soble, B.Eng Architectural Conservation and Sustainability \\ Carleton University
}

\author{
A thesis submitted to the \\ Faculty of Graduate and Postdoctoral Affairs \\ in partial fulfillment of the requirements for the degree of
}

Master of Applied Science in Civil Engineering

Department of Civil and Environmental Engineering

Carleton University

Ottawa, Ontario

April 2020

CCopyright

Adrian J. Soble, 2020 
The undersigned hereby recommends to the

Faculty of Graduate and Postdoctoral Affairs acceptance of the thesis

\title{
Holistic Indoor Environmental Quality \& Energy Simulation: Generative Design Assessment Methodology for Heritage Building Retrofits
}

\section{Submitted by Adrian J. Soble, B.Eng Architectural Conservation and Sustainability Carleton University}

in partial fulfillment of the requirements for the degree of

\section{Master of Applied Science in Civil Engineering}

Dr Liam O’Brien, Thesis Supervisor

\author{
Dr Yasser Hassan, Chair \\ Department of Civil and Environmental Engineering \\ Carleton University \\ Ottawa, Ontario \\ April 2020




\section{Abstract}

Heritage conservation, energy conservation, and indoor environmental quality (IEQ) should all be taken into consideration in the decision-making process when developing an intervention strategy for a historical building. Simulation can be used to identify and inform stakeholders of design intervention options and their impact to energy consumption and the indoor environment. To compare the benefits of specific design options, simulation results must be collected and managed in a way that allows project stakeholders to navigate and understand.

This thesis describes how performance metrics for daylight, acoustics, air quality, thermal comfort and energy can be targeted and simulated to identify appropriate occupantcentric interventions. Design options are generated and presented in a way that can be explored, negotiated and filtered in an interactive way.

The framework proposes a series of steps, with supporting theory that is made possible through a collection of recommended tools. The methodology that supports the framework is founded in fundamentals in energy transfer, mass transfer and other numerical relationships that estimate real world phenomena. The framework is applied to two case studies to contextualize how the workflow applies in different contexts. The first case study is a historic courtyard scenario to be rehabilitated into an indoor atrium. The second case study is a single occupant office to be updated with new building systems. In both case studies, holistically optimal retrofit recommendations are made and compromise between competing design objectives is informed by the framework results. This thesis is structured to be used as a guideline for simulation practitioners to better support heritage 
conservation projects through the clear identification of metrics, ideal ranges goals and simulation tools available. The case studies demonstrate how the simulation models are recommended to be set up and how the data from the optimization run is presented to incorporate the values of generative design.

The results from this thesis indicate that wholistic simulation can be made possible when integrating and combining several different simulation engines. By applying interdisciplinary theory within a flexible coding interface, it is possible to model targeted design performance metrics and the impact of parameter changes. It is possible to simulate energy, light, air quality, thermal comfort and acoustics together and generate a dataset with a wide range of design options. The generative design aspect is made possible by both exploring the solution space with an optimization algorithm and visualizing the results in a way that can be manipulated to identify areas of compromise. 


\section{Acknowledgments}

I first would like to acknowledge and express my thanks for the mentorship of my supervisor Dr. Liam O’Brien, who supported my interests and allowed me the flexibility to explore such a unique and challenging intersection of study to that I feel passionate about. I hope to support and assist future projects with him moving forward; to design buildings better and invoke interest in sustainable design for future students.

I would like to thank Dr. Mario Santana Quintero, Laurie Smith and the NSERC CREATE Heritage Engineering Program for creating a platform that promotes the research fields of Building Digitalization, Simulation and Rehabilitation. The CREATE events promote the sharing of knowledge, interests and creativity in a way that ignites passion for conservation students. The program will be missed if not replaced and has been deeply appreciated.

I would like to thank my friends and professors in the Building Performance Research Center for educating, challenging, inspiring and supporting me through a meaningful period of growth that would have otherwise not been possible anywhere else. I want to especially thank my close friend Larissa Ide for convincing me to pursue a masters and for being the most reliable peer one could ask for in the small world of simulation for heritage.

I want to thank Martin Sing, Daniel Knapp and Brett Kerrigan for taking me on at a professional level at WSP and supporting me, my ideas and my creativity during my internship. Finally, thank you to my family for helping me get to this point; where I could pursue a higher education in a topic that aims to help the planet and people. 


\section{Table of Contents}

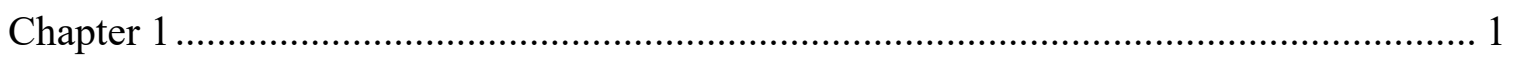

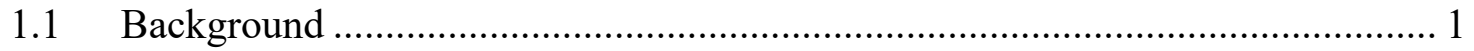

1.1.1 Introduction to Generative Design Theory ………….................................... 3

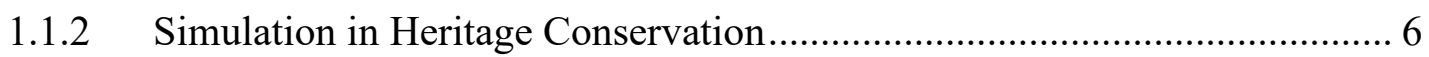

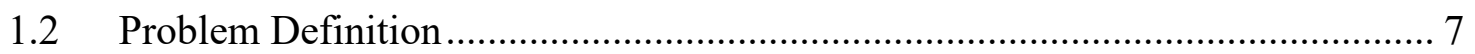

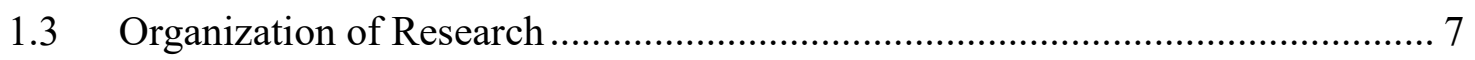

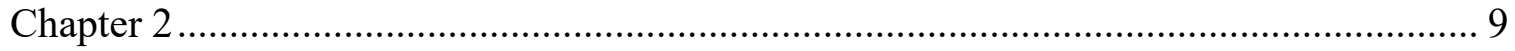

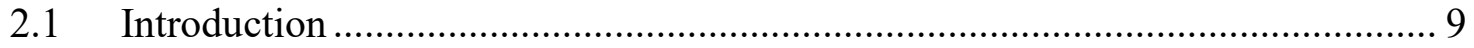

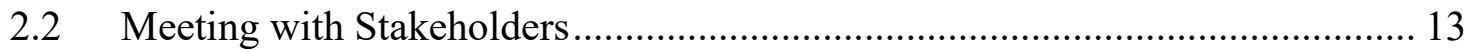

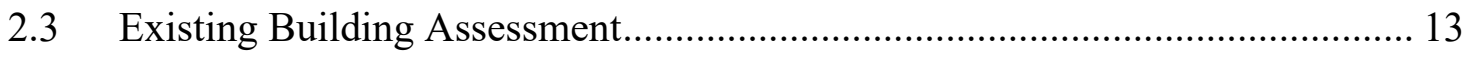

2.4 Understanding Space Properties and Heritage Sensitivity ................................. 15

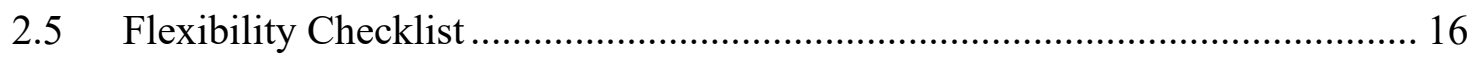

2.6 Metrics and Objective Ranges..................................................................... 17

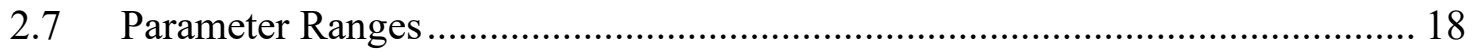

2.8 Architectural Model and Geometric Simplification........................................... 19

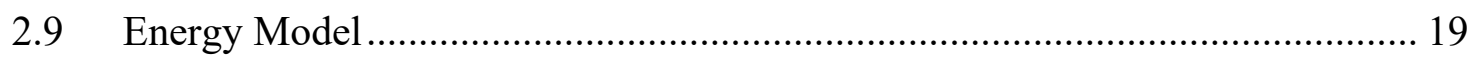

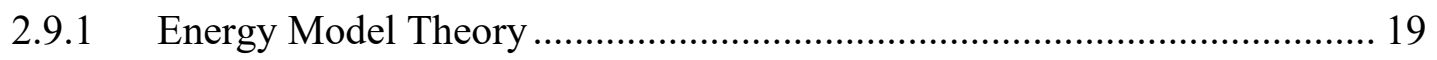

2.9.2 Applying Energy Model Theory in Grasshopper....................................... 22

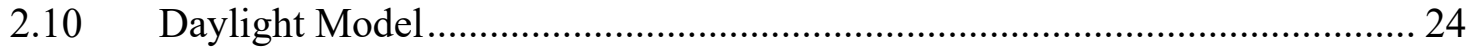

2.10.1 Daylight Model Theory ................................................................... 24

2.10.2 Applying Daylight Model Theory in Grasshopper ..................................... 28

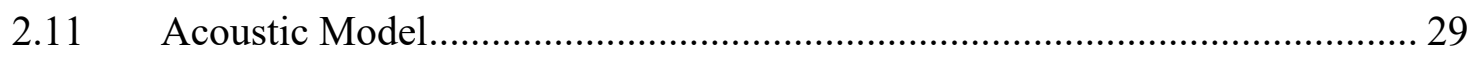

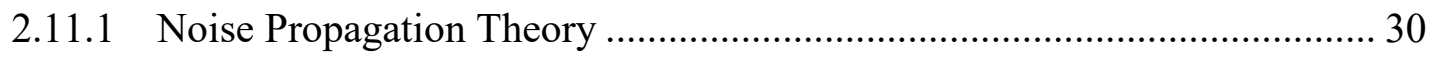

2.11.2 Ambient Zonal Noise due to Ventilation Theory ........................................ 32

2.11.3 Sound Attenuation from Infiltration Theory ............................................... 32

2.11.4 Sound Transmission Loss Theory .............................................................. 33

2.11.5 Applying Acoustic Theory in Grasshopper …………………………….... 35

2.12 Thermal Comfort Model.......................................................................... 35

2.12.1 Thermal Comfort Theory Fundamentals ................................................... 35 


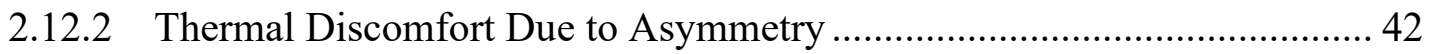

2.12.3 Thermal Discomfort Due to Solar Gains .............................................. 42

2.12.4 Applying Thermal Comfort Theory in Grasshopper ................................. 43

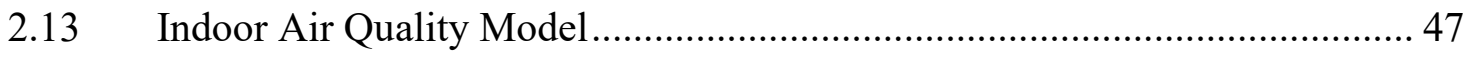

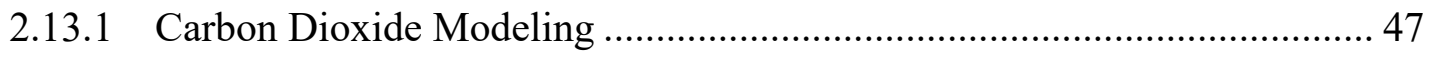

2.13.2 Applying Air Quality Theory in Grasshopper ........................................ 49

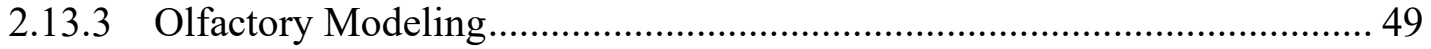

2.13.4 Applying Indoor Air Quality Theory in Grasshopper............................. 51

2.14 Optimization or Parametric Analysis ................................................. 51

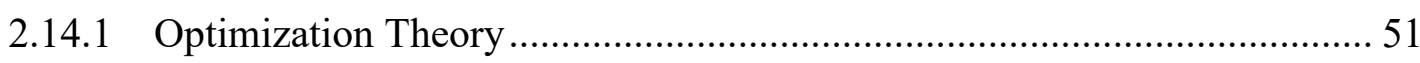

2.14.2 Applying Optimization Theory in Grasshopper ....................................... 53

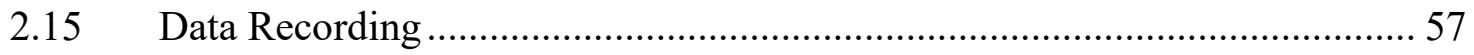

2.16 Interactive Plots and Data Trend Visualization........................................ 57

2.16.1 Parallel Coordinate Plot ................................................................................. 58

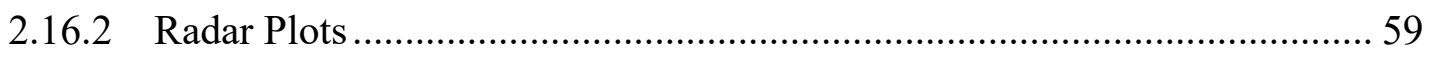

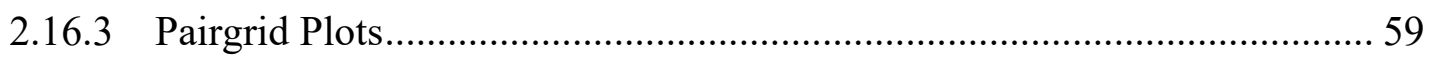

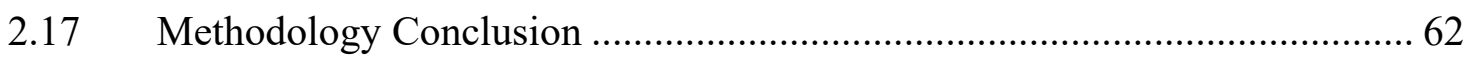

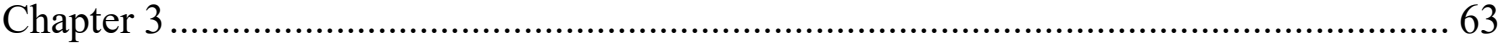

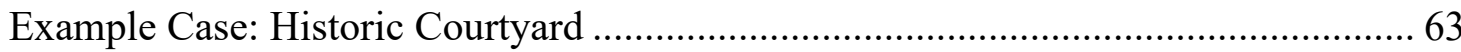

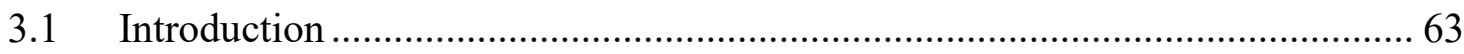

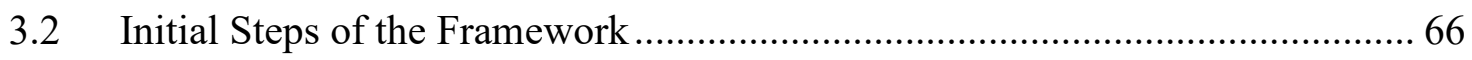

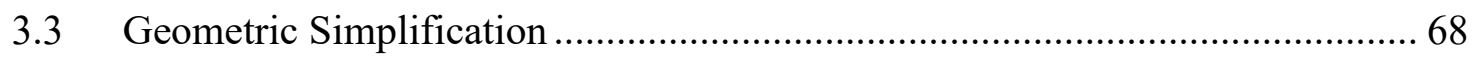

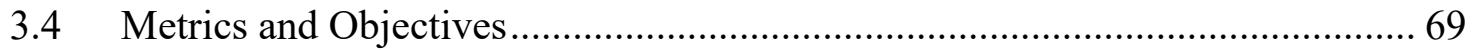

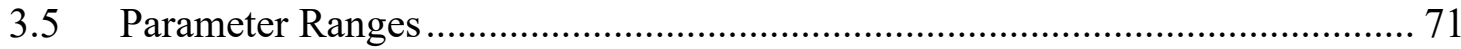

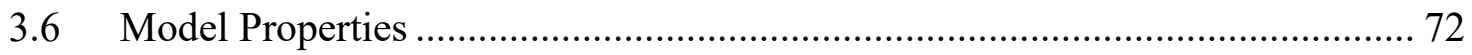

3.7 Interactive Plot and Data Trend Visualization ............................................ 72

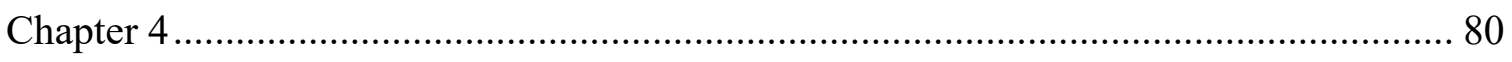

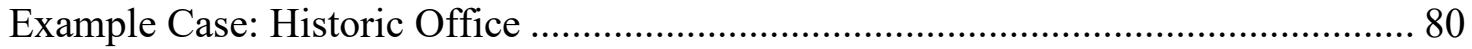

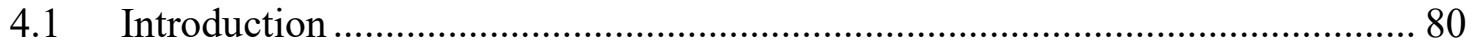

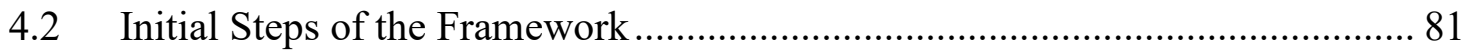

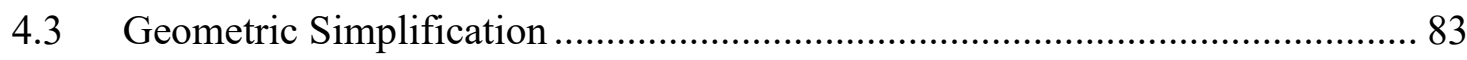

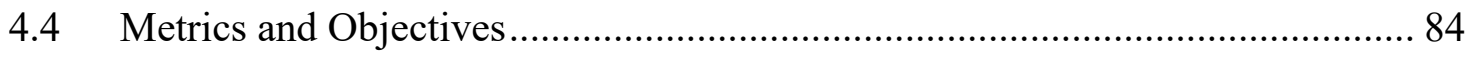




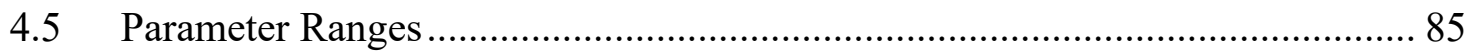

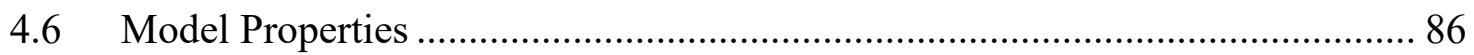

4.7 Interactive Plot and Data Trend Visualization ............................................. 87

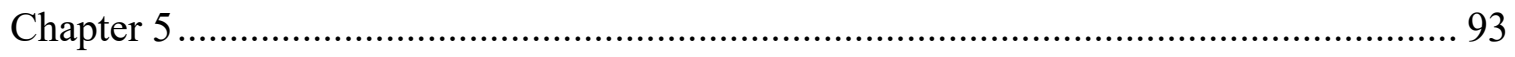

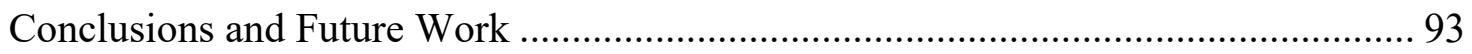

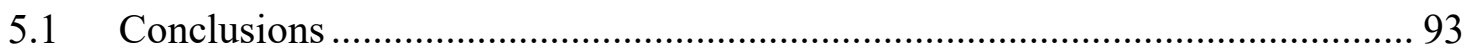

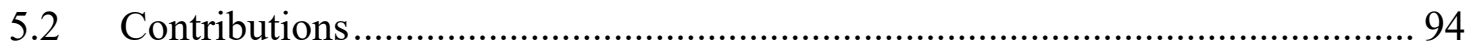

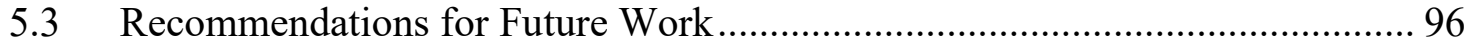

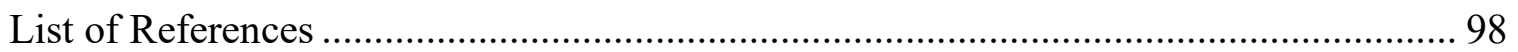

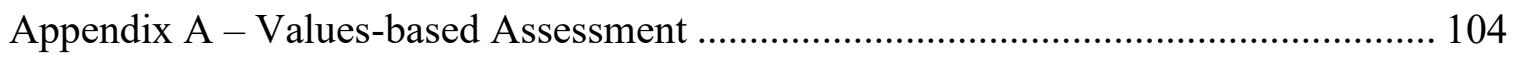

Appendix B - Flexibility Checklist Printout .............................................................. 106

Appendix C - Table of Metrics and Target Ranges ................................................. 108

Appendix D - Case Study Model Properties ................................................................ 109

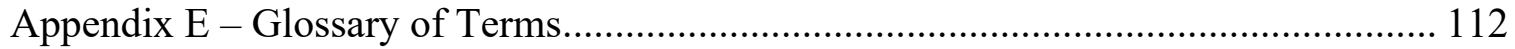




\section{List of Tables}

Table 2.1 - Relevant condition site properties................................................................ 14

Table 2.2 - Example flexibility checklist. ................................................................. 16

Table 2.3 - Typical ranges for parameters frequently relevant in analysis. .................... 18

Table 2.4 - Absorption coefficients for relevant surface materials................................... 31

Table 2.5 - Typical STC ratings of window class ........................................................ 35

Table 2.6 - Allowable radiant temperature asymmetry from ASHRAE standard 55. .... 42

Table 2.7 - Thermal comfort metrics generated by current iteration of tool.................... 46

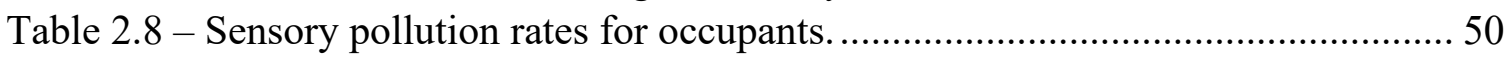

Table 3.1 - Values-based assessment for courtyard case study........................................ 67

Table 3.2 - Metrics recorded for historic courtyard case study....................................... 70

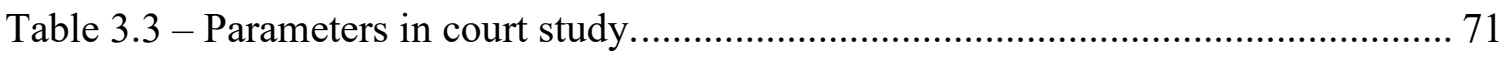

Table 3.4 - Initial analysis of court case........................................................................ 74

Table 3.5 - Final design recommendations for courtyard case study .............................. 77

Table 4.1 - Values-based assessment for office case study............................................. 82

Table 4.2 - Metrics recorded for historic office case study............................................ 85

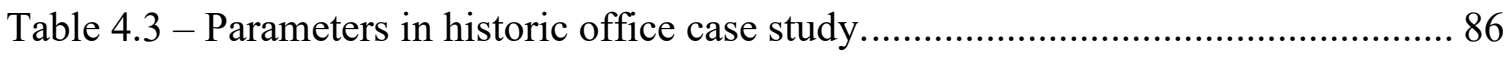

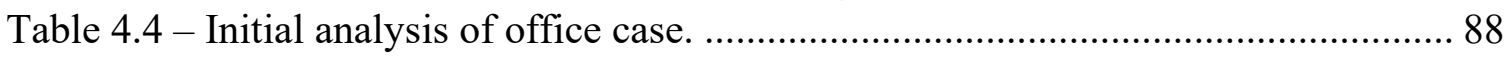

Table 4.5 - Intervention recommendations for office case study.................................. 91 


\section{List of Figures}

Figure 1.1 - Components of a generative design workflow. ............................................ 4

Figure 2.1 - Proposed framework for wholistic building performance simulation.......... 11

Figure 2.2 - Types of factors impacting an energy model. ............................................ 20

Figure 2.3 - Typical Ladybug occupant mannequin used for thermal comfort analysis.. 44

Figure 2.4 - Spectrum of complexity for parametric analysis in generative design......... 52

Figure 2.5 - Opossum interface and typical recommended settings. ............................... 53

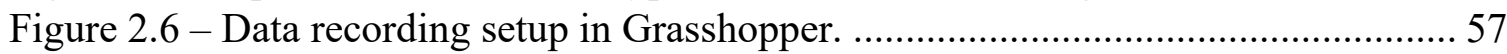

Figure 2.7 - Example parallel coordinate plot displaying optimization data. .................. 58

Figure 2.8 - Example parallel coordinate plot with ranges selected. ............................... 58

Figure 2.9 - Radar plots of three different design options. ............................................ 59

Figure 2.10 - Example pairgrid from a combined energy and light simulation............... 60

Figure 3.1 - Example historic courtyard with daylight access. .............................................. 63

Figure 3.2 - Early design option examples for the representative courtyard. …….......... 65

Figure 3.3 - Real world heritage courtyard. Palacio Nacional, Mexico City, Mexico..... 66

Figure 3.4 - All courtyard intervention design options.................................................. 73

Figure 3.5 - Initial analysis of court case with optimal performing option clusters. ....... 76

Figure 3.6 - Recommended lid geometry.................................................................. 78

Figure 3.7 - Design options of a courtyard with high infiltration and low insulation...... 79

Figure 4.1 - Historic single occupant office geometry................................................. 80

Figure 4.2 - Geometry models used for the historic office study..................................... 84

Figure 4.3 - All office case study design options........................................................ 88

Figure 4.4 - Historic office design options cluster in ideal ranges................................ 90

Figure 4.5 - Historic office intervention alternative design recommendations................ 92 


\title{
Table of Symbols
}

Symbol
$A_{D}$
$A_{P}$
$C_{i}$
$C_{o}$
$c_{p, b}$
$C$
$E$
$F_{p-N}$
$f(\boldsymbol{x})_{\text {Air }}$
$f(\boldsymbol{x})_{\text {Energy }}$
$f(\boldsymbol{x})_{\text {Light }}$
$f(\boldsymbol{x})_{\text {Thermal }}$
$f_{\text {bes }}$
$f_{\text {cl }}$
$f_{\text {eff }}$
$f_{\text {svo }}$
$h_{c}$
$h_{r}$
$h_{\text {total }}$
$h$
$I_{T}$
$I_{\text {TH }}$
$I_{\text {diff }}$
$I_{\text {dir }}$
$I_{i}$
$I_{\delta}$
$I_{\rho}$
$I H O T$
$l$
$\mathrm{~K}$
MET
$M$
$m$
$n$
Olf
$P_{\text {outside treshold }}$
$P_{n q u a l i t y}$

\author{
Meaning \\ Dubois surface area \\ Projected area of occupant's body \\ The indoor $\mathrm{CO}_{2}$ concentration \\ The outdoor $\mathrm{CO}_{2}$ concentration \\ Specific heat capacity of a body \\ Convective heat loss \\ Evaporative heat loss
}

Angle factor between a person and surface $\mathrm{N}$

PPD due to $\mathrm{CO}_{2}$ ans PPD due to olfs

EUI

Percent of total analysis hours outside the comfort thresholds

Percent of total analysis hours outside of comfort thresholds

Fraction of body exposed to sun

Clothing area factor

Fraction of body exposed to sun

Fraction of sky vault exposed to body

Combined convective and radiative heat transfer coefficients

Radiative heat transfer coefficient

Total analysis hours

Analysis hour

Outgoing sound

Total horizontal solar intensity

Diffuse solar intensity

Direct solar beam intensity

Incoming sound

Absorbed sound

Reflected sound

Investigation hours outside threshold

Height

Any $\mathrm{CO}_{2}$ removing process within the zone

Occupant metabolic rate

Rate of metabolic heat production

Mass

Number of analysis points

Olfactory unit

Number of points outside comfort thresholds at every analysis hour

The number of points that are meeting temporal quality requirements 


\begin{tabular}{|c|c|}
\hline$P_{n \text { treshold }}$ & The total analysis hours meeting threshold requirements at point $\mathrm{n}$ \\
\hline$p_{a}$ & The water vapour partial pressure in indoor air \\
\hline$p_{s}$ & $\begin{array}{l}\text { Saturated water vapour pressure at the humid operative } \\
\text { temperature, kpa }\end{array}$ \\
\hline$P$ & Fraction of outdoor air \\
\hline$q_{\text {res }}$ & Total rate of heat loss from respiration \\
\hline$q_{s k}$ & Total rate of heat loss from skin \\
\hline $\mathrm{q}$ & $\mathrm{L} / \mathrm{s}$ of fresh air per olf \\
\hline$Q$ & Outdoor ventilation rate \\
\hline$R_{c l}$ & Thermal clothing resistance \\
\hline$R_{\text {floor }}$ & Floor reflectivity \\
\hline$R$ & Radiative heat loss \\
\hline$S T L_{\text {comp }}$ & Sound transmission loss of a wall construction \\
\hline$S T L_{\text {surface }}$ & Sound transmission loss of a surface \\
\hline$S_{\text {core }}$ & Rate of heat storage in the core compartment of an occupant \\
\hline$S_{\text {skin }}$ & Rate of heat storage in the skin compartment of an occupant \\
\hline $\mathrm{S}$ & Surface area \\
\hline $\mathrm{S}_{\mathrm{CO}_{2}}$ & $\mathrm{CO}_{2}$ generation rate \\
\hline $\bar{t}_{r}$ & Mean radiant temperature \\
\hline$T_{\text {sol }}$ & Glazing solar transmittance \\
\hline$t_{0}$ & Operative temperature \\
\hline$t_{N}$ & Temperature of surface $\mathrm{N}$ \\
\hline$t_{a}$ & Air temperature \\
\hline$t_{\text {core }}$ & Temperature of core compartment \\
\hline$t_{\text {skin }}$ & Temperature of skin compartment \\
\hline $\mathrm{VN}$ & Ventilation noise \\
\hline$V$ & The space volume \\
\hline $\mathrm{W}$ & $\begin{array}{l}\text { weight of the masonry assembly including all materials in } \\
\text { assembly }\end{array}$ \\
\hline$W$ & Rate of mechanical work accomplished \\
\hline$x^{*}$ & Optimal value within a feasible solution space \\
\hline$x$ & Design variable or parameter vector \\
\hline$\alpha_{L W}$ & Longwave radiation absorptivity \\
\hline$\alpha_{S W}$ & Shortwave radiation absorptivity \\
\hline$\alpha_{s k}$ & Fraction of body mass concentrated in the skin compartment \\
\hline$\Delta L_{p}$ & Sound attenuation \\
\hline$\tau_{\text {surface }}$ & Transmissivity of a surface \\
\hline$\theta$ & Time \\
\hline$\phi$ & Radial basis function of $\mathbb{R}+\rightarrow \mathbb{R}, \lambda_{1}, \ldots, \lambda_{k} \in \mathbb{R}$ \\
\hline$\Phi$ & Radial basis function vectorized representation \\
\hline
\end{tabular}




\section{Table of Abbreviations}

$\begin{array}{ll}\text { Abbreviation in text } & \text { Explanation } \\ \text { ACH } & \text { Air changes per hour } \\ \text { ASE } & \text { Annual sunlight exposure } \\ \text { ASHRAE } & \text { American Society of Heating, Refrigerating } \\ & \text { and Air-Conditioning Engineers } \\ \text { BIM } & \text { Building information modeling } \\ \text { cDA } & \text { Continuous daylight autonomy } \\ \text { CDE } & \text { Character defining elements } \\ \text { CFD } & \text { Computational fluid dynamics } \\ \text { CIE } & \text { Commission Internationale de l'Eclairage } \\ \text { CLO } & \text { Clothing level of an occupant } \\ \text { DGP } & \text { Daylight glare probability } \\ \text { DOAS } & \text { Dedicated outdoor air system } \\ \text { ERF } & \text { Effective radiant field } \\ \text { HVAC } & \text { Heating ventilation air conditioning } \\ \text { IDF } & \text { Intermediate data format } \\ \text { IEQ } & \text { Indoor environmental quality } \\ \text { LEED } & \text { Leadership in Energy and Environmental } \\ & \text { Design certification program } \\ \text { MET } & \text { Metabolic rate of an occupant } \\ \text { MRT } & \text { Mean radiant temperature } \\ \text { NC } & \text { Noise criteria } \\ \text { PD } & \text { Percent dissatisfied } \\ \text { PMV } & \text { Predicted mean vote } \\ \text { PPD } & \text { Predicted percent dissatisfied } \\ \text { PPM } & \text { Parts per million } \\ \text { RH } & \text { Relative humidity } \\ \text { RT } & \text { Reverberation time } \\ \text { SDA } & \text { Spatial daylight autonomy } \\ \text { SGCHPC } & \text { Standards and Guidelines for the Conservation } \\ & \text { of Historic Places in Canada } \\ \text { SHGC } & \text { Solar heat gain coefficient } \\ \text { STC } & \text { Sound transmission class } \\ \text { STI } & \text { Speech transmission index } \\ \text { UDI } & \text { Useful daylight illuminance } \\ \text { WELL } & \text { Wellness certification program } \\ & \\ & \end{array}$




\section{Chapter 1}

\section{Introduction}

\subsection{Background}

It is often best practice for building conservation professionals to improve building performance while "Retaining or reinstating character-defining aspects of the interior arrangement which contribute to the historic building's inherent sustainability" [1]. Buildings are responsible for $30-45 \%$ of global energy use, and the average North American person spends 85 - 95\% of their life indoors [2]-[4]. When working with existing and historic buildings, it is critical to implement changes that are appropriate and that do not impede on the values of the building while also ensuring energy efficiency and comfort for the health of the general public[1].

The purpose of this thesis is to present a framework for assessing early design retrofit options for heritage buildings using a generative design approach that incorporates four aspects of IEQ and energy performance. The thesis contains a literature review of current simulation practices for heritage, an outline of the proposed methodology, recommended tools and an example case study. The intent of the research is to holistically inform preliminary design decision making. The framework, designed to facilitate the 
assessment of light, acoustics, thermal comfort, air quality and energy, will be presented and applied to two case studies.

The term holistic, as used in this thesis is to refer to the inclusion of multiple aspects of building performance at once. As discussed in the following sections of this chapter, simulation workflows often only target several performance categories at once and rarely combine all four aspects of indoor environment with energy. The framework presented could be applied to any building, however the framework targets the improvement of existing buildings and preservation of the existing environmental merit of heritage buildings.

Building performance practitioners are often faced with the task of balancing multiple project objectives at once and developing recommendations for decision makers who rely on simulation data but may not be as familiar with the technical details of simulation. There is an increased societal interest in developing spaces that are more comfortable for occupants on top of the urgent need to reduce building's impact on the climate.

In the case of heritage projects, where the buildings also embody social, cultural, political and historical value, the management of design decisions is heavily intertwined with other stakeholders and requires a degree of social tact on the part of the simulation practitioner. The optimization of a heritage building's performance is not necessarily impeded by heritage concerns, but design intervention recommendations must be prescribed on a case by case basis and adhere to the values of the site to ensure the merit of the space can be enjoyed by future visitors. Generative design is a strategy to help facilitate better heritage design. 
Generative design is a strategy of applied parametric simulation that is intended to facilitate data driven compromise decision-making in the early design process for buildings. When comparing IEQ performance metrics with energy consumption the priorities of a project must be balanced and the simulation practitioner can help facilitate that discussion, with the right tools.

\subsubsection{Introduction to Generative Design Theory}

Generative design is a highly discussed topic in the realm of architecture, industrial design and interior design. It is a process of design that is intended to apply artificial intelligence and simulation in a way that also still supports creativity and the human in the process [5]. The objective is to create a multitude of feasible design options for a project that possess varying predicted performance and varying aesthetic attributes [6].

Many software organizations and researchers are taking different angles to the approach, but this introduction will identify the main components of a generative design workflow and the values intended in the design delivery strategy. From reviewing literature on GD methodologies, generative design is broken down into five main pillars. In GD systems, there is a geometric representation of a design, multiple simulation engines or models, an optimization algorithm, the visualization of results (including the model), and the ability to interactively navigate the resulting design options. These features are all present in all the most prevalent GD tools, research, and workflows [7]-[16].

Figure 1.1 displays how the GD systems typically interplay in a building design context. Rhino is typically used as a preliminary design tool more so than Revit and is most commonly used for GD [17]. Rhino and Revit both have a supporting coding interface that supports simulation and scripted tasks. Grasshopper for Rhino and Dynamo for Revit are 
both visual programming languages, where blocks of code are manipulated and connected in an interface that appears to be an interactive dataflow chart. This trend in scripting for architectural design is rooted in making coding more accessible and intuitive for users. There are other tools to achieve generative design such as scripting in Python, Matlab and using other tools, however the most prevalent tools are Dynamo and Grasshopper [18].

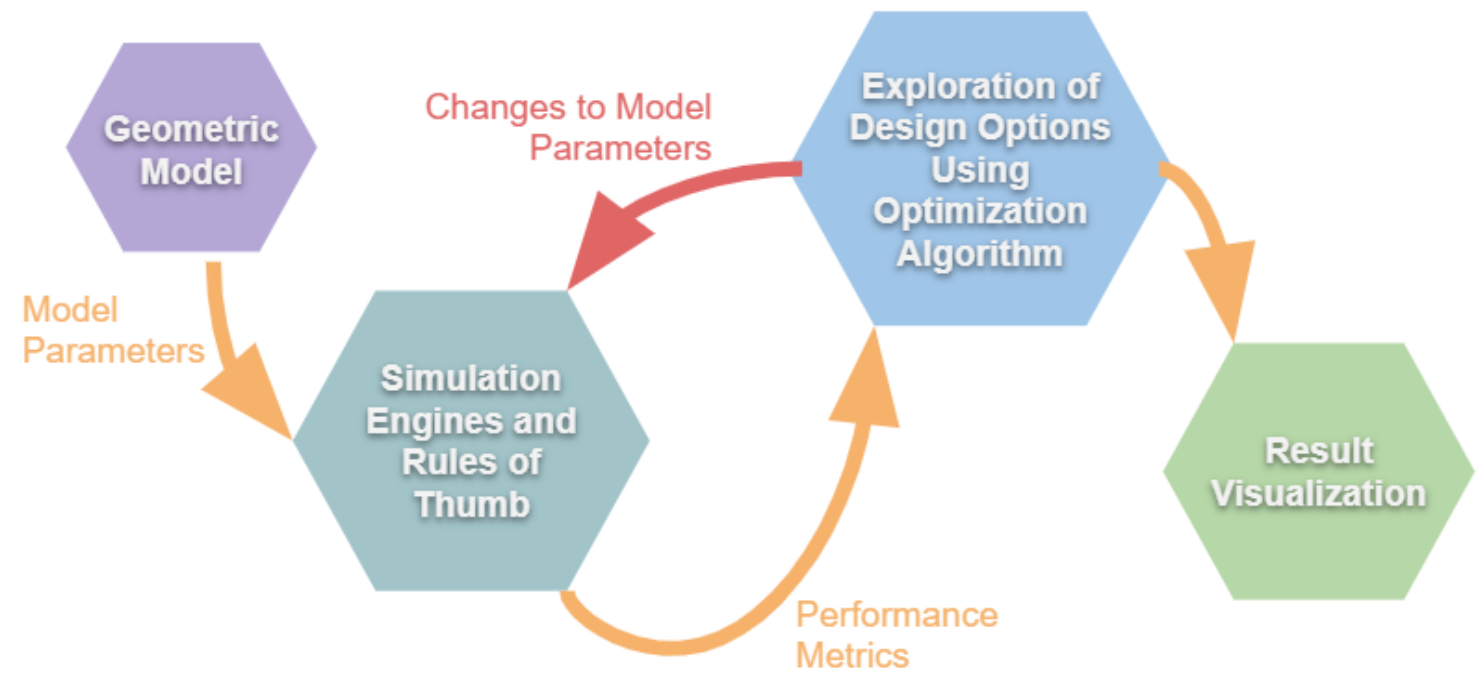

Figure 1.1 - Components of a generative design workflow.

The building geometry is represented in a coordinate system for location of boundaries and geometric aspects that are not subject to change in the study. The geometry is often a simplified version of other BIM models being used for a project.

Simulation engines are software tools that have a collection of mathematical relationships that approximate real world phenomena and have been validated to be appropriately accurate when given the right inputs. Rules of thumb are considered mathematical equations that estimate quality of a design and are rooted in design experience or intuition. Rule of thumb estimates have been applied in cases like Autodesk 
Studio's Project Discover, where rules of thumb were used to incorporate adjacency preference, work style preference, buzz, productivity, daylight and views to the outside [3].

The explorative phase is the application of optimization algorithms on the performance models and rules of thumb. GD processes must be full factorial simulation, and consider the effects of combinations of design parameters [19]. GD workflows often apply an evolutionary optimization algorithm, which incorporates an aspect of randomness and mutation in its optimization process [20]. One of the most important aspects in the optimization stage is ensuring the convergence on the global optimal and ensuring that the entire solution space is explored evenly [21]. In some older GD workflows, the human was also incorporated in the optimization phase where, several options were generated and the preferred was selected by a human in a phased approach. In that case, the optimization algorithms would incorporate feedback from the user to generate further design iterations that were more likely to be chosen [14], [21].

Data visualization and visualization of the design is a critical component of a GD process and is a feature of GD tools that is essential. In order to review and examine performance trends, the simulators and designers need to be able to explore and filter design trends in an intuitive way [16]. Since the optimization and exploration phase generates large clouds of data, it is important for the designers to have the ability to shift scale from the macroscale of the entire run, to the microscale of single design options. The impact the design changes have to the aesthetic to the building must also be explorable for human judgement [6]. 


\subsubsection{Simulation in Heritage Conservation}

Simulation practices for heritage routinely include the analysis of energy and other indoor environmental factors for both comfort objectives and heritage conservation; however, workflows rarely consider all aspects of indoor environmental quality simultaneously [22][25]. Conservation workflows have been developed that draw attention to the need to assess energy conservation measures for heritage and work has been done to couple energy analysis with thermal comfort analysis [26]-[29]. Thermal comfort within heritage buildings is generally acknowledged as a significant concern and a driving force in the need to improve heritage building performance above all other indoor environmental factors [30]. Higher detail modeling methods for thermal comfort could be adopted by including more appropriate modeling of mean radiant temperature using view factors and has not been observed in research [31].

Daylighting simulation practices have been examined as a tool for the preservation of heritage value and visual comfort of occupants [32]. Cultural built heritage has been quantitatively analyzed using daylight simulation tools to support the documentation and conservation of character defining elements related to light, omitting other components of the indoor environment or optimization strategies for cases when interventions were being examined [33], [34]. Air quality in heritage buildings has been monitored thoroughly on site and simulated for contaminants, independently of thermal comfort [35]-[37]. Acoustics have been examined as a character defining element and simulated in an exercise to increase awareness to acoustics as a heritage feature [23].

Although the different performance aspects have experienced significant development in heritage conservation, most performance factors are examined 
independently, without a combined focus on both comfort and heritage. Accordingly, the impacts of retrofits need to be simultaneously viewed under multiple lens to understand the holistic effect and interactions between domains. This thesis will attempt to address this gap with a novel application of a generative design delivery strategy.

\subsection{Problem Definition}

The scope of this thesis includes the exploration and adaptation of the fundamental methodologies used for generative design in literature and identify the key values of a generative design workflow. The deliverables for this thesis include creating a framework for a generative design methodology intended to explore early design options for heritage building retrofits. The identification of performance metrics and how they are co-related to relevant theory, is necessary to build a vocabulary for the quantification of how successful a potential design could be. In order to develop the framework, it is necessary to identify and collect tools supported by simulation theory for each building performance category including energy, daylight, thermal comfort, air quality and acoustics. The management of the simulation tactics is necessary to ensure feasible deployment of the simulation framework within industry and to limit resource intensity within the workflow.

\subsection{Organization of Research}

The thesis is divided into the following chapters:

Chapter 2 describes the proposed assessment workflow. Supporting theory for all environmental categories' simulation are reviewed and the explanation of how supporting theory is implemented into a Grasshopper script is described. The step- 
by-step methodology within this section is structured to guide simulation practitioners to produce similar tools.

Chapter 3 contains an example case study with a scenario where different design options for a cover structure for a heritage courtyard is examined and compared. This is a hypothetical project and the model represents real buildings of similar scale. The courtyard case study displays how the framework can be used as a guideline for the design of new building additions with the performance expectations of atrium type spaces. The case study presents holistically optimal design recommendations for the courtyard cover and discusses how the framework results can be used to support compromise in the design development phase where there are competing objectives.

Chapter 4 contains an example case study with a scenario where a single occupant historic office is to be optimized for overall performance. The office case study displays how the framework can be used as a guideline for updating a historic space with the performance expectations of an office and strict restrictions on geometric changes. This is a hypothetical project and the model represents real buildings of similar scale. The case study presents holistically optimal design recommendations for the office and discusses how the framework results can be used to support compromise in areas where there are competing objectives.

Chapter 5 discusses the limitations of the current workflow, future recommended work, and the concluding remarks. 


\section{Chapter 2}

\section{Methodology and Framework}

\subsection{Introduction}

The methodology proposed here is intended to be a guideline for building simulation practitioners supporting early design development and offers flexibility in assessing multiple aspects of the building's performance including energy, daylight, acoustics, thermal comfort and air quality. The framework is intended to be applied to existing and heritage buildings and the results are formatted into an interactive parallel coordinate plot that can be manipulated to filter desired ranges of parameters and corresponding performance metrics.

In its essence, the framework can be conceptually followed as a reference document and does not need to be fully followed to still increase the quality and relevance of the simulation practitioner in project design delivery. Conservation and architectural projects require case-by-case management, in the context of the technical and social needs of the

project. Figure 2.1 displays the breakdown of the proposed framework. The following sections within Chapter 2 further explain each of the recommended steps, supporting theory and recommended application of theory to facilitate the simulation.

The framework is intended to meet a gap in common simulation practices seen in industry and academia. In many cases, simulation is left out of the design process and used more as a verification and design refining step to meet building or certification codes. In a 
traditional workflow the architects develop a design, model the design in a BIM environment and then the simulation practitioner is asked to verify if the design will meet performance objectives. This does not necessarily lead to the highest performing design and leaves the simulation practitioner to play a relatively low impact role in the overall process. The objective in the context of this thesis, is to integrate the practice of simulation into the initial design development, this ensures that design concepts that are being explored, by default, meet required performance goals and consequence of design decisions are clearly communicated. The simulator is ideally working as an extension of the architectural designer.

This requires an increase in flexibility and accessibility on the part of the simulation practitioner to facilitate better design development. The simulation practitioner in a generative design workflow, must almost act like a project manager; collecting and defining the design's scope of work and objectives from the designers. The role of the simulator shifts from a passive role as an advisor to an active role as a facilitator for decision making. The goal is to communicate possibility and communicate consequence within the range of design changes being considered. This entails that although the technical aspect that supports the simulation process is very important, the presentation of results and involvement of other project members is more important, as it aims to increase the perceived value of the results. 


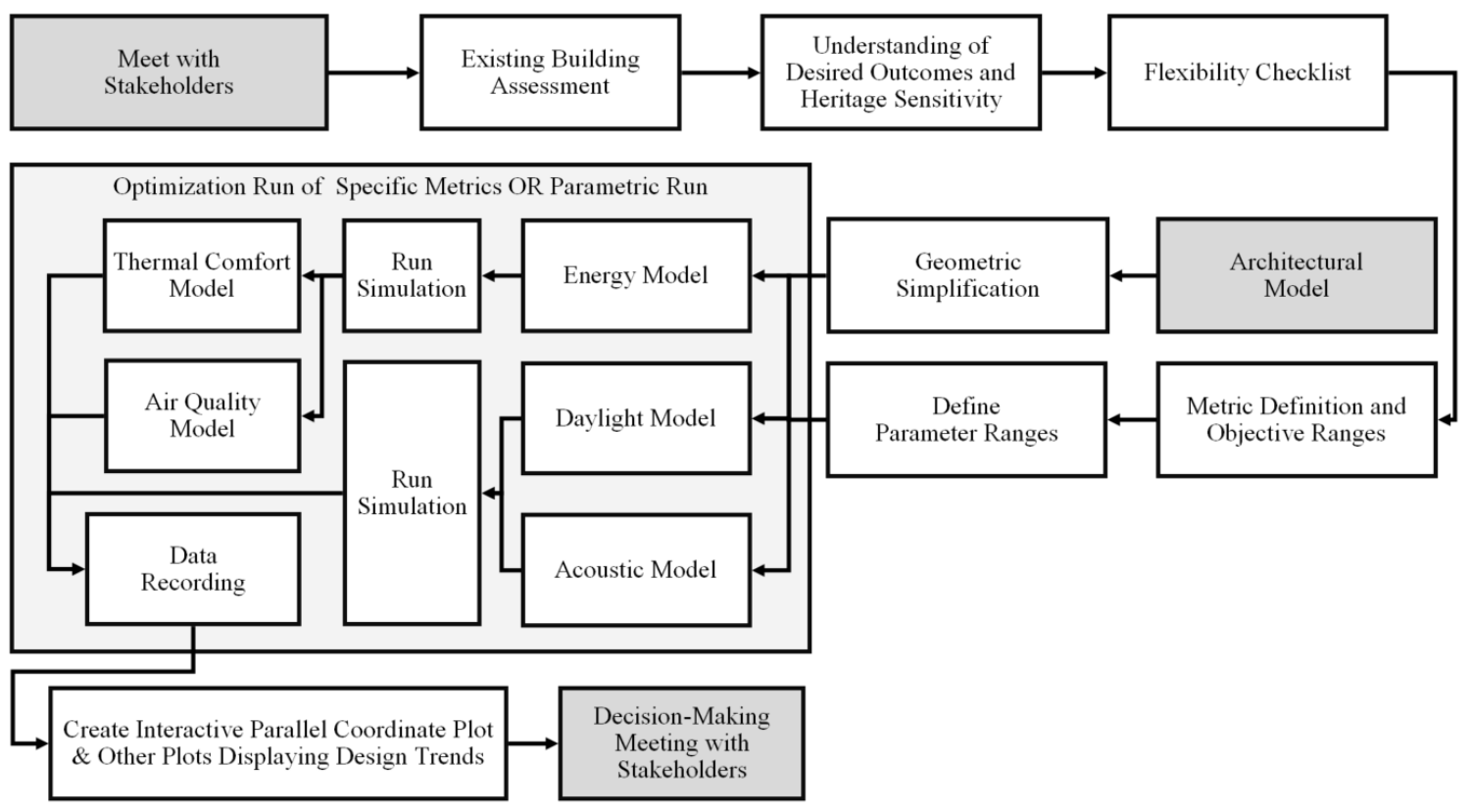

Figure 2.1 - Proposed framework for wholistic building performance simulation.

Inspired by the Standard and Guidelines for the Conservation of Historic Places in Canada (SGCHPC), the framework is broken down into three main sections. The understanding phase of the framework contains steps recommended for identifying values of the site outside the concern of a conventional simulation practitioner, such as heritage values, architectural features and desired IEQ outcomes. A significant focus must be placed on how a design could be considered successful, and a clear understanding of what is restricted and free to change is necessary. The simulation phase of the proposed framework includes manipulating geometric data to create models. The models are then used to produce data to predict the quality of the building's performance to possible combinations of interventions. The communication phase of the framework is where results are visualized in engaging and intuitive ways for discussion with the project stakeholders. Decision makers of a project rarely have as technical a background as thorough as simulation 
practitioners and it is in the best interest of all stakeholders if the results, and benefits of higher performing design options, are presented in a clear engaging format.

Each of the following sections will explain the rational behind each of the recommended steps, the supporting technical theory if relevant and the software tools identified to feasibly complete the exercise. Grasshopper was selected as the coding interface for this thesis. There is a collection of open source building performance simulation tools available to facilitate the workflow within Grasshopper that would otherwise need to be developed in any other scripting tool. Other coding tools like Dynamo, Python or Matlab could also be used to facilitate the presented framework however building performance simulation packages are less readily available for immediate use. 


\subsection{Meeting with Stakeholders}

Stakeholders could be considered any group or individual of people who influence or are influenced by a project. Site owners, property facility managers, occupants, surrounding community and people with associated values to the site can all be considered stakeholders [1]. A preliminary meeting with stakeholders establishes details about the project and defines the interventions scope of work. Details like pre-existing documentation and building condition assessment reports are important for developing a good understanding of the site. The components of the building that possess value, the building's character defining elements (CDEs), are identified by stakeholders. Aspects which may be related to aesthetic, historical, cultural or spiritual importance are all considered CDEs. Aspects of the site that are critical in terms of architecture are acknowledged for preservation in order to ensure future generations visiting the space can enjoy the same merit as prior to the intervention.

Collecting information on the scope of the intervention is also necessary. For example, identifying the types of changes being considered, whether they be additions to the building, changes in the HVAC system, building envelope or occupancy profile.

\subsection{Existing Building Assessment}

Information about the site in it its current conditions and the buildings current management strategies shed light on how to improve conditions. Table 2.1 displays properties to take note of during a site visit to better inform the development of later stages. 
Table 2.1 - Relevant condition site properties.

\begin{tabular}{|c|c|}
\hline Site Property & Description \\
\hline Building geometry & $\begin{array}{l}\text { Collected using site surveying tools, point cloud or } \\
\text { photogrammetry. Surface orientation, window } \\
\text { location and size, shading, wall and slab thickness, } \\
\text { heat source location, controls location, placement } \\
\text { of sedentary occupants and partition walls }\end{array}$ \\
\hline Surrounding topography & $\begin{array}{l}\text { Location, dimensions and opacity of surrounding } \\
\text { obstructions from the sun }\end{array}$ \\
\hline Exterior wall insulation & \multirow{3}{*}{$\begin{array}{l}\text { Composition of building envelope if available } \\
\text { and } / \text { or effective thermal resistance of insulation } \\
\left(\mathrm{K} \cdot \mathrm{m}^{2} / \mathrm{W}\right) \text {. Can be determined using heat flux } \\
\text { meter }\end{array}$} \\
\hline Ceiling insulation & \\
\hline Base insulation & \\
\hline Occupancy profile & $\begin{array}{l}\text { Density of occupants, activity level and schedule of } \\
\text { occupants. }\end{array}$ \\
\hline Existing renewables & If the site already generates energy \\
\hline Thermostat setpoints & Operation of the system(s) \\
\hline Glazing specifications & $\begin{array}{l}\text { Collect the window specifications for } \mathrm{U} \text {, SHGC } \\
\text { and visible transmittance }\end{array}$ \\
\hline Window frame type & Material property and anticipated seal quality \\
\hline Thermal mass elements & Volume, location and material \\
\hline Air circulation rate & L/s by control zone \\
\hline Infiltration & ACH by building \\
\hline Lighting specs and density & Light type and frequency $\left(\right.$ per $\left.\mathrm{m}^{2}\right)$ \\
\hline Equipment and plug load & Density $\left(\right.$ per $\mathrm{m}^{2}$ ) \\
\hline Mechanical systems & $\begin{array}{l}\text { Specifications for: heating system, ventilation } \\
\text { system, heat recovery }\end{array}$ \\
\hline $\begin{array}{l}\text { Occupant or facility manager } \\
\text { feedback }\end{array}$ & Cases of chronic occupant discomfort \\
\hline
\end{tabular}

Other measurements beyond the values mentioned in Table 2.1, like timestep data, are

helpful for better insight. Measurements like energy consumption, natural gas consumption, carbon dioxide concentrations in occupied areas, internal surface temperatures, relative humidity, frequency of occupant thermostat interface and workplane illuminance all provide insight to the quality of the space. Exterior site-specific 
measurements like direct and diffuse illuminance, soil temperature and windspeeds could also all be relevant for the effective modeling of the site. If these values could be collected over a period of time, at as granular a timestep as possible, information could be drawn from more than what a single site visit could offer. Any historical data available could be leveraged for modeling if available. Table 2.1 - Relevant condition site properties.

\subsection{Understanding Space Properties and Heritage Sensitivity}

Understanding how the site's IEQ properties correspond with potential character defining elements or heritage values is a critical step. An assessment of the building environment categories, such as how light behaves in the historical space or how sound reverberates in some areas are noted as unique site features in this step. The associated values, relating to the experiential factors of the space under analysis are noted in order to establish the need for simulation and the appropriate level of detail. Simulation tools offer varying degrees of detail, at the cost of simulation time, the objective of this step is to identify the minimal amount of simulation effort for the maximum relevance for a project.

Identifying the key timeframes, locations of interest, and the relevance environmental properties have to the heritage values of the site define the focus on where simulation needs to occur for appropriate assessment. A values-based assessment can be found in Table A.1 of Appendix A.

The heritage value association column is for identifying the relevance of heritage values to the environmental factors. The future use expectation column is for understanding what the appropriate changes for heritage are and a high-level definition of how the environmental properties should be managed for comfort. The simulation result value 
column identifies the kind of simulation analysis that can provide insight to the quality of the proposed intervention design choices.

\subsection{Flexibility Checklist}

The purpose of the flexibility checklist is to clearly understand and define what aspects of a project are under the scope of analysis and what design features are free to be explored. This is necessary to manage computational time and analysis scope, due to the wide range of parameters that could be incorporated into a study. Appendix B contains an example Flexibility Checklist that can be used by practitioners starting a project to better understand what parameters of the model are rigid, assumed as constants, flexible in a spectrum and flexible in a list of options. In example Table 2.2, one can see how the table could be filled out. Parameters identified as floating point are a numerical range of potential values while integer parameters are a list of values to choose between.

Table 2.2 - Example flexibility checklist.

\begin{tabular}{|l|l|l|l|l|l|l|}
\hline & & & & & \\
\hline
\end{tabular}




\subsection{Metrics and Objective Ranges}

A list of relevant performance metrics is selected for a project. Table C.1 of Appendix C, outlines quantifiable performance goals commonly accepted in industry or used in building certifications such as LEED or WELL [38], [39]. Embodied energy could also be incorporated as a metric goal but will be omitted from this thesis' scope of work. Metric goals and performance thresholds may need to be adjusted from convention for the exception of heritage. 


\subsection{Parameter Ranges}

Parameter ranges are defined for floating point or integer values that are identified within the scope of the analysis. Table 2.3 displays a series of parameter ranges that apply to a wide range of projects [40], [41]. Other ranges may apply for different analysis projects including geometry. The purpose of this step is to clearly define the minimum and maximum possible values of design changes being considered and define how continuous the step between limit thresholds will be.

Table 2.3 - Typical ranges for parameters frequently relevant in analysis.

\begin{tabular}{|c|c|c|}
\hline Parameter & Typical min & Typical max \\
\hline Equipment load per area & $2 \mathrm{~W} / \mathrm{m}^{2}$ & $15 \mathrm{~W} / \mathrm{m}^{2}$ \\
\hline Infiltration rate per area & $\begin{array}{l}0.0001 \mathrm{~m}^{3} / \mathrm{s} \text { per } \mathrm{m}^{2} \\
\text { facade }\end{array}$ & $\begin{array}{c}0.0006 \mathrm{~m}^{3} / \mathrm{s} \text { per } \mathrm{m}^{2} \\
\text { façade }\end{array}$ \\
\hline Lighting density per area & $3 \mathrm{~W} / \mathrm{m}^{2}$ & $15 \mathrm{~W} / \mathrm{m}^{2}$ \\
\hline Number of people per area & $0.02 \mathrm{ppl} / \mathrm{m}^{2}$ & $0.5 \mathrm{ppl} / \mathrm{m}^{2}$ \\
\hline Ventilation per area & $0.0002 \mathrm{~m}^{3} / \mathrm{s}$ per $\mathrm{m}^{2}$ & $0.0025 \mathrm{~m}^{3} / \mathrm{s}$ per $\mathrm{m}^{2}$ \\
\hline Ventilation per person & $0.001 \mathrm{~m}^{3} / \mathrm{s}$ & $0.0033 \mathrm{~m}^{3} / \mathrm{s}$ \\
\hline Recirculated air per area & $0 \mathrm{~m}^{3} / \mathrm{s}$ per $\mathrm{m}^{2}$ & $0.001 \mathrm{~m}^{3} / \mathrm{s}$ per $\mathrm{m}^{2}$ \\
\hline Heating air supply temperature & $20^{\circ} \mathrm{C}$ & $38^{\circ} \mathrm{C}$ \\
\hline Cooling air supply temperature & $10^{\circ} \mathrm{C}$ & $20^{\circ} \mathrm{C}$ \\
\hline $\begin{array}{l}\text { Number of glass panes in } \\
\text { windows }\end{array}$ & 1 & 3 \\
\hline Glass solar transmittance & 0.1 & 0.9 \\
\hline Glass solar reflectance & 0.1 & 0.9 \\
\hline Glass visible transmittance & 0.1 & 0.9 \\
\hline Glass visible reflectance & 0.1 & 0.9 \\
\hline Glass front emissivity & 0.1 & 0.9 \\
\hline Glass back emissivity & 0.1 & 0.9 \\
\hline Air velocity over occupant & $0.25 \mathrm{~m} / \mathrm{s}$ & $0.50 \mathrm{~m} / \mathrm{s}$ \\
\hline
\end{tabular}




\subsection{Architectural Model and Geometric Simplification}

The geometry of the building as represented in any point cloud model or building information models must be simplified into closed thermal zones for energy simulation. A significant challenge in building performance simulation is input and management of building model geometry from other architectural resources [42]. The most important features to preserve in the geometric simplifications are surface orientations, window sizes and window locations. The number of thermal zones required are to be minimized however zones must be broken down by internal loads, boundary condition, orientation and floor if needed [43]. If interventions include plans for radiant panels, the general location of the radiant panel and the location of the sedentary occupants are defined in the geometry as well.

\subsection{Energy Model}

\subsubsection{Energy Model Theory}

Energy models conduct heat and mass transfer calculations across boundary conditions and represent HVAC equipment. Fundamentally, simulation tools, use numerical approximations of phenomena in a discrete time basis. Energy simulation engines, like EnergyPlus, incorporate factors as seen in Figure 2.2 through mathematical relationships that represent real-world phenomena as feasibly as possible [41], [44]. In the context of the proposed holistic simulation framework, the energy model is responsible for producing hourly internal surface temperature values for use in the thermal comfort model and accurate air changes for the air quality model on top of producing energy usage intensity 
predictions. This means special attention should be placed on the representation of building envelope, infiltration, and HVAC systems.

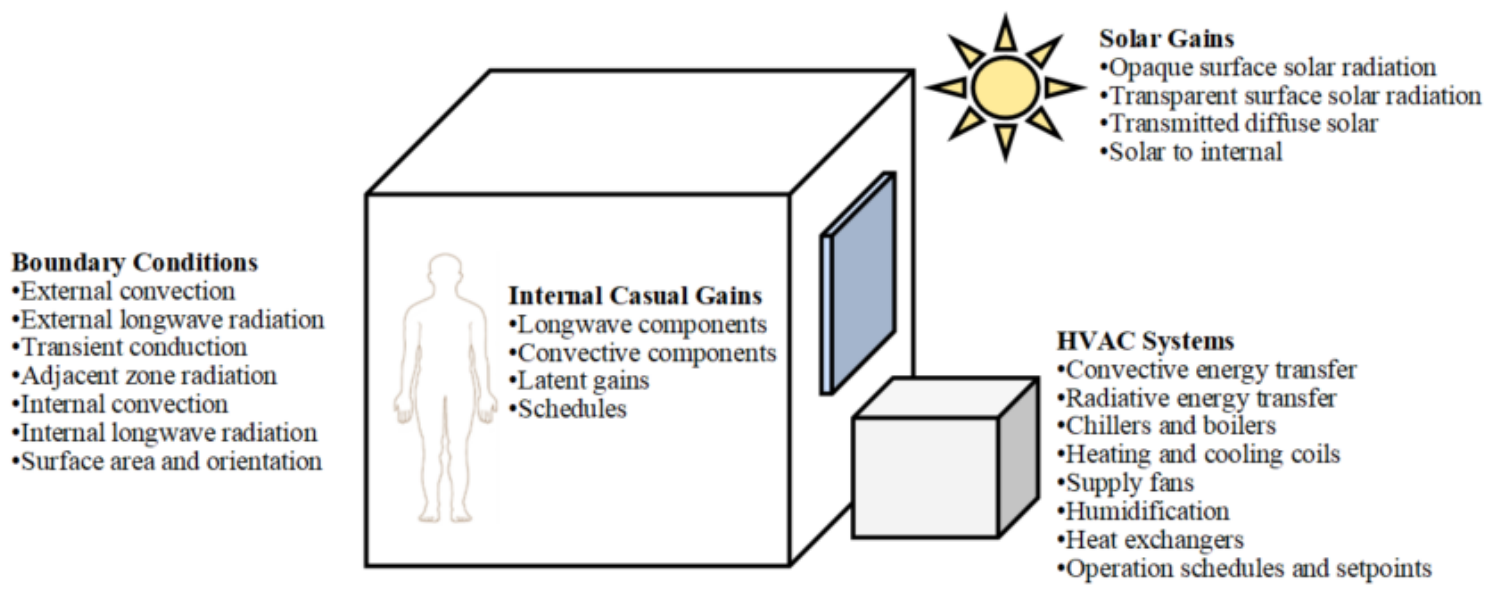

Figure 2.2 - Types of factors impacting an energy model.

In all energy model simulation engines, the heat transfer, mass transfer and mechanical systems are represented as numerical estimations. For example, the zone outside surface heat transfer is estimated using a heat balance at the exterior of the surface where shortwave radiation, longwave radiation and convective exchange equates to the conductive heat flux through a wall as expressed in equation (1). Each of the items is calculated using a numerical estimate that takes climatic weather file data and determines the energy flux caused by that heat transfer component [45]. 


$$
q^{\prime \prime}{ }_{\alpha s o l}+q^{\prime \prime}{ }_{L W R}+q_{c o n v}-q^{\prime \prime}{ }_{k o}=0
$$

Where:

$q^{\prime \prime}{ }_{\alpha s o l}=$ Absorbed direct and diffuse solar radiation heat flux

$q^{\prime \prime}{ }_{L W R}=$ Net long wavelength radiation flux exchange with surroundings

$q^{\prime \prime}{ }_{c o n v}=$ Convective flux exchange with outside air

$q^{\prime \prime}{ }_{k o}=$ Conduction heat flux into the wall

In most energy model programs a thermal zone is assumed to be a well mixed mass of air and is treated like a single node in an energy exchange. The conductive, convective and radiative components of heat transfer are assumed to apply to the volume of a zone evenly. This means that the larger a thermal zone is, the more risk there is of inaccuracies due to uneven heat transfer; factors like thermal bridges or fluid dynamics are assumed insignificant and there is an associated risk by doing so. In equation (2), each term is represented by a numerical model that estimates the real-world phenomena, and in some programs there are multiple types of models to choose from as our understanding of the mechanic has changed over time.

$$
q^{\prime \prime}{ }_{L W X}+q^{\prime \prime}{ }_{S W}+q_{L W S}+q^{\prime \prime}{ }_{k i}+q^{\prime \prime}{ }_{s o l}+q_{c o n v}=0
$$

Where:

$q^{\prime \prime}{ }_{L W X}=$ Net longwave radiant exchange flux between zone surfaces

$q^{\prime \prime}{ }_{s W}=$ Net short-wave radiation flux to surface from lights

$q^{\prime \prime}{ }_{L W S}=$ Longwave radiation flux from equipment in zone

$q^{\prime \prime}{ }_{k i}=$ Conduction flux through the wall

$q^{\prime \prime}{ }_{s o l}=$ Transmitted solar radiation flux absorbed at surface

$q^{\prime \prime}{ }_{\text {conv }}=$ Convective heat flux to zone air 
OpenStudio and by association, EnergyPlus, is the simulation engine recommended for the energy component of the holistic analysis. EnergyPlus is a widely accepted analysis tool with an extensive and transparent supporting literature that articulates the equations and supporting theory for much of the tool's capabilities [41].

\subsubsection{Applying Energy Model Theory in Grasshopper}

The OpenStudio simulation engine is made accessible in Grasshopper through the Honeybee component assembly. The energy model requires the input of climate data, energy model parameters, thermal zone attributes and requested simulation outputs. Climate weather files are available from a range of sources online and represent the climate properties.

Energy modeling parameters are specified including an hourly timestep, solar distribution settings like full interior and exterior with reflections and a city terrain for the model's surroundings. The thermal zone is defined with a collection of surfaces that must create a closed geometry. Each of the surfaces have their boundary conditions specified. A surface is assigned as adiabatic if the surface is assumed to experience an insignificant amount of heat transfer. Each surface in the geometry is assigned a construction where the material composition has been specified. Each material within a construction is specified a roughness, thickness, conductivity, density, specific heat, thermal absorptivity and radiative absorptivity. For transparent surfaces, the materials are specified by thickness, solar transmittance, solar reflectance, visible transmittance, visible reflectance, emissivity and conductivity. Any one material property can be changed as a parameter in the scope of 
a parametric analysis. The thermal zone is then assigned internal loads typically in the range presented in Table 2.3 .

Honeybee allows the specification of HVAC systems using a series of templates for HVAC scenarios. Each of the systems can have air details, heating details and cooling details adjusted from default template settings. Once an HVAC type has been selected and changes have been made to system details it is necessary to open the EnergyPlus model within the project domain and examine how the specific template and combination of inputs has been interpreted by Honeybee into EnergyPlus. Higher control of HVAC systems is made possible with the Ironbug assembly, which facilitates articulation of mechanical systems within EnergyPlus to a higher detail than Honeybee. The level of detail for HVAC systems offered with-in Ironbug is outside the scope of this thesis but could be a beneficial addition for future work.

Simulation outputs must be specified to generate the inside surface temperatures and air change rates that are not typically generated by Honeybee without direct editing of the output table that is fed into EnergyPlus. Any additional changes to the model that are not supported by standard Honeybee components may be inserted manually to the EnergyPlus IDF. 


\subsection{Daylight Model}

\subsubsection{Daylight Model Theory}

The daylight component of wholistic simulation requires physically based daylight calculations. Daylight simulation emulates the behavior of light from the sky and how it interacts with building materials [46]. The light behavior must be represented in a metric

like the ones mentioned in Table C.1- Common performance metrics and goals.. The widely used simulation engine Radiance, is a mixed stochastic deterministic light backward raytracer, used to complete the calculations for hourly illuminance values on an analysis plane [47].

Natural light is effectively represented as a combination of direct and diffuse sunlight from a sky dome above the geometry. The direct component is represented as a source in the sky at an infinite distance and the diffuse light is represented as a glowing source also at an infinite distance. The sky can be represented in several ways including a uniform sky, CIE overcast sky, CIE clear sky, and Perez all weather sky; each of which represents diffuse light in the dome in different ways [46].

Rays of light are projected from a source onto a geometric surface with user assigned material modifiers. The assigned material modifiers have associated optical models to emulate the effect of material properties on reflection. At the impact point of the initial ray on a surface, the light is recursively traced and projected again onto another surface. The number of rays is controlled by user specifications and is recommended to 
range between three to seven bounces [46], [48]. The ray is affected by the reflectance's of all previous bounces.

Opaque building surfaces are represented with a specified diffuse red reflectance, green reflectance and blue reflectance. A ray that impacts a surface is represented as a hemisphere and redistributed. Opaque materials also have a specified roughness that impacts the specular rays coming off the reflectance point as a cone if nonzero. Typical floors, ceiling and wall surfaces should be assigned 15\%, 80\%, and 40\% reflectance respectively [46]. Transparent materials are represented with specified red, green and blue transmittance in addition to a refractive index.

An analysis grid is specified within the space under examination with a series of points. The recommended density of analysis points is $0.6 \mathrm{~m}$ on center, but may need to be adjusted depending on the size of the analysis zone, and the computational resources available [46]. Each point in the grid is a receiving location for rays of light within the analysis space [49]. It is important to preserve $0.2 \mathrm{~m}$ setback for the analysis plane from any material surfaces [50]. Radiance then conducts mixed stochastic deterministic light backward raytracing for each of the analysis points for every hour specified in the analysis period. The results generated from radiance are a matrix of hourly illuminance results at each point in the analysis grid. The illuminance values are informative alone but can be manipulated to better communicate the overall quality of light in a space.

Metrics like spatial daylight autonomy (sDA) and annual sunlight exposure (ASE) are two effective ways to quantify the quality of light in a space and incorporate how a typical occupant perceives the quality of the light [49]. In the context of an office or working space, occupants have been found to prefer lighting levels ranging between 300 
lux to 1000 lux [39]. Given vastness of the high spatial and temporal resolution of annual daylight simulation results, the sDA metric combines both the quality of the light at a point and the quality of the point over the year to quantify the quality of the entire space. Equation (3) quantifies the quality of light at a specific point and provides the total number of analysis hours that a point experiences within the comfort threshold. Typical analysis hours are 8 am to $6 \mathrm{pm}$ for the entire year, and typical thresholds include no less than 300 lux [49]. Equation (4) quantifies the quality of the point and is the sum of points that are above a certain temporal quality threshold. Typically, a point that is within comfort thresholds for more than $50 \%$ of all analysis hours is deemed sufficient. Equation (5) incorporates the spatial property and provides the percentage of total analysis points that fall within the light and time quality thresholds. In a case where we are looking for sDA $500 / 40 \%$ the 500 is the light quality threshold and the $40 \%$ is the temporal threshold to identify quality points. Continuous daylight autonomy (cDA) would award fractional points in the $T($ ) function for light that is below the illuminance quality threshold. 


$$
\begin{gathered}
P_{n \text { treshold }}=\sum_{h=8: 00}^{18: 00} T\left(L_{n}(h)\right) \\
P_{n \text { quality }}=\sum Q\left(P_{n \text { treshold }}\right) \text { for all } \mathrm{n} \\
s D A_{\frac{300}{50} \%}=\frac{P_{n \text { quality }}}{n} \times 100 \%
\end{gathered}
$$

Where:

$n=$ Number of analysis points

$h=$ Analysis hour

$P_{n \text { treshold }}=$ The total analysis hours meeting threshold requirements at point $\mathrm{n}$

$L_{n}(h)=$ Function of an analysis point n's illuminance value at a given hour (h)

$T=$ Function equal to 1 if $\mathrm{L}(\mathrm{h})$ is grater than 300 or 0 otherwise

$P_{n \text { quality }}=$ The number of points that are meeting temporal quality requirements

$Q_{\text {Test }}=$ A function equal to 1 if $P_{n \text { treshold }}$ is greater than half the analysis $\mathrm{h}$

Annual sunlight exposure (ASE) is another lighting metric that is used to examine excess daylight within a space. Similarly, to sDA there is a temporal and a spatial component of the metric. Rather than testing for sufficient light above 300 lux, the test is for excessive light above 1000 lux. For ASE, the quality of a point is specified by a temporal threshold of 250 hours rather than a percentage like in sDA.

Useful daylight illuminance (UDI) is a metric that tries to combine the minimum and maximum thresholds of 100 lux and 3000 lux in a temporal sense for a single point [51]. The threshold limits are under discussion within the industry and depend on the needs of the space. It is defined as the percentage of total analysis hours a point's illuminance is within the comfort range. Most UDI results are not aggregated into a single number for the entire space but rather represented as a heat map. 


\subsubsection{Applying Daylight Model Theory in Grasshopper}

Annual daylight simulations using radiance are the most computationally expensive part of the proposed framework. An annual light simulation with four ambient bounces takes about 15 minutes per iteration. A typical optimization can be up to 500 runs [6]. This time requirement is a significant bottleneck in the analysis process and is infeasible for many industry applications. To more feasibly manage daylight for an optimization process, the scope of analysis hours was significantly reduced.

Rather then running analysis for every hour of the year and manipulating a wide set of analysis grid illuminance data, specific hours were selected for simulation. 9 am, noon and 3pm were selected as indicator hours on the $21^{\text {st }}$ of June and December. The summer and winter solstice capture the extreme solar angles; and the equinox dates could be added to capture mid range conditions. The sky has been selected as a CIE sunny with sun sky, meaning that the direct and diffuse light from the sun are both incorporated into the raytracing simulation. This triggers six hours of analysis to roughly estimate the quality of natural light within the analysis space without excess computation time. This reduction in illuminance data limits the accuracy and temporal sense of the daylight metrics and should not be used as a replacement for full annual simulation results in the context of further developed design analysis or building certification. The change in daylight analysis hours was adjusted several times in the development in the methodology to feasibly meet higher turnover rates. This simplification may also not be feasible in cases were building or shading geometry is complex.

Data from the simplified simulation is manipulated in a way similar to a combination of cDA, ASE and UDI but to better reflect the sentiment of predicted percent 
dissatisfied (PPD) like for thermal comfort or air quality, a higher metric value indicates a worse performance. The minimum illuminance, maximum illuminance and average illuminance experienced in the analysis grid within the 6 different indicator hours is also recorded per design iteration. Equations (6) and (7) represent how IHOT is calculated to estimate quality of light only using select analysis hours.

$$
\begin{gathered}
P_{\text {outside treshold }}=\sum T_{\text {out }}\left(L_{n}(h)\right) \text { for all } \mathrm{h} \\
\text { IHOT }=\frac{P_{\text {outside treshold }}}{h_{\text {total }}} * 100 \%
\end{gathered}
$$

Where:

$P_{\text {outside treshold }}=$ Number of points outside comfort thresholds at every hour $T_{\text {out }}=$ Equal to 1 if $\mathrm{L}(\mathrm{h})$ is less than 300 or more than 1000 or 0 otherwise $I H O T=$ Investigation hours outside threshold $h_{\text {total }}=$ Total analysis hours

Improvements for the analysis include addition of blind operations and electrical lighting, which was omitted from the scope of this thesis.

\subsection{Acoustic Model}

The acoustic simulation for the proposed methodology takes three experimental approaches to try to incorporate acoustics as best as possible. The examination of how changes to geometry, envelope, infiltration and ventilation impact acoustics are incorporated as models. These strategies are estimates and require significant further investigation beyond the scope of this thesis for more confident results. 


\subsubsection{Noise Propagation Theory}

Sound propagation in a space is treated similarly to light simulation, where a source produces rays of sound that bounce off the building's materials and an analysis point measures the receiving strength of the ray. Pachyderm Acoustic is an open source simulation engine available in a selection of formats used for acoustic raytracing within a space [52]. The source is modeled to release a pulse of sound rather than a continuous noise at a specified spectrum of power levels. The strength of the sound ray bouncing off a surface is affected by the material properties of that surface, and is dictated by an absorption coefficient which is derived from equation (8). The angle of the reflected soundwaves is assumed to be reciprocal to the incoming angle. The analysis point or receiver is measuring the strength of the sound waves over a specified time. The recommended number of rays is approximately 37 rays per cubic meter of analysis space volume and the analysis timeframe following the pulse of noise is recommended to be $75 \%$ of the expected reverberation time of the room type being examined [53].

$$
I_{i}=I_{\rho}+I_{\delta}+I_{T}
$$

Where:

$$
\begin{aligned}
& I_{i}=\text { Incoming sound }, \mathrm{dB} \\
& I_{\rho}=\text { Reflected sound }, \mathrm{dB} \\
& I_{\delta}=\text { Absorbed sound }, \mathrm{dB} \\
& I_{T}=\text { Outgoing sound }, \mathrm{dB}
\end{aligned}
$$


Absorption coefficients for a material is specified over a band of frequencies, traditionally ranging from $62.5 \mathrm{~Hz}$ to $8 \mathrm{kHz}$. Table 2.4 outlines some typical absorption coefficients for building materials [54].

Table 2.4 - Absorption coefficients for relevant surface materials.

\begin{tabular}{|l|c|c|c|c|c|c|}
\hline \multirow{2}{*}{ Surface treatment } & \multicolumn{7}{|c|}{ Frequency } \\
\cline { 2 - 7 } & $\mathbf{1 2 5}$ & $\mathbf{2 5 0}$ & $\mathbf{5 0 0}$ & $\mathbf{1 0 0 0}$ & $\mathbf{2 0 0 0}$ & $\mathbf{4 0 0 0}$ \\
\hline Acoustic tile, rigid & 0.2 & 0.4 & 0.7 & 0.8 & 0.6 & 0.4 \\
\hline Plaster, on lath & 0.2 & 0.15 & 0.1 & 0.05 & 0.04 & 0.05 \\
\hline Gypsum wallboard & 0.3 & 0.1 & 0.05 & 0.04 & 0.07 & 0.1 \\
\hline Concrete poured & 0.01 & 0.01 & 0.02 & 0.02 & 0.02 & 0.03 \\
\hline Brick & 0.03 & 0.03 & 0.03 & 0.04 & 0.05 & 0.07 \\
\hline Carpet & 0.02 & 0.06 & 0.15 & 0.4 & 0.6 & 0.6 \\
\hline
\end{tabular}

Noise Criteria (NC), Reverberation Time (RT), and Speech Transmission Index (STI) are some effective metrics for quantifying the acoustic properties of a space [55]. Noise criteria is a metric defined by the relationship between sound pressure level (SPL) a point experiences and frequency of the sound [39]. NC itself is determined by using noise rating graphs, where the closest NC curve to a point defined by SPL identifies the NC level.

STI is calculated using a complex process that incorporates ambient noise within the space across each frequency and the pulse test noise across each frequency from ray tracing results [56], [57], [58]. STI is used to indicate the quality or intelligibility of a verbal communication at the receiving point. STI values are considered acceptable over 0.6 [55]. Reverberation time is defined as the amount of time it takes a sound pulse to drop in strength by $60 \mathrm{~dB}$ within a space.

With the tool Pachyderm, it is possible to compute energy time curves of sound pulse within a space and examine how surface absorptivity and geometry effects acoustic 
quality. To better integrate the effect of other design decisions into acoustic performance, other theories were also explored.

\subsubsection{Ambient Zonal Noise due to Ventilation Theory}

Noise due to ventilation is an experimental concept to examine how changes to the ventilation rate of the analysis zone effects the STI of a space. Taking the results from the ASHRAE study conducted to determine the relationship between HVAC airflow rates and noise levels, equation (9) is a mathematical function that roughly estimates noise level in $\mathrm{dB}$ based on the ventilation rate of a typical duct [59]. This is intended to be an estimate of noise behavior.

$$
\mathrm{VN}=21.53 \cdot \mathrm{Q}+13.94
$$

Where:

$$
\begin{aligned}
& \mathrm{VN}=\text { Ventilation noise }, \mathrm{dB} \\
& \mathrm{Q}=\text { Ventilation rate, } \mathrm{m}^{3} / \mathrm{s}
\end{aligned}
$$

The estimated ambient noise level is then distributed across the acoustic spectrum and used to calculate STI within the space in combination with the acoustic raytracing results.

\subsubsection{Sound Attenuation from Infiltration Theory}

An additional experimental concept incorporated into the proposed workflow, is corelating zonal infiltration to the quality of sound attenuation the building envelope provides from the outdoor ambient noise. This is most relevant if the building is in an area with anticipated exterior ambient noise such as by a road or airport. The study conducted, examined a historical building with masonry walls and created a correlation between the air changes 
per hour of the zone and the estimated amount of sound lost through the building envelope as seen in equation (10), [60].

$$
A C H=-0.0462 \Delta L p^{2}+2.543 \Delta L_{p}-33.29
$$

Where:

$$
\begin{aligned}
& A C H=\text { Air change rate, } 1 / \mathrm{h} \\
& \Delta L_{p}=\text { Sound attenuation, } \mathrm{dB}
\end{aligned}
$$

By solving for $\Delta \mathrm{L}_{\mathrm{p}}$ parametrically at a range of specified infiltration rates, one can loosely predict how the envelope will provide sound protection from the exterior.

\subsubsection{Sound Transmission Loss Theory}

Sound Transmission Loss (STL) is the predicted ability that a construction assembly possesses to reduce the noise passing through it as seen in equation (11). It is often determined through laboratory tests and there are construction guidelines to meet specific performance ratings. Equation (12) displays how a wall's STL is a proportional combination of all the surface types within that wall; for example, a window of a different material property will change the STL of the entire wall [61].

$$
S T L_{\text {surface }}=10 \cdot \log \left(\frac{1}{\tau_{\text {surface }}}\right)
$$

Where:

$$
\begin{aligned}
& S T L_{\text {surface }}=\text { Sound transmission loss of a surface } \\
& \tau_{\text {surface }}=\text { Transmissivity of a surface }
\end{aligned}
$$




$$
S T L_{\text {comp }}=10 \cdot \log \left(\frac{\sum S}{\sum \tau S}\right)
$$

Where:

$$
\begin{aligned}
& S T L_{c o m p}=\text { Sound transmission loss of a wall construction } \\
& \mathrm{S}=\text { Surface area, } \mathrm{m}^{2}
\end{aligned}
$$

Changes to the exterior building envelope and its effect on the composite sound transmission level have been incorporated into the proposed workflow. As it is difficult to determine the performance of a wall assembly without specialized wall tests following ASTM International Classification E413 and E90. A Sound Transmission Class (STC) rating is an established STL performance curve across several frequencies. When an assembly is tested, the closest STC performance arc is used to generalize the STL capabilities of a tested assembly. STCs generally range around the median value of the STL curve across several frequencies. For the purposes of this exercise, a collection of STC values will be used for the STL in the $S T L_{\text {comp }}$ calculation as a rough estimate. The STC of masonry wall assemblies can be estimated using equation (13) and the STC ratings of single, double and triple pane windows can be seen in Table 2.5 [62], [63].

$$
S T C_{\text {Masonry }}=0.0368 \cdot W+40
$$

Where:

$$
\mathrm{W}=\text { Weight of the masonry assembly including all materials in assembly, } \mathrm{kg} / \mathrm{m}^{2}
$$

There is little research available on the STC ratings of masonry assemblies with additional insulation applied to it. For the purposes of this thesis the weight of the entire assembly including the insulation will be used as an estimate. 
Table 2.5 - Typical STC ratings of window class

\begin{tabular}{|l|c|}
\hline Window Type & STC \\
\hline Single pane & 26 \\
\hline Dual pane & 34 \\
\hline Triple pane & 43 \\
\hline
\end{tabular}

Significant further research is recommended to improve the accuracy of the models and relationships selected for implementation in this thesis.

\subsubsection{Applying Acoustic Theory in Grasshopper}

Once the geometry of the analysis space is defined in Rhino, the material absorption coefficients are assigned within a Pachyderm acoustics panel. The location of the sound source and sound receiver are specified as points in the Rhino model and the ray tracing simulation is computed in Grasshopper. The theory presented above was applied as Python components within Grasshopper to produce estimates for attenuation, STL, STI and RT. Recommendations for further work include creating components which more easily allow the change of surface absorbance coefficients within Grasshopper, as material properties are currently assigned in Rhino.

\subsection{Thermal Comfort Model}

\subsubsection{Thermal Comfort Theory Fundamentals}

Following Fanger's widely accepted theory on thermal comfort, six factors effect an occupants comfort [64]. Metabolic rate, clothing insulation, air temperature, radiant temperature, air speed and humidity have all been proven to affect the sensation an occupant experiences indoors [64],[65]. Thermal comfort is usually represented in metrics 
such as the thermal sensation scale, predicted mean vote, percent dissatisfied and unmet hours [66].

Fundamental thermal comfort theory is rooted in the thermal balance between a human body and its surroundings. Equation (14) displays how the thermal mass balance for a human body can be represented, given that the human body is typically $33^{\circ} \mathrm{C}$ to $34^{\circ} \mathrm{C}$ [66]. It should be noted that the work and metabolic term can be represented as $\eta$ which is the body's mechanical efficiency defined by the ratio of work [67].

Where:

$$
\begin{aligned}
M-W=q_{s k} & +q_{\text {res }}+S \\
& =(C+R+E)_{\text {skin }}+(C+E)_{\text {respiration }}+S_{\text {skin }} \\
& +S_{\text {core }}
\end{aligned}
$$

$M=$ Rate of metabolic heat production, $\mathrm{W} / \mathrm{m}^{2}$

$W=$ Rate of mechanical work accomplished, $\mathrm{W} / \mathrm{m}^{2}$

$q_{s k}=$ Total rate of heat loss from skin, $\mathrm{W} / \mathrm{m}^{2}$

$q_{\text {res }}=$ Total rate of heat loss from respiration, $\mathrm{W} / \mathrm{m}^{2}$

$C=$ Convective heat loss, $\mathrm{W} / \mathrm{m}^{2}$

$R=$ Radiative heat loss, $\mathrm{W} / \mathrm{m}^{2}$

$E=$ Evaporative heat loss, $\mathrm{W} / \mathrm{m}^{2}$

$S_{\text {skin }}=$ Rate of heat storage in the skin compartment of an occupant, W/m $\mathrm{m}^{2}$

$S_{\text {core }}=$ Rate of heat storage in the core compartment of an occupant, $\mathrm{W} / \mathrm{m}^{2}$

Metabolic rate is usually predicted by assuming the type of activity level occurring in the space on an average day of operation. Values range from $40 \mathrm{~W} / \mathrm{m}^{2}$ to $300 \mathrm{~W} / \mathrm{m}^{2}$ of a human body's surface area for sleeping and high intensity training cardio respectively. A typical conversion rate used in the proposed methodology is $117 \mathrm{~W} / \mathrm{met}$ [45].

A thermal or mass balance relies of the properties of the boundary conditions between the system and surroundings; in the case of thermal comfort the human body can be considered the system. The geometry of the human body, complex as it is, can be represented by and equation which correlated the weight of a person and their height [66]. 
The equation estimates the total skin surface area a body has, which is critical information for the balancing of energy between an occupant's body and their surroundings. The surface area of a person can be calculated using equation (15) and is referred to as the DuBois surface area [68].

$$
A_{D}=0.202 m^{0.425} l^{0.725}
$$

Where:

$$
\begin{aligned}
& A_{D}=\text { DuBois surface area, } \mathrm{m}^{2} \\
& m=\text { Mass, } \mathrm{kg} \text { (average person is } 70 \mathrm{~kg} \text { ) } \\
& l=\text { Height, } \mathrm{m} \text { (average person } 1.73 \text { ) }
\end{aligned}
$$

Since the human body, like any mass, can store thermal energy, the $S_{\text {skin }}$ and $S_{\text {core }}$ values must be determined for the thermal balance of an occupant. The human body is separated into separate storage compartments. Equation (16) and (17) display how the storage of the human core and skin is modeled for thermal comfort [64],[66].

$$
\begin{gathered}
S_{\text {core }}=\frac{\left(1-\alpha_{s k} i n\right) m c_{p, b}}{A_{D}} \times \frac{d t_{\text {core }}}{d \theta} \\
S_{\text {skin }}=\frac{\alpha_{\text {skin }} m c_{p, b}}{A_{D}} \times \frac{d t_{\text {skin }}}{d \theta}
\end{gathered}
$$

Where:

$$
\begin{aligned}
& \alpha_{s k}=\text { Fraction of body mass concentrated in the skin compartment, } \mathrm{m}^{2} \\
& m=\text { Mass, } \mathrm{kg} \\
& c_{p, b}=\text { Specific heat capacity of a body, } 3490 \mathrm{~J} /(\mathrm{kg} \mathrm{K}) \\
& A_{D}=\text { DuBois surface area, } \mathrm{m}^{2} \\
& t_{\text {core }}=\text { Temperature of core compartment, }{ }^{\circ} \mathrm{C} \\
& t_{\text {skin }}=\text { Temperature of skin compartment, }{ }^{\circ} \mathrm{C} \\
& \theta=\text { Time, } \mathrm{s}
\end{aligned}
$$


The other values in the occupant body heat balance equation are heavily affected by the properties of the space. Both convective and radiative heat transfer off the human skin are influenced by the operative temperature of the space. Equation (18) displays how operative temperature is calculated. The heat transfer coefficients are combined due to the complex relationship between the two factors and the human skin [66].

$$
t_{0}=\frac{h_{r} \bar{t}_{r}+h_{c} t_{a}}{h_{r}+h_{c}}
$$

Where:

$t_{0}=$ Operative temperature, $\mathrm{K}$

$h_{r}=$ Radiative heat transfer coefficient, $\mathrm{W} /\left(\mathrm{m}^{2} \mathrm{~K}\right)$

$\bar{t}_{r}=$ Mean radiant temperature, $\mathrm{K}$

$h_{c}=$ Convective heat transfer coefficient, $\mathrm{W} /\left(\mathrm{m}^{2} \mathrm{~K}\right)$

$t_{a}=$ Air temperature, $\mathrm{K}$

The mean radiant temperature is calculated using the temperature of the space surfaces and space geometry. As seen in equation (19), the mean radiant temperature is determined by taking the sum of all the rooms surface temperatures, multiplied by angle factors for each surface value. Fanger determined the angle factor relationships in 1982 and articulated the results in charts. Determining the mean radiant temperature can be a source of computational complexity if trying to accurately model thermal comfort. In most simulation software's, such as in EnergyPlus the view factor calculation is simplified or omitted entirely [66].

$$
\bar{t}_{r}=t_{1} F_{p-1}+t_{2} F_{p-2}+\cdots+t_{N} F_{p-N}
$$

Where:

$\bar{t}_{r}=$ Mean radiant temperature, $\mathrm{K}$

$t_{N}=$ Temperature of surface $\mathrm{N}, \mathrm{K}$

$F_{p-N}=$ Angle factor between a person and surface $\mathrm{N}$ 
With the operative temperature determined, the convective and radiative heat transfer term off the human skin can be calculated. Equation (20) defines how the convective and radiative heat loss occurs on the skin. The $R_{c l}$ term is determined by the level of clothing the occupant is expected to wear in the space. The $\mathrm{R}$ term has been standardized using a unit called clo, which is used to quantify the level of clothing someone wears. Low to high clo levels range from 0.36 to 1.37 . To determine an $R_{c l}$ estimate the clo metric is multiplied by $0.155\left(\mathrm{~m}^{2} \mathrm{kPa}\right) / \mathrm{W}$ [69]. ASHRAE offers a description of different outfit ensemble types and the corresponding clo levels [66].

Where:

$$
C+R=\frac{t_{\text {skin }}+t_{O}}{R_{c l}+\frac{1}{\left(f_{c l} h_{c}\right)}}
$$

$t_{\text {skin }}=$ Skin temperature, $\mathrm{K}$

$R_{c l}=$ Thermal clothing resistance, $\left(\mathrm{m}^{2} \mathrm{kPa}\right) / \mathrm{W}, R_{c l}=0.155 \times$ clo level

$f_{c l}=$ Clothing area factor (ratio of clothing to exposed skin)

$h_{c}=$ Combined convective and radiative heat transfer coefficients, $\mathrm{W} /\left(\mathrm{m}^{2} \mathrm{~K}\right)$

The evaporative component of heat loss on the skin can be quantified by equation (21) $E_{\text {skin }}$ is determined by taking the sum of evaporative heat loss by diffusion of water through the skin with the evaporative heat loss by regulatory sweating [66].

$$
E_{\text {skin }}=0.35\left(1.92 t_{\text {skin }}-25.3-p_{a}\right)+0.42(M-W-58)
$$

Where:

$$
p_{a}=\text { The water vapour partial pressure in indoor air, } \mathrm{kPa}
$$

As a person breathes there are also losses attributed to the respiratory process. These losses can be broken down into convective and evaporative relationships. The operative temperature and humidity level of the space directly impact how heat loss is experienced 
by a person. Equation (22) displays the sum of the convective and evaporative heat loss due to respiratory processes in the human body [66].

$$
\begin{aligned}
C_{\text {respiration }}+ & E_{\text {respiration }} \\
& =0.0014 M\left(34-t_{0}\right)+1.73 \cdot 10^{-5} M\left(5870-p_{s}\right)
\end{aligned}
$$

Where:

$$
p_{s}=\text { Saturated water vapour pressure at the humid operative temperature, } \mathrm{kPa}
$$

With all the terms substituted into the initial thermal balance between and occupant and their surroundings, the thermal comfort equation can be computed. The objective as the engineer is to maintain the storage of the human body's energy by ensuring the surrounding environment does not remove excessive energy from the occupant. As noted earlier in this section, the predicted mean vote model (PMV), established by Fanger in 1970 is a metric frequently used in thermal comfort studies and is based on a re-arranged format of the occupant thermal balance equation. It was established by examining occupants in a controlled environment while they documented their thermal experience. Equation (23) is the mathematical representation of the PMV model [66]. The optimal condition of comfort is articulated by a PMV value of 0 , however a range between -0.5 and +0.5 is considered acceptable [70].

$$
\begin{gathered}
P M V=[0.352 \exp (-0.043 M)+0.032] \times\{M(1-\eta) \\
-0.35\left[43-0.061 M(1-\eta) p_{a}\right]-0.42[M(1-\eta)-58] \\
-0.0023 M\left(44-p_{a}\right)-0.0014 M\left(34-t_{0}\right)-f_{c l} \alpha_{c}\left(t_{h}-t_{0}\right) \\
\left.-3.96 \cdot 10^{-8} f_{c l}\left[\left(t_{h}+273\right)^{4}\right]\right\}
\end{gathered}
$$

A more non-technical format often used to describe thermal comfort, one better used to present to non-technical stakeholders, is predicted percent dissatisfied (PPD). This metric is based on studies conducted by Fanger in which occupant personal satisfaction was 
correlated with thermal experience. The model can be mathematically calculated using equation (24) [66].

$$
P P D=100-95 \exp \left[-\left(0.03353 P M V^{4}+0.2179 P M V^{2}\right)\right]
$$

In many cases, it is difficult to go through the process of modeling all the different biometric aspects of the human body and thermal aspects of the built environment. To simplify the thermal comfort modeling process for practitioners, ASHRAE developed Standard 55 for air properties [71]. Standard 55 defines acceptable operative temperature conditions that should be maintained within a space and takes into consideration the fact that humans alter their clo level in the summer and winter months. The unmet hours metric is typically defined as the hours in a year where the space in question is not meeting the standard 55 recommendations.

Standard 55 also outlines an assortment of recommendations for acceptable conditions like tolerable air movement, radiant asymmetry and floor temperature. Many building codes, such as the Ontario Building Code, LEED or the WELL building standard require compliance of ASHRAE standard 55 through either predictive performance modeling or prescriptive design recommendation which guarantee standard compliance $[72],[38],[39]$. This entails that modeling of thermal comfort is a critical aspect of industry, especially in design cases where aspects of codes or certification programs require justification of design choices. 


\subsubsection{Thermal Discomfort Due to Asymmetry}

Thermal discomfort can also be caused due to the asymmetry of temperature within a space. This is most significant if there are large windows on one side of a space or if radiant panels operate at too extreme of a temperature. ASHRAE offers recommended thresholds, seen in Table 2.6, of temperature surface difference along with the recommendation to prevent any more than a $3^{\circ} \mathrm{C}$ temperature gradient over the occupants body [71].

Table 2.6 - Allowable radiant temperature asymmetry from ASHRAE standard 55.

\begin{tabular}{|c|c|c|c|}
\hline $\begin{array}{c}\text { Ceiling warmer } \\
\text { than floor }\end{array}{ }^{\circ} \mathbf{C}$ & $\begin{array}{c}\text { Ceiling cooler } \\
\text { than floor }{ }^{\circ} \mathbf{C}\end{array}$ & $\begin{array}{c}\text { Wall warmer than } \\
\text { air }^{\circ} \mathbf{C}\end{array}$ & $\begin{array}{c}\text { Wall cooler than } \\
\text { air }^{\circ} \mathbf{C}\end{array}$ \\
\hline$<5$ & $<14$ & $<23$ & $<10$ \\
\hline
\end{tabular}

\subsubsection{Thermal Discomfort Due to Solar Gains}

In order to fully incorporate all aspects of thermal discomfort in the proposed methodology there must also be consideration of how natural light radiating on a person causes discomfort. Effective radiant field (ERF) is the radiant energy flux to or from a human body and is added to the mean radiant temperature calculated by equation (25) [73]. ERF

relies on solar climate data, the degree of exposure the body has, the reflectivity of surrounding surfaces, the solar transmittance of any glass and the absorptivity of the persons surface. 


$$
\begin{aligned}
E R F_{\text {solar }}=( & 0.5 f_{\text {eff }} f_{\text {svv }}\left(I_{\text {diff }}+I_{T H} R_{\text {floor }}\right) \\
& \left.+A_{P} f_{\text {bes }} I_{\text {dir }} / A_{D}\right) T_{\text {sol }}\left(\alpha_{S W} / \alpha_{L W}\right)
\end{aligned}
$$

Where:

$$
\begin{array}{ll}
f_{\text {eff }}=\text { Fraction of body exposed to sun } & f_{\text {bes }}=\text { Fraction of body exposed to sun } \\
f_{\text {svv }}=\text { Fraction of sky vault exposed to } & I_{\text {dir }}=\text { Direct solar beam intensity } \\
\text { body } & A_{D}=\text { DuBois surface area of person } \\
I_{\text {diff }}=\text { Diffuse solar intensity } & T_{s o l}=\text { Glazing solar transmittance } \\
I_{T H}=\text { Total horizontal solar intensity } & \alpha_{S W}=\text { Shortwave radiation absorptivity } \approx 0.67 \\
R_{f l o o r}=\text { Floor reflectivity } \approx 0.2 & \alpha_{L W}=\text { Longwave radiation absorptivity } \approx 0.95 \\
A_{P}=\text { Projected area of occupant's body } &
\end{array}
$$

\subsubsection{Applying Thermal Comfort Theory in Grasshopper}

Thermal comfort models in EnergyPlus provide the PMV and PPD metrics calculated in equations (23) and (24) but are limited in accuracy and implementation by how the mean radiant temperature can be calculated. This is because the default in energy plus is to take an average of all the surface temperatures in the room or a weighted average of every surface temperature in the room. There is also the option in EnergyPlus to input angle factors from an occupant's location manually, making it difficult to keep up with parametrically changing or complex geometries.

Thermal comfort modeling within Grasshopper is made possible with a series of Ladybug components. First an occupant mannequin made up of 481 surfaces is placed at a user specified point within the analysis space. The body posture is specified and the angle that the person is facing is also specified. The center point of all 481 of the mannequin's surfaces is identified and 31 points evenly distributed across the body are kept for further calculation. Figure 2.3 visualizes a thermal mannequin with 31 selected analysis points highlighted in green. 


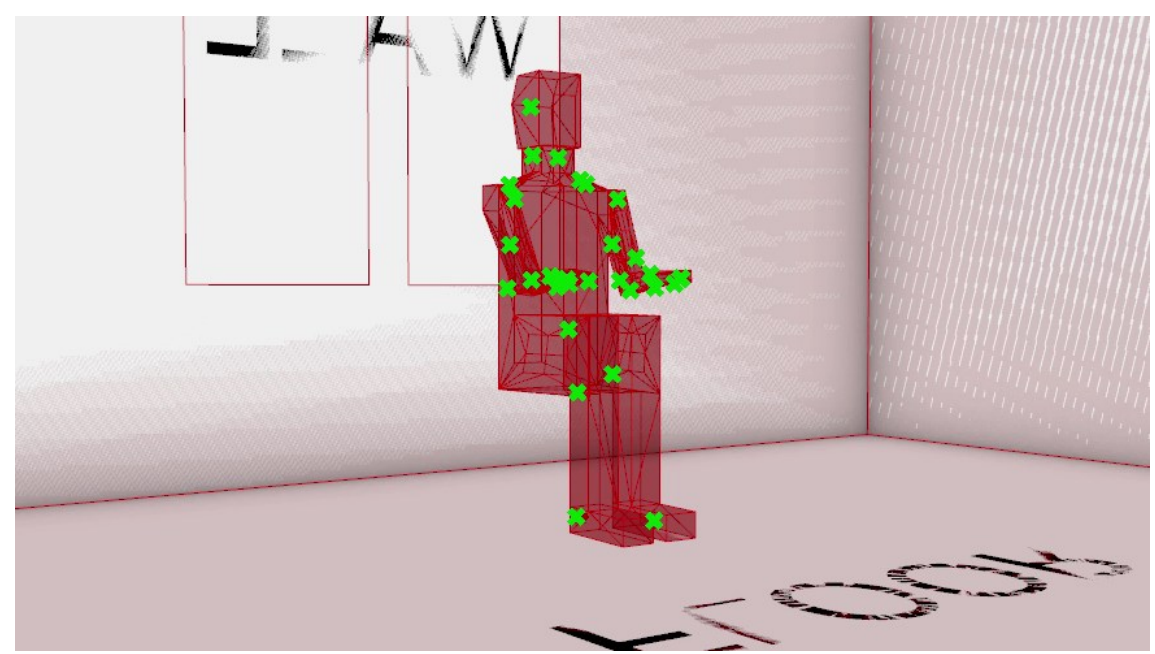

Figure 2.3 - Typical Ladybug occupant mannequin used for thermal comfort analysis.

View factors are calculated for all 31 points on the mannequin to all the surfaces within the analysis zone. Within the Ladybug view factors tool, rather than explicitly performing calculations using Fanger's view factor charts, view factors are calculated using ray tracing; by breaking down a spherical view percentage of area that each surface occupies at the analysis point. Hourly internal surface temperatures are extracted from the energy model. The view factors are then used to calculate the effect of internal surface temperature on mean radiant temperature, using equation (19), at all 31 points on the occupant mannequin.

The highest, lowest and average mean radiant temperatures that the occupant mannequin experiences is used to calculate PMV/PPD. This provides a range of coldest, warmest and average experiences and provides insight to the risk of discomfort due to radiant factors. The PMV/PPD is calculated using equations (23) and (24) in a Ladybug component. Hourly dry bulb temperature is collected from the energy model results and applied to the equations. 
A Python component was written to incorporate thermal comfort due to asymmetry as specified in Table 2.6 and to test for any more than a $3^{\circ} \mathrm{C}$ temperature gradient over the occupants body. Hours of discomfort due to radiant asymmetry are recorded for each design iteration.

Assumptions have been made to more feasibly manage air velocity and relative humidity within the analysis space. Air velocity experienced over the occupant and relative humidity within the analysis space is specified by the user and assumed controlled or must be included in the parametric analysis.

Air velocity over the occupant is difficult to predict without highly costly computational fluid dynamics (CFD). This is because placement of air diffusers, volumetric flow rate of supply air, air temperature, surface temperatures and location of occupants all play a role in the behavior of air movement. The anticipated movement of air experienced by an occupant also changes depending on if the HVAC system is a DOAS/Radiant or fan coil. To omit the need for CFD, the air velocity is inputted into the analysis script as a parameter slider ranging from $0 \mathrm{~m} / \mathrm{s}$ to $0.5 \mathrm{~m} / \mathrm{s}$ as this is a range of air velocities assumed to be anticipated in an average space. Future work recommendations include incorporating a component that estimates experienced air velocity based on a ruleof-thumb or adding a stable simplified CFD model into the script.

Relative humidity is not well represented in energy models produced by Honeybee without additional system specification using Ironbug. Systems generated to represent a radiant DOAS scenario lack the incorporation of humidity management as a default. For the purposes of this iteration of the framework, relative humidity is assumed to be maintained constant or can be incorporated in the iterative analysis to observe the impact 
of a changing $\mathrm{RH}$ to hours of comfort. Future work recommendations include the incorporation of humidification and dehumidification systems using the Ironbug suite.

Direct solar radiation discomfort has been incorporated using a Honeybee component following supporting theory used to develop equation (25). The component incorporates the shading of opaque surfaces, ground reflectivity and the visible transmissivity of the window in the analysis space. The solar adjusted MRT is then passed through a PMV/PPD calculator to calculate the hours of discomfort with solar irradiance incorporated.

Thermal comfort is a topic well covered in literature and supported by tools like Ladybug or Honeybee. Table 2.7 displays a review of what metrics are produced by the thermal comfort model and a brief review of why the data was managed in this way.

Table 2.7 - Thermal comfort metrics generated by current iteration of tool.

\begin{tabular}{|c|c|}
\hline Result Recoded per Iteration & Comments \\
\hline Hours of discomfort from highest MRT & \multirow{3}{*}{$\begin{array}{l}\text { In the script, the MRT is calculated for all } \\
31 \text { points at every hour of the year. This } \\
\text { leads to } 271560 \text { datapoints. The min, max } \\
\text { and average are pulled to simplify } \\
\text { PMV/PPD computation costs. }\end{array}$} \\
\hline Hours of discomfort from lowest MRT & \\
\hline Hours of discomfort from average MRT & \\
\hline $\begin{array}{l}\text { Hours of discomfort from average MRT } \\
\text { augmented with direct solar }\end{array}$ & $\begin{array}{l}\text { The average MRT experienced over the } \\
\text { occupant's body is morphed to incorporate } \\
\text { the direct solar heat gains. }\end{array}$ \\
\hline Hours of discomfort due to asymmetry & $\begin{array}{l}\text { Number of hours that fall outside } \\
\text { specified surface temperature difference } \\
\text { limits }\end{array}$ \\
\hline Total hours of discomfort & $\begin{array}{l}\text { The total hours of discomfort are the sum } \\
\text { of the values in the table above. If the } \\
\text { occupant was uncomfortable for the entire } \\
\text { year, for all reasons, the maximum } \\
\text { possible hours of discomfort are } 26350 \text {. }\end{array}$ \\
\hline PPD from highest MRT & \multirow{3}{*}{$\begin{array}{l}\text { PPD is also recorded, for a metric with } \\
\text { more intuitive meaning. }\end{array}$} \\
\hline PPD from lowest MRT & \\
\hline PPD from average MRT & \\
\hline
\end{tabular}




\subsection{Indoor Air Quality Model}

There are many different types of air contaminants that can reduce the quality of the air within a space. Particulates are difficult to model due to the complex nature of how they settle, store and re-agitate [74]. Gaseous contaminants that can more easily be assumed to be well mixed in a zone can be modeled using fundamental mass balance theory once the source rates of the contaminant have been identified and there is no significant decay rate for the contaminant. There is a range of air contaminants that can be perceived by an occupant and if there are extenuating circumstance or a specific source in a zone, one could model that specific gaseous contaminant using ASHRAE resources [74]. The most common air quality measures are carbon dioxide and the perception of odour, which both rely on mass balance theory and occupant perception data to create models as discussed in the next sections.

\subsubsection{Carbon Dioxide Modeling}

Carbon dioxide concentration levels is a primary indicator for air quality within the analysis space as it is the most prevalent air quality indicator metric in supporting literature and industry standards [75]. Comfort related to carbon dioxide levels in a space is influenced by occupant density, occupant activity level, building infiltration rates and ventilation rates. Typical desired conditions for carbon dioxide range below 700 ppm above outdoor air concentration, given that the outdoor air is at acceptable levels of about $350 \mathrm{ppm}$ [41]. A mass balance is required to calculate how the carbon dioxide changes within a space over time. 
The fundamental mass balance to determine change in carbon dioxide air concentration is seen in equation (26).

Where:

$$
\frac{d C_{i}}{d t}=\frac{S_{C O_{2}}}{V}+P C_{o} Q-C_{i} Q-k C_{i}
$$

$C_{i}=$ The indoor $\mathrm{CO}_{2}$ concentration, $\mathrm{mg} / \mathrm{m} 3$

$C_{o}=$ The outdoor $\mathrm{CO}_{2}$ concentration, $\mathrm{mg} / \mathrm{m}^{3}$

$S_{\mathrm{CO}_{2}}=$ The $\mathrm{CO}_{2}$ generation rate, $\mathrm{mg} / \mathrm{hr}$

$V=$ Is the space volume, $\mathrm{m}^{3}$

$P=$ Fraction of outdoor air

$Q=$ Outdoor ventilation rate, $\mathrm{m}^{3} / \mathrm{hr}$

$\mathrm{K}=$ Is any $\mathrm{CO}_{2}$ removing process within the zone

In order to examine the carbon dioxide concentration within an analysis space at any given timestep, the equation is solved assuming well mixed air and static source behavior as seen in equation (27). Where $C_{i}(0)$ is the indoor air concentration initially, assumed to be outdoor air concentration if it is the first hour of the year [76].

$$
C_{i}(t)=\frac{P Q C_{0}+\frac{S_{C O_{2}}}{V}}{(Q+k)}\left(1-e^{-(Q+k)^{t}}+C_{i}(0) e^{-(Q+k) t}\right)
$$

Given the predicted indoor air concentration, it is possible to predict the percent dissatisfied of the occupants within the space. The correlation between indoor air carbon dioxide concentration and the typical dissatisfaction a person would have to the quality of the air within the space is expressed as PD in equation (28), [76]. Values of percent dissatisfied aim to remain below $700 \mathrm{ppm}$, or $15 \%$.

$$
P D=395 * \exp \left[-17.55 *\left(C_{\text {in }}-C_{\text {out }}\right)^{-0.25}\right]
$$




\subsubsection{Applying Air Quality Theory in Grasshopper}

Within EnergyPlus there is the ability to model carbon dioxide concentration at each timestep and the ability to specify a carbon dioxide generation rate based on an occupant's metabolic rate. This feature is less accessible in EnergyPlus's Grasshopper representation without significant manual insertion of additional strings to the idf file. To make the simulation of carbon dioxide be more accessible in Grasshopper, rather then having the simulation engine complete the calculation itself, an additional Python script component using equation (27) is used after the energy model has been run. The results for zone mechanical ventilation air changes, zone infiltration air change rate, occupant count, metabolic rate and outdoor air concentration can be used as inputs to feed into the equation (27). The $\mathrm{CO}_{2}$ generation rate is assumed to be $26,000 \mathrm{mg} / \mathrm{met}$ and the outdoor air concentration is assumed to be $350 \mathrm{ppm} \mathrm{[45].} \mathrm{Equation} \mathrm{(28)} \mathrm{is} \mathrm{then} \mathrm{used} \mathrm{to} \mathrm{determine} \mathrm{the}$ predicted percent dissatisfied. The minimum, maximum and average PD and $\mathrm{CO}_{2}$ is recorded in the optimization phase.

\subsubsection{Olfactory Modeling}

Human responses to odour within a space is also a well supported air quality aspect in literature [77]. There has been research conducted on how people perceive specific indoor pollutants and the associated odour intensity however it is difficult to identify, measure and track which exact combinations of contaminants will be present within a space and how occupants will perceive them [78]. The olfactory unit is a generalized unit intended to quantify the perception odour, of an unspecified chemical composition, within a space [79].

One olf is quantified as the air pollution from one sedentary person at any instantaneous 
time. A correlation between predicted percent dissatisfied and $\mathrm{L} / \mathrm{s}$ of fresh air per olf in a space has been created by Fanger in a series of studies as seen in equation (29), where $\mathrm{q}$ is L/s of fresh air per olf [79].

$$
\begin{array}{lr}
P D=395 * \exp \left[-3.66 * q^{0.36}\right] & \text { for } q \leq 0.332 \\
P D=100 \% & \text { for } q \leq 0.332
\end{array}
$$

Buildings themselves are anticipated to also produce odour and is incorporated into the total olfactory loading of a zone. Typical odor loading ranges from $0.1 \mathrm{olf} / \mathrm{m}^{2}$ to $0.2 \mathrm{olf} / \mathrm{m}^{2}$ and depend on the freshness or emission of finishes within a space [77]. Typical olfactory loading profiles can be seen in Table 2.8.

Table 2.8 - Sensory pollution rates for occupants.

\begin{tabular}{|l|c|}
\hline Source & Sensory Load \\
\hline Sedentary person (1 Met) & 1 Olf \\
\hline Low level exercise (3 Met) & 4 Olf \\
\hline Medium level exercise (6 Met) & 10 Olf \\
\hline Children & 1.2 Olf \\
\hline Youth & 1.3 Olf \\
\hline
\end{tabular}

The data in Table 2.8 can also be represented in terms of a simplified linear function in order to better incorporate changes to occupant's activity level. The simplified, linear relationship of olfactory loading based on occupant metabolic rate can be seen in equation (30).

$$
O L F=1.8158 * M E T-1.0526
$$




\subsubsection{Applying Indoor Air Quality Theory in Grasshopper}

Olfactory loading is not an available feature in EnergyPlus and must be calculated using results generated by the energy model. An occupant's metabolic rate is specified given the predicted use of the space and then applied to the occupant count of the space on an hourly basis. The building olfactory emission rate is also specified and then calculated given the known floor area of the zone. The ventilation and infiltration rates of the analysis zone are pulled from the energy model and then equation (29) is used to estimate the predicted percent dissatisfied. The average, lowest, and maximum values of PD are also recorded in the chance they provide additional insight.

\subsection{Optimization or Parametric Analysis}

\subsubsection{Optimization Theory}

Optimization and parametric analysis are processes used to explore a solution space of parameters in the context of generative design [21]. Optimization is considered a form of parametric analysis in most contexts [6], [80]. Parametric analysis is the manipulation of parameters in a function or model to observe the change in results, however the possible strategies used to manipulate the parameters varies in complexity. There is an expansive range of research in the topic of parametrics and optimization however Figure 2.4 visualizes the spectrum of analysis strategy complexity available from lowest complexity to highest. In every case, the purpose is to generate data that can be used to examine the relationship between changes to the input parameters and the function/model results [6], [81], [82]. 


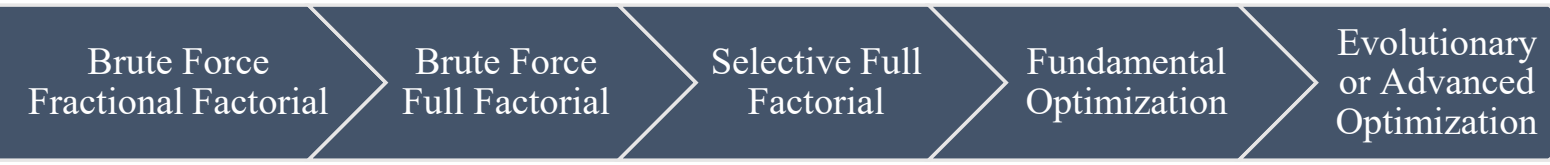

Figure 2.4 - Spectrum of complexity for parametric analysis in generative design.

Fractional factorial analysis is the lowest complexity of parametrics; where each parameter is manipulated individually. This is best for examining the impact of specific changes to a design but omits the effect of combining parameter changes. Full factorial is the combining of sets of parameter changes, this approach allows the study of combination of changes but exponentially increases the required number of computations. Brute force implies the exhaustive search of values within the acceptable range of every parameter at a set interval and is a very time intensive approach. Selective full factorial implies parametric studies with large solution spaces that are examined by managing the scope of analysis; by defining larger integer steps for parameter ranges or conducting a staged approach where most sensitive parameters are examined in higher detail. Fundamental optimization refers to the application of more basic optimization algorithms which take longer to converge on a global optimum while evolutionary algorithms incorporate more advanced math to achieve equation (31), [19].

$$
\min _{x \in \boldsymbol{X}} f(\boldsymbol{x})=f\left(x^{*}\right) \quad \text { OR } \quad \max _{x \in \boldsymbol{X}} f(\boldsymbol{x})=f\left(x^{*}\right)
$$

Where:

$\boldsymbol{x}=$ Design variable or parameter vector

$x^{*}=$ Optimal value within a feasible solution space 
Technical and mathematical details of how evolutionary and other optimization algorithms extend past the scope of this thesis' theory.

\subsubsection{Applying Optimization Theory in Grasshopper}

There are three main tools available to facilitate optimization within Grasshopper however there are many tools being published on Grasshopper's open-source collaboration websites. Galapagos, Grasshopper's mainline optimization tool offers evolutionary optimization capabilities and is intended to explore the entire solution space, to identify local and global optimums [83]. Wallacei is also an evolutionary optimization tool. These two tools are effective for design exploration but require significant computational power and have indicated stability issues when dealing with heavy daylight, energy or acoustic simulations.

Opossum is an optimization tool that utilizes IBM's RBFOpt algorithms [84]. Rather than being an evolutionary solver, it uses the radial basis function to more quickly find a global optimum and has been proven to be faster at converging [85].The Opossum tool interface can be seen in Figure 2.5.
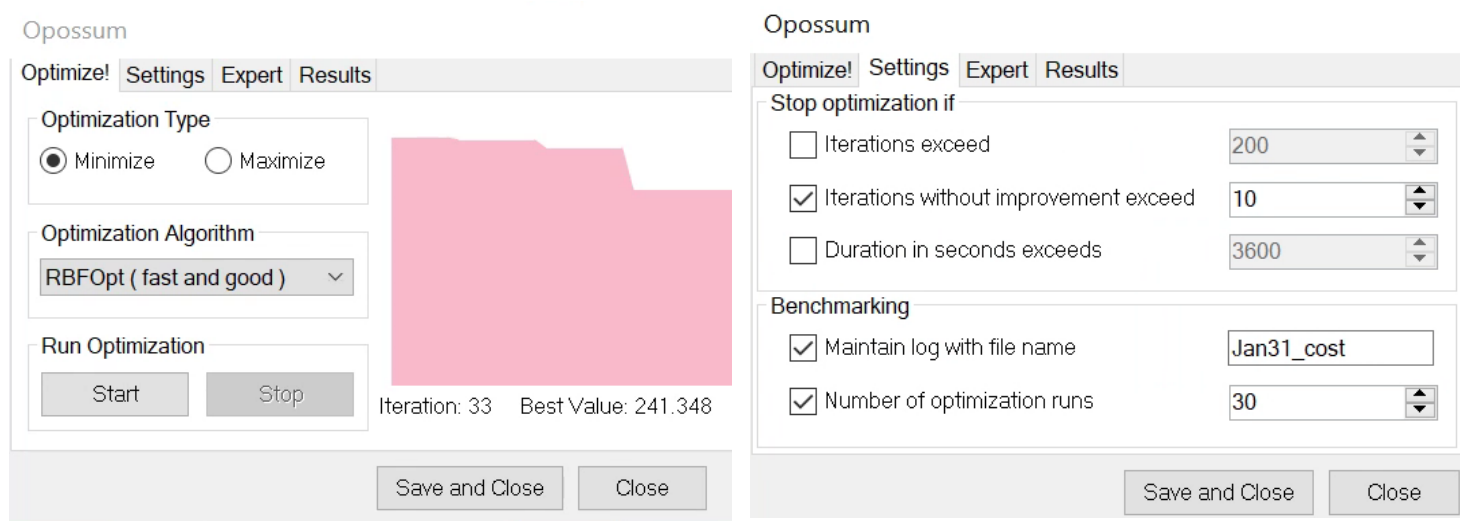

Figure 2.5 - Opossum interface and typical recommended settings. 
The tool's default recommends 20 iterations without improvement as the termination threshold and with one optimization run. This means that if the algorithm cannot find a better solution after twenty attempts, the optimization run will stop. For the purposes of more complex solution spaces like the ones being examined for this thesis, a lower iteration threshold was selected, and a higher number of optimization runs was selected. The purpose of specifying more optimization runs is to have the optimization restart and begin the analysis at randomly different regions of the solution space. In order to ensure the algorithm does not converge at a local optimum rather than the ideal global optimum, several optimization runs provide better confidence in the results as long as the convergence between runs agrees with one another.

Evolutionary optimization algorithms find optimal values for vector $\boldsymbol{x}$ in equation (31) by combining successful parameter vectors with semi-randomly generated parameter vectors until it is no longer possible to positively alter the outcome further [86]. Radial basis function optimization represents $f(\boldsymbol{x})$ in equation (31) as a series of arrays, or nodes if represented spatially, and identifies the value of $\boldsymbol{x}$ required to minimize the array. As a spatial representation, the radial basis function finds the shortest path between nodes to find the global shortest path which ends up identifying the optimal value of $\boldsymbol{x}$ within equation (31) [85]. The radial basis linear system as seen in equation (32) determines the global optimum by iterating through different combinations of $x$, within $\mathrm{F}$ and $\Phi$ [84]. The relationship is solved with different sets of $x$ for each iteration until the relationship produces a consistent and real values. If no further changes to $\mathrm{x}$ improve the target value, the optimum has been determined. 


$$
\left(\begin{array}{cc}
\Phi & P \\
P^{T} & 0_{(n+1) \times(n+1)}
\end{array}\right)\left(\begin{array}{l}
\lambda \\
h
\end{array}\right)=\left(\begin{array}{c}
F \\
0_{n+1}
\end{array}\right)
$$

With:

$$
\Phi=\left(\phi\left(\left\|x_{i}-x_{j}\right\|\right)\right)_{i, j=1, \ldots, k}, P=\left(\begin{array}{cc}
x_{1}^{T} & 1 \\
\vdots & \vdots \\
x_{k}^{T} & 1
\end{array}\right), \lambda=\left(\begin{array}{c}
\lambda_{1} \\
\vdots \\
\lambda_{k}
\end{array}\right), F=\left(\begin{array}{c}
f\left(x_{1}\right) \\
\vdots \\
f\left(x_{k}\right)
\end{array}\right)
$$

The value that the optimization algorithm will minimize or maximise must be specified. There are two strategies for exploring a solution space for the combined analysis of energy, thermal comfort, daylight, air quality and acoustics in the context of this thesis:

1. Conduct separate optimizations for each environmental category, while recording changes to all metric data. This identifies best possible conditions for all environmental categories but would take more resources to execute.

2. Create a generalized cost function combining metrics of similar scale. The cost function implemented in the case studies in future chapters is expressed in equation (33).

$$
f_{\text {cost function }}(\boldsymbol{x})=\sum\left(f(\boldsymbol{x})_{\text {Light }}+f(\boldsymbol{x})_{\text {Energy }}+f(\boldsymbol{x})_{\text {Air }}+f(\boldsymbol{x})_{\text {Thermal }}\right)
$$

Where:

$\boldsymbol{x}=$ Design variable or parameter vector

$f(\boldsymbol{x})_{\text {Light }}=$ Percent of total analysis hours outside the comfort thresholds

$f(\boldsymbol{x})_{\text {Energy }}=$ EUI in $\mathrm{kWh} / \mathrm{m}^{2}$

$f(\boldsymbol{x})_{\text {Air }}=$ PPD due to $\mathrm{CO}_{2}$ and PPD due to OLFs

$f(\boldsymbol{x})_{\text {Thermal }}=$ Percent of total analysis hours outside of comfort thresholds 
In the first strategy, the optimal value for each performance metric would be identified through separate optimization runs. The benefit of this approach is observing the exact optimal values that could be achieved for each of the performance metrics if all other performance categories were to be disregarded. This strategy would also help identify the sensitivity of metrics to specific parameters more clearly than if using a cost function. The problem with this approach is how much longer it would take to compute.

The second strategy is to use a cost function. In the context of this thesis, this is the selected and applied approach as it is computationally less intensive. The cost function balances all the different performance metrics by summing values that are similar in magnitude; all performance categories excluding energy are represented as percent dissatisfied and cannot exceed the value of $100 \%$. The cost function as seen in equation (33) sums the values of the indicator metrics for each of the performance categories, and the higher the value of the cost function the worse the overall performance of the analysis space. Energy is represented as $\mathrm{kWh} / \mathrm{m}^{2}$ and is driven to be as low a value as possible. The disadvantage of using a cost function is it is difficult to balance the performance categories evenly or prioritize performance metrics without arbitrary scaling factors. The single most optimal design combination would vary depending on what assumptions are made to make a cost function. In the case of this thesis, all performance categories were weighted evenly excluding energy.

Acoustics was omitted in the cost function as its metrics are less flexible to represent in a concise percentage or scale appropriate format. Acoustic results are still recorded and can be examined using the interactive plot. 


\subsection{Data Recording}

Data recording is a critical component of the optimization or parametric process within visual programming. As the parameters are changed and the functions or simulation engines are producing results, all inputs and outputs must be recorded and stored for analysis. The optimization tools in Grasshopper tend to only record parameters and the value that it is optimizing; creating the need for data recording of other still relevant performance metrics. Figure 2.6 shows how components can be assembled to ensure effective data recording in grasshopper. The last panel seen in blue streams results and saves any content that passes through it to an external file.

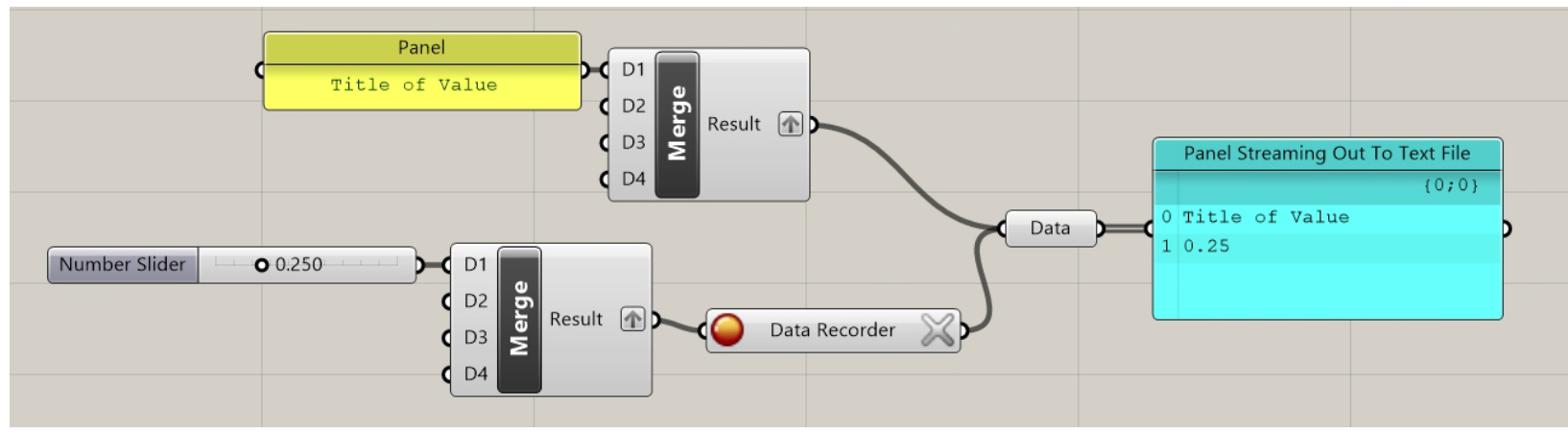

Figure 2.6 - Data recording setup in Grasshopper.

\subsection{Interactive Plots and Data Trend Visualization}

As discussed in Chapter 1, visualization and communication of results is a significant and very important component of the generative design process. The objective is to present data from parametric runs in a way that is accessible for stakeholders and decision makers. Three types of plots were investigated as useful tools for reviewing parametric results. Parallel coordinate plots, radar plots and pairgrid plots. 


\subsubsection{Parallel Coordinate Plot}

Interactive parallel coordinate plots are a data visualization strategy where design iterations are visualized as lines or threads across a series of vertical axes as seen in Figure 2.7 [87]. The vertical axes represent the numerical domain of the parameters and resulting metrics. Each design iteration is represented as a thread passing through all the vertical axis. Darker lines on the plot indicate higher frequency or density of design iterations. The interactive nature of the code used to produce this graph allows the user to select ranges on the vertical axis and observe design iteration threads that pass through the specified ranges as seen in Figure 2.8. This allows the navigation of data and helps facilitate other stakeholders in the understanding of results.

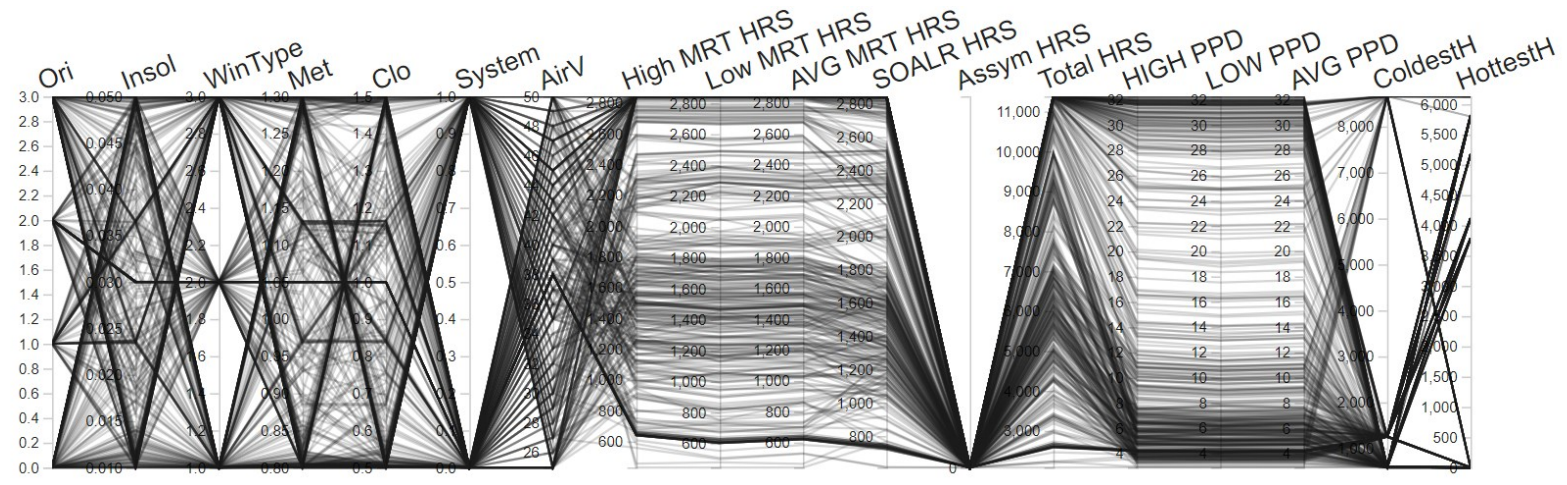

Figure 2.7 - Example parallel coordinate plot displaying optimization data.

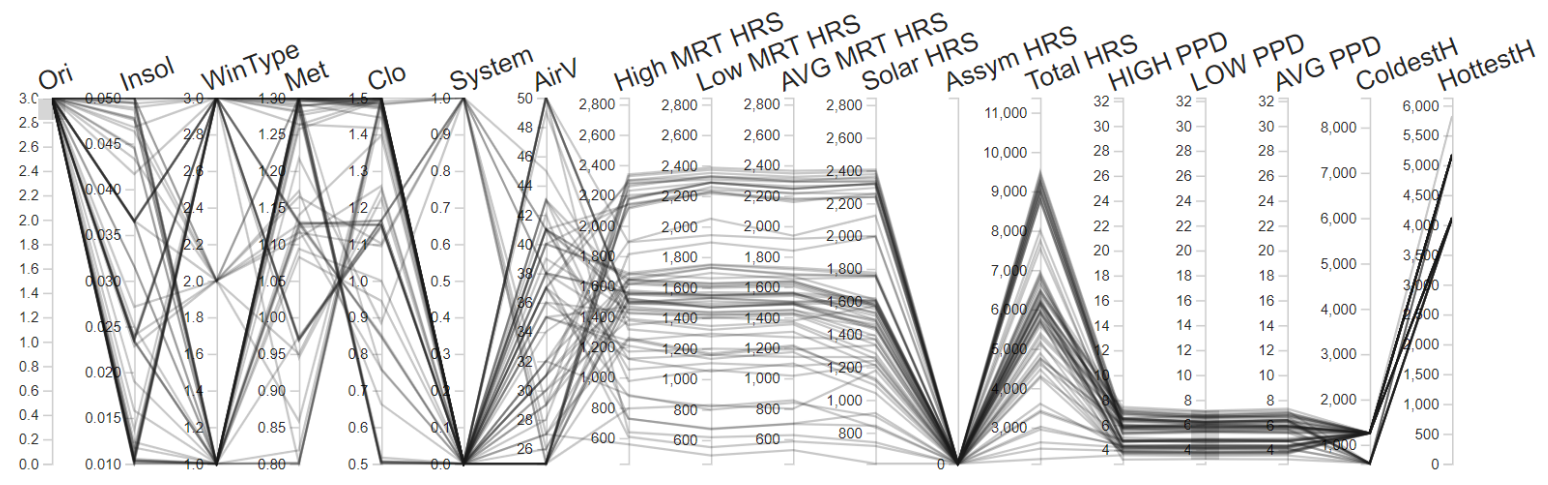

Figure 2.8 - Example parallel coordinate plot with ranges selected. 


\subsubsection{Radar Plots}

Radar plots (sometimes called spider plots) are an effective way to compare a smaller number of design options to one another. The Grasshopper visualization component Embryo can generate radar plots where each axis radiating out of the central point is a different performance metric. In Figure 2.9, the plots are comparing design options 198, 207 and 644 from an optimization run within Grasshopper. This is an additional strategy that can be used to review general profiles of design options but is limited by needing to ensure each axis is appropriate in the context of one another.
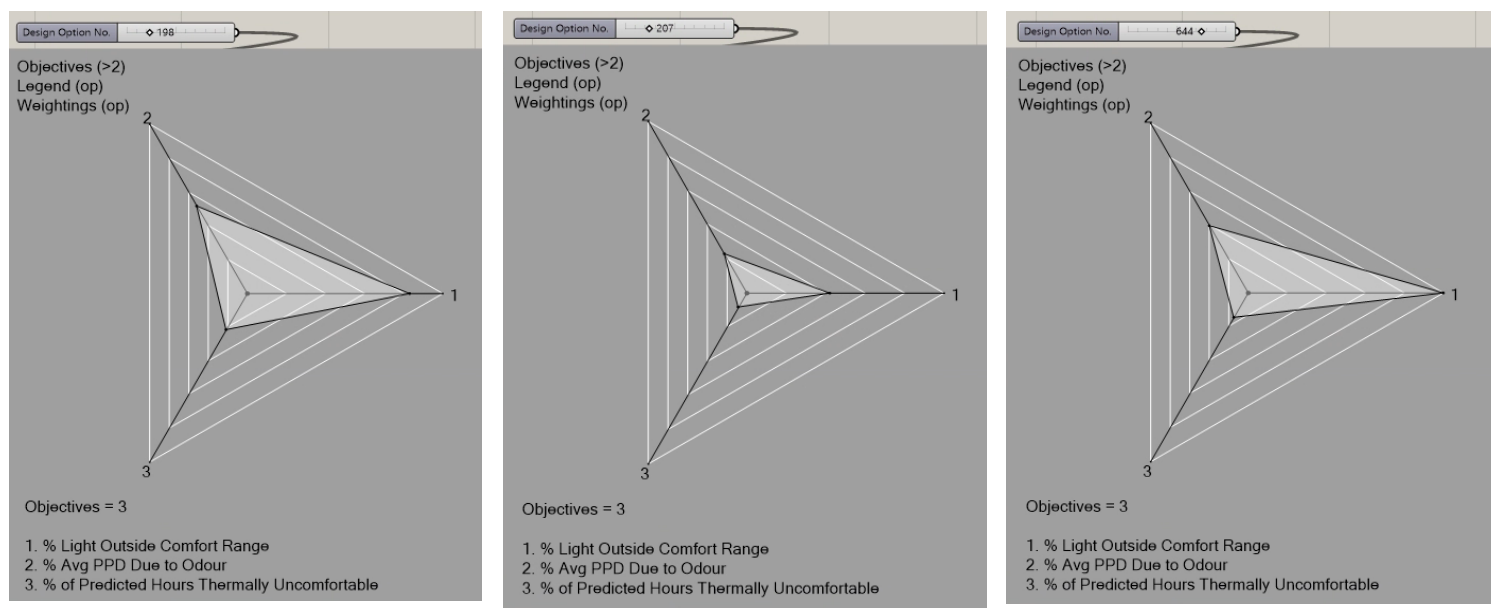

Figure 2.9 - Radar plots of three different design options.

\subsubsection{Pairgrid Plots}

Pairgrid plots are a static visualization strategy to display a large collection of data. They are effective for identifying the sensitivity of parameters on certain metrics however they present a significant amount of information making it more difficult for stakeholders to 
interpret and are limited by the number of values being crossed compared. As seen in Figure 2.10, a pairgrid contains density plots, distribution plots and scatter plots.
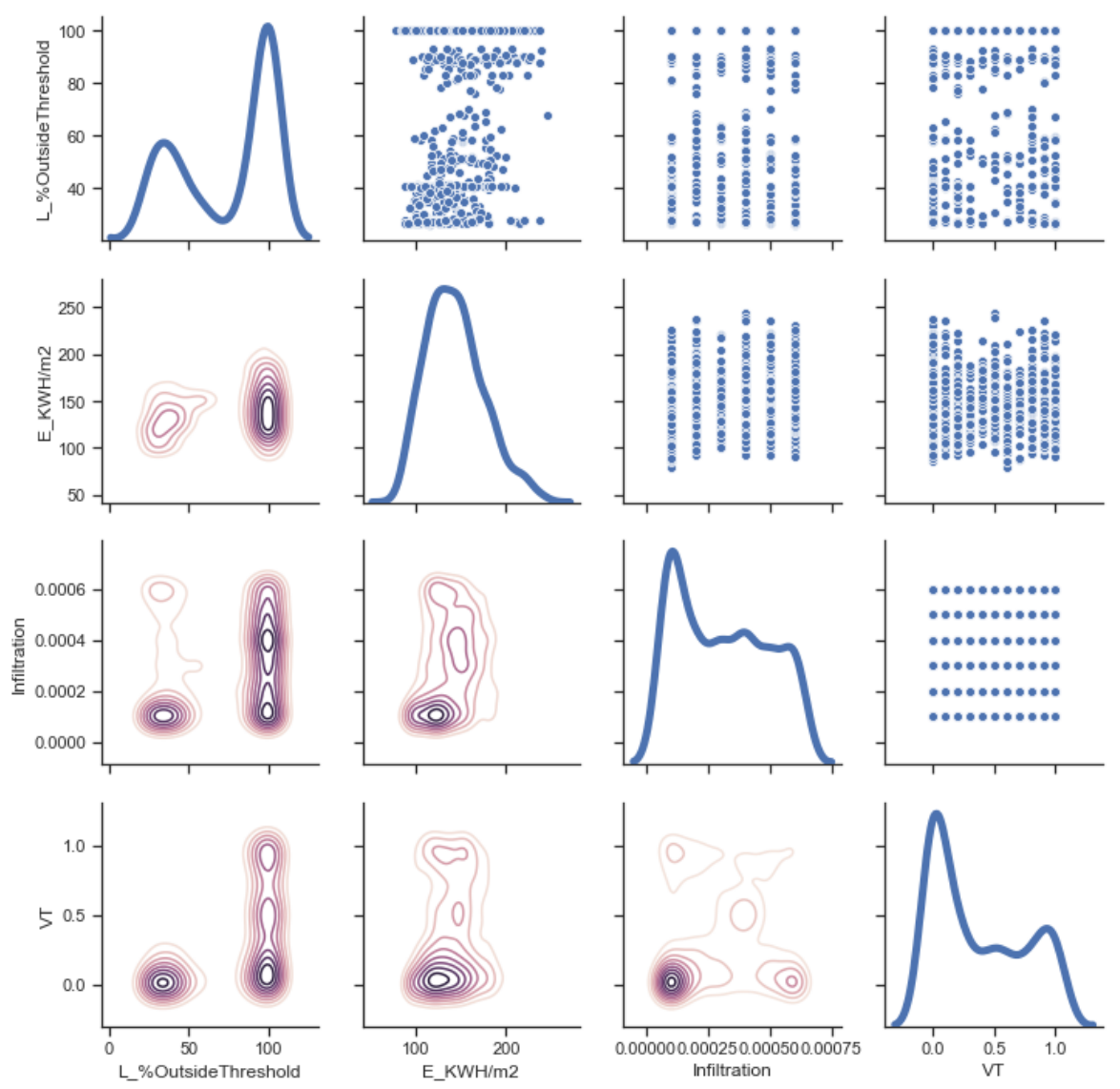

Figure 2.10 - Example pairgrid from a combined energy and light simulation.

Pairgrids present a matrix of plots displaying all selected simulation data in a static form. The lower half of the matrix is a density plot while the top half includes scatterplots. The diagonal plots are histograms displaying the frequency of values. With this combination of plots, it is possible to observe the global and local optimums that were identified by the optimization algorithm as well as verify how thoroughly the solution space was explored. In cases where the scatterplot evenly occupies the $\mathrm{x}$ and $\mathrm{y}$ spectrum, an evenly distributed range of values was explored, which is more ideal. For example, in Figure 2.10 the scatterplots display how a value of 78 for \% Outside Threshold can rarely be achieved at 
any value with the range explored, and that the full range of VT values were tested in an even distribution. This gap is also represented in the topmost histogram were the largest dip in the curve corresponds with the same value of $78 \%$ observed in the top row of scatter plots. The density plot is a good tool for observing the frequency of values. The darker the shade within the density plot, the higher density or frequency of points within that area. High density of plots indicate values that the optimization algorithm tested more frequently. The minimum and maximum of parameter ranges are tested more frequently while exploring the solution space and should not be confused for values necessarily correlated to optimal performance values. In cases where there are multiple shaded clusters or a shaded length of area within the density plot, it is less clear if those clouds are a result of the optimization algorithm honing in on an optimum or frequently testing boundaries of parameter ranges.

In the decision-making meeting, stakeholders should be walked through the definition of selected metrics, geometry simplifications made, and result visualizations. The objective is to share observations in data trends and facilitate compromise; making the modeling and the results more accessible and useful for other people involved in the design process.

Stakeholders can be given the parallel coordinate plot file and encouraged to navigate the results themselves. The Grasshopper scripts can be opened, and live manipulated to help stakeholders understand the process and increase understanding and interest of the methodology. The objective is to focus on transparency and accessibility of the technology used. 


\subsection{Methodology Conclusion}

The presented theory, framework and recommended tools can be followed in full or partially as a guideline to increase the value and significance of simulation in the early design phase of interventions. Using tools like Grasshopper to represent and manipulate models for energy, light, thermal comfort, air and acoustics, data can be produced to inform how changes to parameters impact performance metrics. The sharing and presenting of the information are critical to ensure relevance and value to the data as a decision-making tool and should not be overlooked. 


\section{Chapter 3}

\section{Example Case: Historic Courtyard}

\subsection{Introduction}

To provide an example of how the methodology could be implemented, a representation of a typical courtyard that might be found in a heritage building was developed in Rhino. The purpose of this exercise is to display how the framework could be applied in the context of a project where different geometries for an addition are being considered. In this case study scenario, a heritage building is being retrofitted to increase the usable indoor space available. Its exterior courtyard is to be covered with a structure to transform the space into usable interior space. As seen in Figure 3.1, the representative courtyard has two levels and windows that open into surrounding internal spaces.

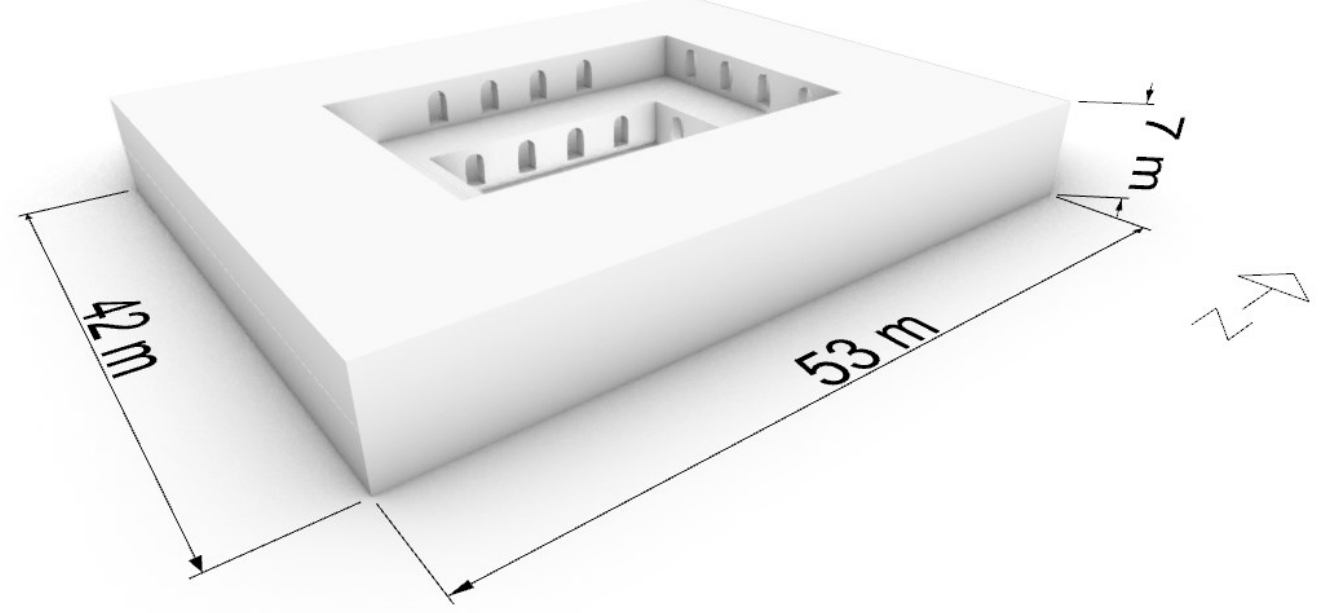

Figure 3.1 - Example historic courtyard with daylight access. 
In this scenario, three different structure options with varying aesthetic properties are being considered. The stakeholders in a situation like this would want to know the overall benefit of each of the designs and understand if there is a design option that stands out as an overall better choice. The courtyard cover, referred to as a lid, is a commonly seen intervention for heritage buildings being updated to increase usable floor area. As seen in Figure 3.2, the designs being considered are a flat lid option, a saw-tooth roof, and an inverted pyramid. The flat lid design is being considered to examine the effects of a high glazing option with no shading devices. The saw-tooth lid option was selected to examine the performance of an option with limited direct solar gains but with still a higher amount of glazing. The prism option was selected to examine the effects of a low glazing design. All three options are intended to also vary greatly in terms of aesthetics. 

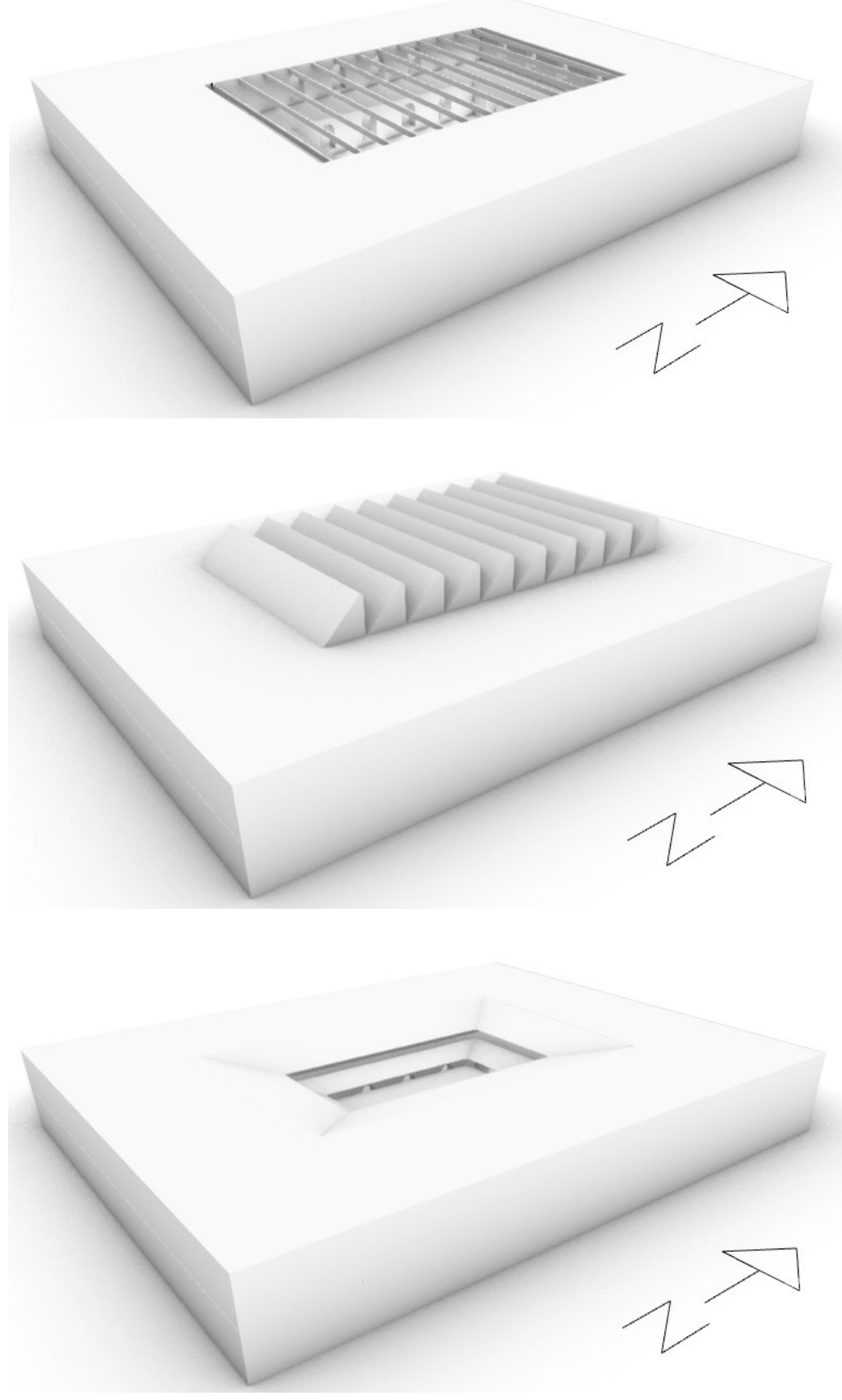

Figure 3.2 - Early design option examples for the representative courtyard.

The design considerations are to see which lid geometry is expected to offer the best overall performance and is worthy of investigating further in the design process. The key considerations are what difference does the change in geometry make and how other 
building design decisions are affected in the context of different lid options. For example, what should the properties of the glazing be for each lid option.

Common attributes to a heritage court include opportunity for occupant circulation, ventilation, access to direct and indirect sunlight and an amplified sensation of space. An example of a real-world heritage courtyard can be seen in Figure 3.3.

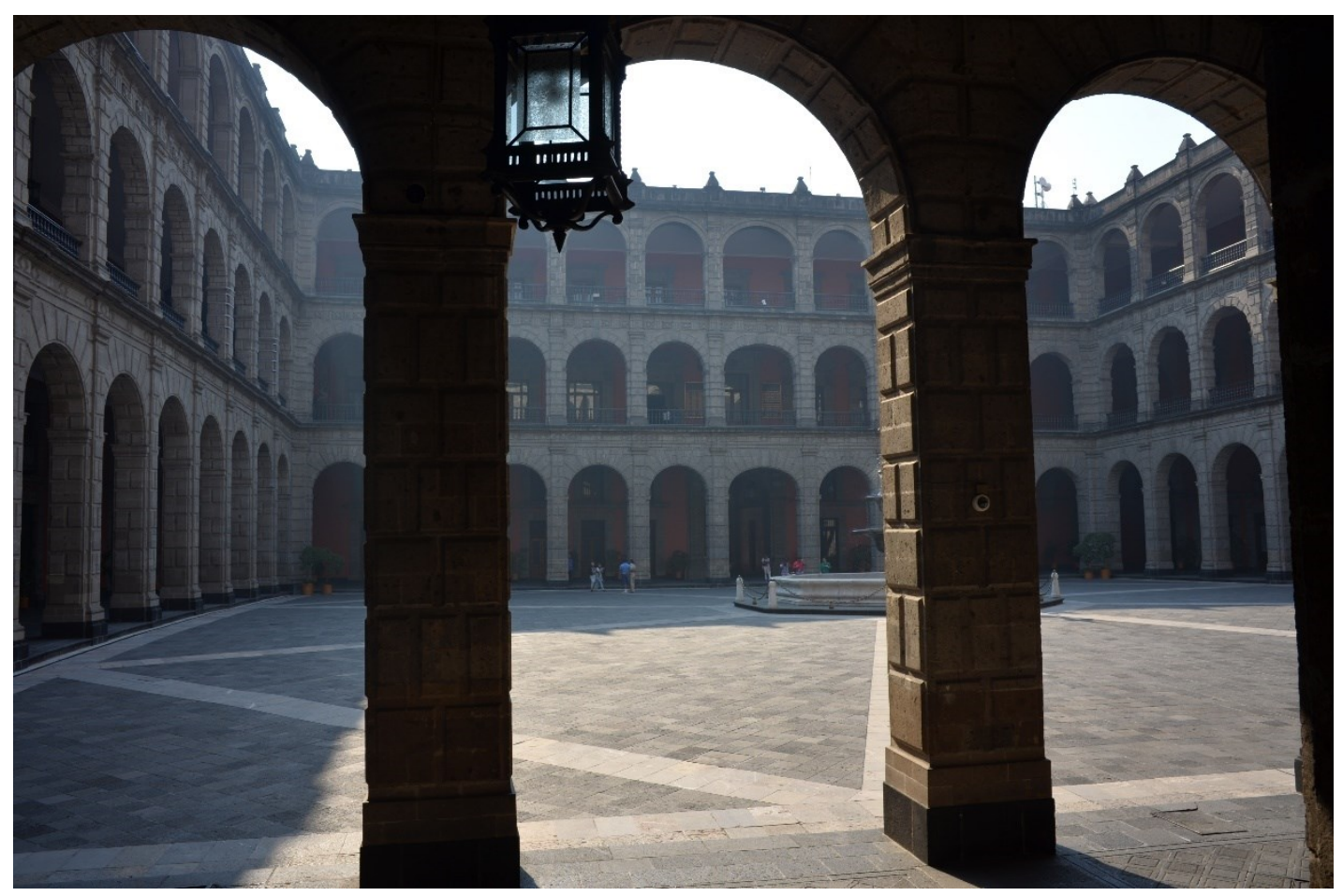

Figure 3.3 - Real world heritage courtyard. Palacio Nacional, Mexico City, Mexico.

\subsection{Initial Steps of the Framework}

In the context of a real-world project, the initial steps of the framework would be followed to understand the values of the site. The stakeholders of the site would be interviewed and any pre-existing documentation available would be collected. The site would be visited and examined to see if there are properties or performance conditions omitted from 
documentation. The court in this scenario, is to be used as a flexible event space and the expectations for how the space would be used in the future would be outlined by the client.

An example values-based assessment can be seen in Table 3.1 for this case study.

Table 3.1 - Values-based assessment for courtyard case study.

\begin{tabular}{|c|c|c|c|}
\hline & Heritage value association & Future use expectation & Simulation result value \\
\hline 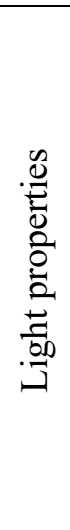 & $\begin{array}{l}\text { How does natural light within } \\
\text { the building correlate to } \\
\text { heritage values in the analysis } \\
\text { area? } \\
\text { High association: the } \\
\text { courtyard is a natural } \\
\text { daylighting strategy and merit } \\
\text { of the natural light within the } \\
\text { surrounding spaces would } \\
\text { subjectively be lost if fully } \\
\text { covered. }\end{array}$ & $\begin{array}{l}\text { How does light need to be } \\
\text { managed for the future } \\
\text { use of the analysis area? } \\
\text { Variable lighting } \\
\text { conditions appropriate: } \\
\text { solar conditions like } \\
\text { outside may be too harsh } \\
\text { for the space if occupants } \\
\text { are anticipated to be } \\
\text { stationary or work for } \\
\text { long periods of time. }\end{array}$ & $\begin{array}{l}\text { What types of light } \\
\text { analysis are required to test } \\
\text { quality of intervention? } \\
\text { Lighting within a specific } \\
\text { threshold: as the space is } \\
\text { to be used as an event area, } \\
\text { control of lighting } \\
\text { extremes is necessary but } \\
\text { should be considered more } \\
\text { flexible than if designing } \\
\text { for an office space. }\end{array}$ \\
\hline 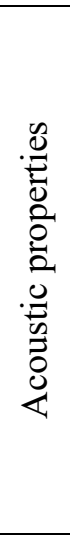 & $\begin{array}{l}\text { How does acoustics within } \\
\text { the building correlate to } \\
\text { heritage values in the analysis } \\
\text { area? } \\
\text { Low association: acoustics } \\
\text { does not have any associated } \\
\text { heritage values in the context } \\
\text { of this example. }\end{array}$ & $\begin{array}{l}\text { How should the acoustics } \\
\text { of the space be managed } \\
\text { in the future use of the } \\
\text { analysis area? } \\
\text { Speech clarity is a } \\
\text { concern: as the courtyard } \\
\text { will be a large open } \\
\text { space, clarity of sound } \\
\text { should be appropriate for } \\
\text { an event space of this } \\
\text { size. }\end{array}$ & $\begin{array}{l}\text { What types of sound } \\
\text { analysis can be simulated } \\
\text { to test quality of } \\
\text { intervention? }\end{array}$ \\
\hline 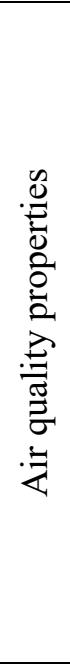 & $\begin{array}{l}\text { How does air quality, or } \\
\text { supporting systems within the } \\
\text { building correlate to heritage } \\
\text { values in the analysis area? } \\
\text { Some association: } \\
\text { courtyards were used in the } \\
\text { past to provide natural } \\
\text { ventilation to internal spaces. } \\
\text { If the new court were to be } \\
\text { mechanically ventilated, this } \\
\text { aspect to the building would } \\
\text { be lost. This should be } \\
\text { discussed with stakeholders as } \\
\text { a potential lost value. }\end{array}$ & $\begin{array}{l}\text { How can the space be } \\
\text { sufficiently ventilated } \\
\text { without unnecessarily } \\
\text { wasting energy or } \\
\text { invasively effecting } \\
\text { heritage fabric? } \\
\text { Sufficient ventilation: } \\
\text { ensure the ventilation } \\
\text { system is providing } \\
\text { enough fresh air. }\end{array}$ & $\begin{array}{l}\text { What types of air quality } \\
\text { can be examined to test the } \\
\text { quality of the intervention? } \\
\text { Peak discomfort: } \\
\text { determine the magnitude } \\
\text { and frequency of peak } \\
\text { discomfort due to poor air } \\
\text { quality. }\end{array}$ \\
\hline
\end{tabular}




\begin{tabular}{|c|c|c|c|}
\hline 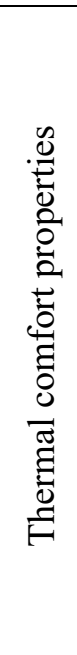 & $\begin{array}{l}\text { How does thermal comfort, or } \\
\text { supporting systems within the } \\
\text { building correlate to heritage } \\
\text { values in the analysis area? } \\
\text { Some association: } \\
\text { courtyards were used in the } \\
\text { past to provide natural } \\
\text { ventilation of internal spaces. } \\
\text { If the new court were to be } \\
\text { mechanically ventilated, this } \\
\text { aspect to the building would } \\
\text { be lost. This should be } \\
\text { discussed with stakeholders as } \\
\text { a notential lost value. }\end{array}$ & $\begin{array}{l}\text { How should heating and } \\
\text { cooling be supplied to the } \\
\text { space to minimize } \\
\text { discomfort and energy } \\
\text { consumption? } \\
\text { Appropriate system } \\
\text { type selection: examine } \\
\text { heating options to see } \\
\text { which provide better } \\
\text { overall comfort. }\end{array}$ & $\begin{array}{l}\text { What types of thermal } \\
\text { comfort tests can be run to } \\
\text { assess the quality of the } \\
\text { intervention? } \\
\text { Peak discomfort: } \\
\text { determine the magnitude } \\
\text { and frequency of peak } \\
\text { thermal discomfort. }\end{array}$ \\
\hline
\end{tabular}

In this scenario, geometry and constructions of the addition are considered flexible and changes to building systems are acceptable.

\subsection{Geometric Simplification}

The architectural Rhino model is broken down into a collection of surfaces and then converted into a single closed thermal zone for each of the lid options. Significant attention must be made to first close the zone with all opaque surfaces before identifying glazing geometry. This is because zones in energy models must be represented as closed boundaries in order to properly calculate energy transfer. Walls that box in the courtyard are considered for the daylighting and acoustic models but ignored for the energy model. This means that the courtyard and surrounding internal spaces are incorporated as a single thermal zone for this particular exercise. In order to get an idea of how an occupant would experience the courtyard in a thermal sense, the occupant thermal comfort mannequin is placed in the center of the courtyard. For the acoustic raytracing analysis, the sound source 
and sound receiver were arbitrarily placed in opposite corners of the courtyard to emulate the sound behavior of someone speaking across the court.

\subsection{Metrics and Objectives}

Table 3.2 summarises the metrics that have been obtained from simulation for the study. The table contains values or objectives that indicate acceptable conditions as per recommendations of ASHRAE, WELL, LEED and design intuition. The full list of recommended metric values and supporting sources, can be found in Table C.1 in Appendix C. In this case the performance inside a courtyard is examined, as such, to make the IHOT metric more relevant for a courtyard, the maximum desirable illuminance level value has increased to take into consideration that occupants are not sedentary and have the option to move if they are experiencing intolerable glare. Ideal reverberation time has been adjusted to 1.7 seconds to take into consideration the larger space [88]. 
Table 3.2 - Metrics recorded for historic courtyard case study.

\begin{tabular}{|c|c|c|}
\hline & Recorded metric & Recommended \\
\hline \multirow{4}{*}{ 泀 } & $\%$ IHOT & Minimize \\
\hline & Avg illuminance & \\
\hline & Min illuminance & $100 \operatorname{lux}$ \\
\hline & Max illuminance & $5000 \operatorname{lux}$ \\
\hline 它 & $\begin{array}{l}\text { Energy usage intensity per area } \\
\text { (including heating, cooling, lighting etc.) }\end{array}$ & Minimize \\
\hline \multirow{7}{*}{ 妾 } & Average $\mathrm{CO}_{2}$ concentration & \\
\hline & Minimum $\mathrm{CO}_{2}$ concentration & $350 \mathrm{ppm}$ \\
\hline & Maximum $\mathrm{CO}_{2}$ concentration & $1050 \mathrm{ppm}$ \\
\hline & Maximum PPD from $\mathrm{CO}_{2}$ concentration & $10 \%$ \\
\hline & Average PPD from OLF & \\
\hline & Lowest PPD from OLF & \\
\hline & Highest PPD from OLF & $10 \%$ \\
\hline \multirow{9}{*}{ 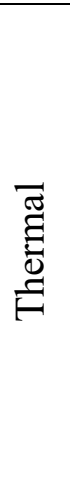 } & Hours of discomfort from highest MRT & \\
\hline & Hours of discomfort from lowest MRT & \\
\hline & Hours of discomfort from average MRT & \\
\hline & $\begin{array}{l}\text { Hours of discomfort from average MRT augmented } \\
\text { with direct solar }\end{array}$ & \\
\hline & Hours of discomfort due to asymmetry & \\
\hline & Total hours of discomfort & Minimize \\
\hline & PPD from highest MRT & $<20 \%$ \\
\hline & PPD from lowest MRT & $<20 \%$ \\
\hline & PPD from average MRT & \\
\hline \multirow{5}{*}{ 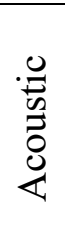 } & High attenuation & \\
\hline & Low attenuation & \\
\hline & STL of composition & \\
\hline & STI & \\
\hline & RT & $1.7 \mathrm{~s}$ \\
\hline
\end{tabular}




\subsection{Parameter Ranges}

The parameter ranges for the model were defined in Table 3.3. The HVAC system was assigned using OpenStudio templates and the default settings for each system was determined sufficient for each of the HVAC type cases.

Table 3.3 - Parameters in court study.

\begin{tabular}{|c|c|c|}
\hline Parameter & Min & Max \\
\hline Infiltration rate per area & $\begin{array}{l}0.0001 \mathrm{~m}^{3} / \mathrm{s}_{\text {per }} \mathrm{m}^{2} \\
\text { facade }\end{array}$ & $\begin{array}{l}0.0006 \mathrm{~m}^{3} / \mathrm{s}_{\text {per }} \mathrm{m}^{2} \\
\text { facade }\end{array}$ \\
\hline Lighting density per area & $3 \mathrm{~W} / \mathrm{m}^{2}$ & $15 \mathrm{~W} / \mathrm{m}^{2}$ \\
\hline Ventilation per area & $0.0002 \mathrm{~m}^{3} / \mathrm{s}$ per $\mathrm{m}^{2}$ & $0.0004 \mathrm{~m}^{3} / \mathrm{s}$ per $\mathrm{m}^{2}$ \\
\hline Ventilation per person & $0.0025 \mathrm{~m}^{3} / \mathrm{s}$ & $0.0033 \mathrm{~m}^{3} / \mathrm{s}$ \\
\hline Heating air supply temperature & $20^{\circ} \mathrm{C}$ & $38^{\circ} \mathrm{C}$ \\
\hline Cooling air supply temperature & $10^{\circ} \mathrm{C}$ & $20^{\circ} \mathrm{C}$ \\
\hline Insulation thickness & $0.01 \mathrm{~m}$ & $0.05 \mathrm{~m}$ \\
\hline Number of panes in windows & 1 & 3 \\
\hline Refractive index & 1.4 & 2.4 \\
\hline Glass solar transmittance & 0.1 & 0.9 \\
\hline Glass solar reflectance & 0.1 & 0.9 \\
\hline Glass visible transmittance & 0.1 & 0.9 \\
\hline Glass visible reflectance & 0.1 & 0.9 \\
\hline Glass front emissivity & 0.1 & 0.9 \\
\hline Glass back emissivity & 0.1 & 0.9 \\
\hline Air velocity over occupant & $0.25 \mathrm{~m} / \mathrm{s}$ & $0.50 \mathrm{~m} / \mathrm{s}$ \\
\hline HVAC system type & \multicolumn{2}{|c|}{$\begin{array}{l}\text { Radiant panels and DOAS, fan coil units or radiant } \\
\text { floors and DOAS }\end{array}$} \\
\hline Lid geometry type & \multicolumn{2}{|c|}{ Flat lid, sawtooth lid and inverted lid } \\
\hline
\end{tabular}




\subsection{Model Properties}

The models were set up following the methodology discussed in Chapter 2. Certain assumptions were made to represent aspects of the model that were not subject to parametric analysis. Appendix D contains Tables D.1 through D.4 that outline the values input into the model. Inputs like the number of rays to use in the acoustic model are directly prescribed in the methodology theory, while inputs like the occupant's metabolic rate were identified using intuition of what the occupant would most likely be doing in the space. Walls assumed to be touching other spaces in the imaginary building scenario were assumed to be adiabatic.

\subsection{Interactive Plot and Data Trend Visualization}

The script was run to produce 469 design iterations and 24,336 data points across the solution space. It took approximately 2 days of run time on a system with 64 GB of RAM and an Intel Xenon Gold 6154 CPU. The data from the run was collected and presented in an interactive parallel coordinate plot in Figure 3.4. When all data is presented at once, some trends can be observed such as, in this case, a low risk for discomfort due to carbon dioxide but a high risk of discomfort for odour during peak occupancies. The interval nature of how the parameters were explored can be easily seen as a geometric, criss-cross like pattern. 


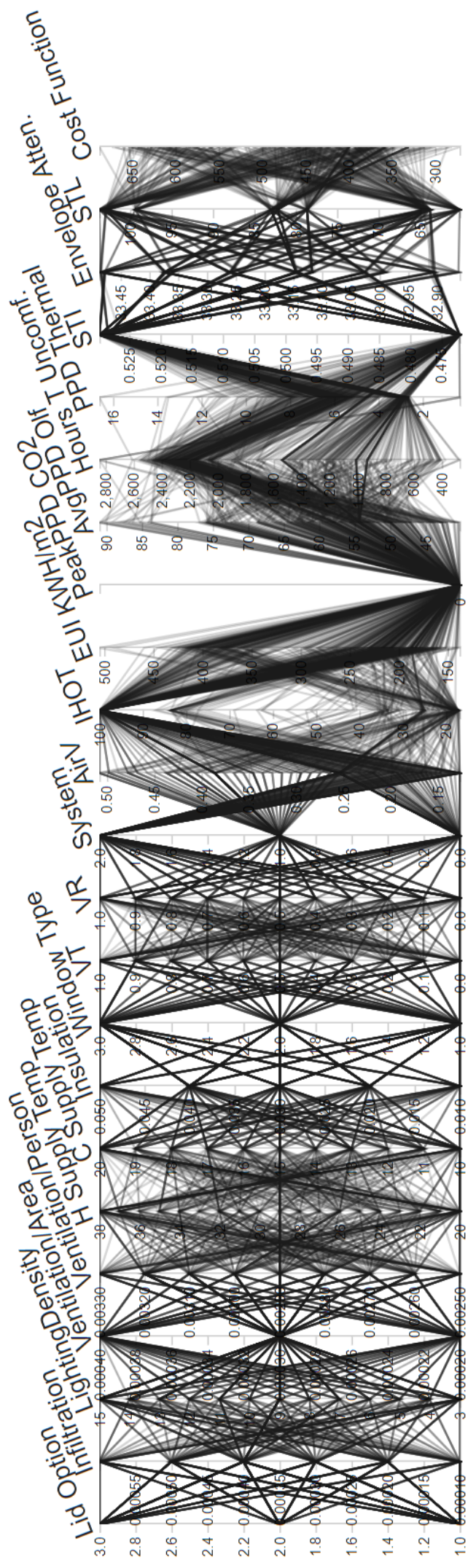

Figure 3.4 - All courtyard intervention design options. 
High level trends of the design scenario can be examined before defining any ranges on the interactive plot. Each metric can be observed for distribution across the solution space and darker clusters indicate more frequent occurrence of the value. Table 3.4 displays preliminary interpretation of the interactive plot.

Table 3.4 - Initial analysis of court case.

\begin{tabular}{|c|c|c|}
\hline Metric & Observation & Implication \\
\hline IHOT & $\begin{array}{l}\text { Loose clusters of data } \\
\text { around } 20,25,80 \text {, and } 100 .\end{array}$ & $\begin{array}{l}\text { There are some design } \\
\text { decisions that shift the light } \\
\text { performance significantly } \\
\text { while other design } \\
\text { decisions slightly change } \\
\text { the result. }\end{array}$ \\
\hline $\mathrm{EUI} \mathrm{kWh} / \mathrm{m}^{2}$ & $\begin{array}{l}\text { Data cloud with heavy } \\
\text { density ranging between } \\
200 \text { to } 250 \text {. }\end{array}$ & $\begin{array}{l}\text { Energy is affected by many } \\
\text { of the design changes and } \\
\text { the cost function continued } \\
\text { to consistently provide } \\
\text { results in this range. }\end{array}$ \\
\hline Peak PPD $\mathrm{CO}_{2}$ & Entire range is 0 . & $\begin{array}{l}\text { All design options that } \\
\text { effect carbon dioxide are } \\
\text { valid and effective. }\end{array}$ \\
\hline Average PPD OLF & $\begin{array}{l}\text { Majority of values fall } \\
\text { within } 0 \text { to } 75 .\end{array}$ & $\begin{array}{l}\text { Odours are a dominant } \\
\text { concern for air quality. } \\
\text { There may be need for } \\
\text { design options with } \\
\text { increased on-demand } \\
\text { ventilation. Further } \\
\text { investigation required. }\end{array}$ \\
\hline $\begin{array}{l}\text { Total hours thermally } \\
\text { uncomfortable }\end{array}$ & $\begin{array}{l}\text { Value ranging from } 600 \text { to } \\
2,600 \text {. }\end{array}$ & $\begin{array}{l}\text { Many design options affect } \\
\text { thermal comfort. There is a } \\
\text { full spectrum of potential } \\
\text { results. }\end{array}$ \\
\hline $\begin{array}{l}\text { PPD thermally } \\
\text { uncomfortable }\end{array}$ & $\begin{array}{l}\text { Values ranging from } 2 \text { to } \\
10 .\end{array}$ & $\begin{array}{l}\text { Most design options } \\
\text { provide an acceptable } \\
\text { thermal environment. }\end{array}$ \\
\hline STI & Values are 0.47 or 0.53 & $\begin{array}{l}\text { Most design decisions } \\
\text { result in one of two } \\
\text { outcomes. }\end{array}$ \\
\hline
\end{tabular}




\begin{tabular}{|c|l|l|}
\hline Envelope attenuation & $\begin{array}{l}\text { All design options result in } \\
\text { a value of 31 }\end{array}$ & $\begin{array}{l}\text { The design options in this } \\
\text { scenario do not affect } \\
\text { attenuation significantly. }\end{array}$ \\
\hline STL & $\begin{array}{l}\text { There are three clusters of } \\
\text { STL: } 60,80 \text { and } 100 .\end{array}$ & $\begin{array}{l}\text { As there are 3 types of } \\
\text { windows, the window type } \\
\text { is most likely the dominant } \\
\text { parameter. }\end{array}$ \\
\hline
\end{tabular}

If one manipulates to have a preferred range of $30 \%$ to $20 \%$ IHOT, an EUI of $150 \mathrm{kWh} / \mathrm{m}^{2}$ to $200 \mathrm{kWh} / \mathrm{m}^{2}$ and a thermal PPD from $0 \%$ to $10 \%$, there are 50 design options with this result. With these ranges shown in Figure 3.5, lid 2 - the sawtooth option, appears to provide the ideal conditions. In this case, the fan coil system uses the least amount of energy to maintain the space. 


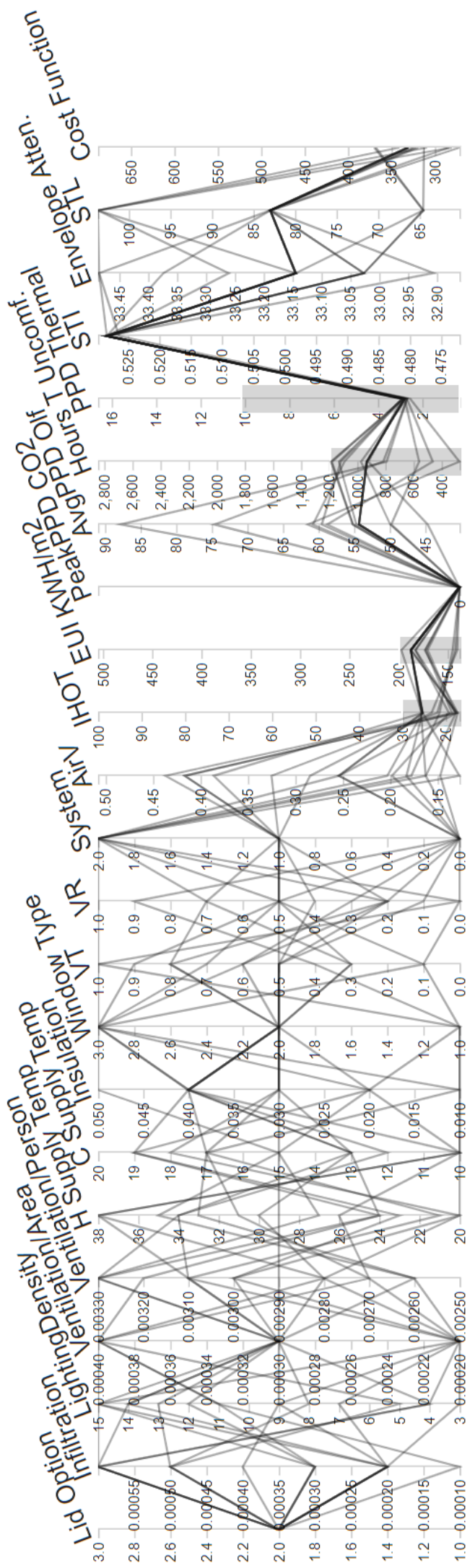

Figure 3.5 - Initial analysis of court case with optimal performing option clusters. 
The results presented in this format can be shown to stakeholders and then manipulated to support an informed design discussion. The results presented here indicated it would be recommended to further investigate the implications of a sawtooth option and revisit the risk of odour within the space. The other data visualization strategies can be adopted to compare more specific design clusters and to examine the effect of specific parameters.

From looking at the results, recommendations can be made that the sawtooth lid option provides the best overall performance. The recommended parameters for the case study can be seen in Table 3.5 and the recommended geometry can be seen in Figure 3.6.

Table 3.5 - Final design recommendations for courtyard case study.

\begin{tabular}{|l|c|}
\hline \multicolumn{1}{|c|}{ Parameter } & \begin{tabular}{c} 
Recommendation \\
\hline Infiltration rate per area
\end{tabular} \\
$\begin{array}{c}0.0005 \mathrm{~m}^{3} / \mathrm{s} \mathrm{per} \mathrm{m}^{2} \\
\text { facade }\end{array}$ \\
\hline Lighting density per area & $8 \mathrm{~W} / \mathrm{m}^{2}$ \\
\hline Ventilation per area & $0.0002 \mathrm{~m}^{3} / \mathrm{s} \mathrm{per} \mathrm{\textrm {m } ^ { 2 }}$ \\
\hline Ventilation per person & $0.0029 \mathrm{~m}^{3} / \mathrm{s}$ \\
\hline Heating air supply temperature & $28^{\circ} \mathrm{C}$ \\
\hline Cooling air supply temperature & $19^{\circ} \mathrm{C}$ \\
\hline Insulation thickness & $0.04 \mathrm{~m}$ \\
\hline Number of panes in windows & 2 \\
\hline Glass solar reflectance & 0.6 \\
\hline Glass visible transmittance & 0.7 \\
\hline Glass visible reflectance & 0.9 \\
\hline HVAC system type & Radiant Floor \\
\hline Lid geometry type & Sawtooth Lid \\
\hline
\end{tabular}




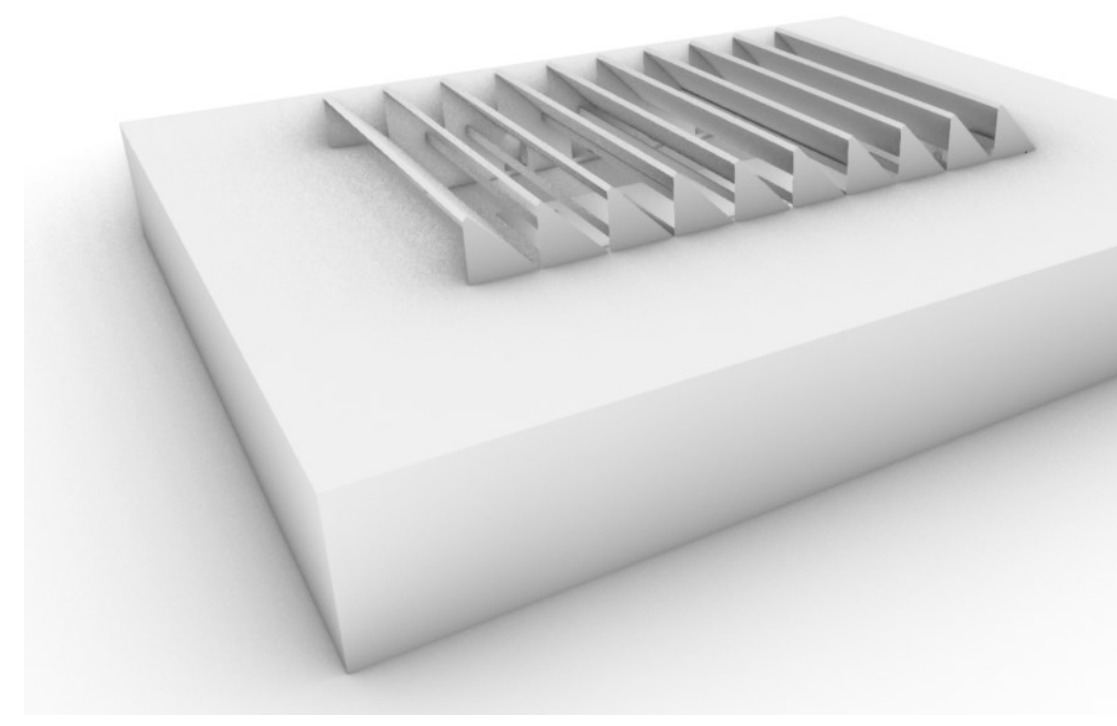

Figure 3.6 - Recommended lid geometry.

This workflow allows the negotiation of project factors and the presentation of associated consequence of certain design limitations. For example, if stakeholders begin to deem that an invasive building envelope rehabilitation would be too severe on the heritage fabric of the building, one could display the implications of that decision by assuming insulation of the walls would be lower and infiltration to be higher. This change would make it less clear which lid option is better performing, and that in order to achieve similar levels of energy efficiency as the original recommended design, loss in court lighting quality would have to be accepted as seen in the correlations shown in Figure 3.7. In order to preserve energy performance, the values of the building envelope or lighting properties are in conflict. The project stakeholders would have to negotiate and discuss which changes are appropriate for heritage or if they are willing to compromise on energy performance. For best practice, if those limitations on building envelope were to be enforced, a re-run of the optimization phase would be required to make appropriate new recommendations. 


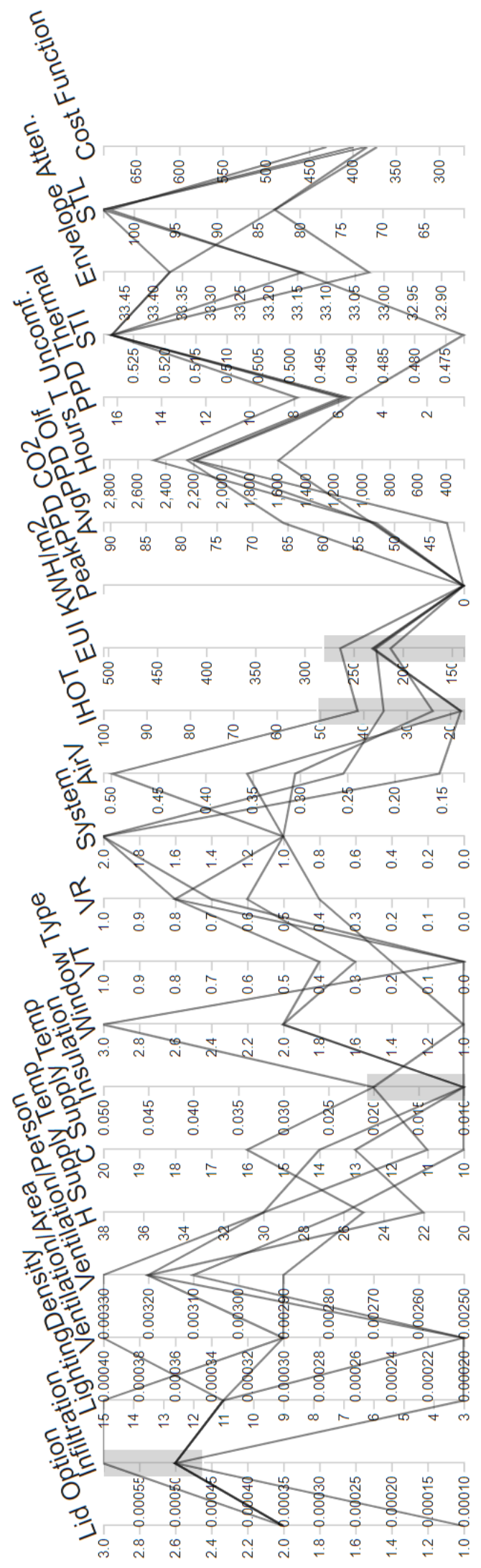

Figure 3.7 - Design options of a courtyard with high infiltration and low insulation. 


\section{Chapter 4}

\section{Example Case: Historic Office}

\subsection{Introduction}

To exhibit the application of the framework on an office type scenario, a single occupant office space was developed in Rhino, see Figure 4.1. The design objective in this scenario is to identify the overall highest performing combination of design changes that do not impact geometry or the aesthetics of the space. Recommendations on the type of climate control system to be used is a significant aspect of this scenario. The framework was conceptually followed in a way it is expected to be applied; as a guideline. In this example, there is higher comfort expectations and restrictions to changes in geometry.

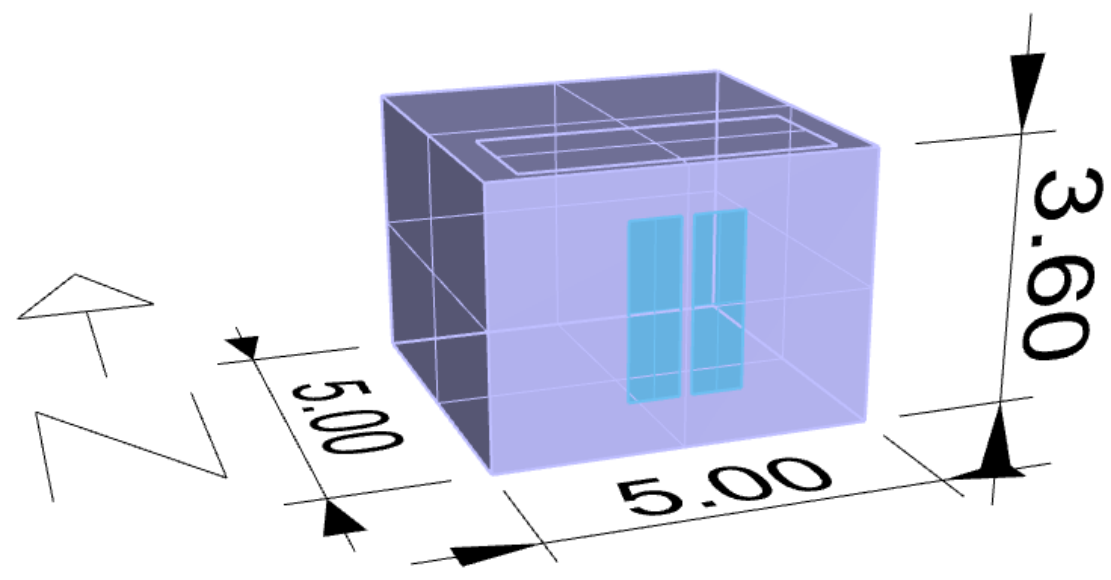

Figure 4.1 - Historic single occupant office geometry.

In historical buildings, it is common to see a collection of single occupant offices connected with a series of doors, like as seen in parliamentary buildings. To create an opportunity to 
examine the effects of noise propagation, three offices are placed beside one another, with open doors connecting them. The study of sound from one office entering another will be the subject of the acoustic raytracing analysis. This type of layout is typical for historic institutional buildings.

\subsection{Initial Steps of the Framework}

In the context of a real-world project, the initial steps of the framework would be followed to understand the values of the site. The stakeholders of the site would be interviewed and any pre-existing documentation available would be collected. The site would be visited and examined to see if there are properties or performance conditions omitted from documentation. The space in this scenario, is to be used as an office and the expectations for how the space would be used in the future would be outlined by the client. An example values-based assessment can be seen in Table 4.1 for this case study. 
Table 4.1 - Values-based assessment for office case study.

\begin{tabular}{|c|c|c|c|}
\hline & $\begin{array}{l}\text { Heritage value } \\
\text { association }\end{array}$ & Future use expectation & Simulation result value \\
\hline 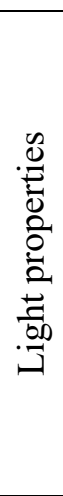 & $\begin{array}{l}\text { How does natural light } \\
\text { within the building } \\
\text { correlate to heritage values } \\
\text { in the analysis area? } \\
\text { Some association: natural } \\
\text { light is valued to some } \\
\text { degree as a feature within } \\
\text { a space like this. }\end{array}$ & $\begin{array}{l}\text { How does light need to be } \\
\text { managed for the future } \\
\text { use of the analysis area? } \\
\text { Work appropriate } \\
\text { lighting levels required: } \\
\text { light levels that are bright } \\
\text { enough to work in } \\
\text { without extreme light is } \\
\text { ideal. }\end{array}$ & $\begin{array}{l}\text { What types of light } \\
\text { analysis are required to test } \\
\text { quality of intervention? } \\
\text { General work plane } \\
\text { illuminance: will inform } \\
\text { the quality of light within } \\
\text { the space. }\end{array}$ \\
\hline 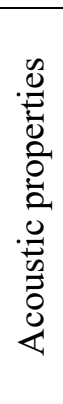 & $\begin{array}{l}\text { How does acoustics within } \\
\text { the building correlate to } \\
\text { heritage values in the } \\
\text { analysis area? } \\
\text { Some association: single } \\
\text { occupant spaces were } \\
\text { presumably designed for } \\
\text { quiet work. }\end{array}$ & $\begin{array}{l}\text { How should the acoustics } \\
\text { of the space be managed } \\
\text { in the future use of the } \\
\text { analysis area? } \\
\text { Speech privacy is a } \\
\text { concern: an attention to } \\
\text { privacy between rooms is } \\
\text { recommended. }\end{array}$ & $\begin{array}{l}\text { What types of sound } \\
\text { analysis can be simulated } \\
\text { to test quality of } \\
\text { intervention? } \\
\text { Privacy of sound: } \\
\text { simulation for the analysis } \\
\text { of privacy is most valuable. }\end{array}$ \\
\hline 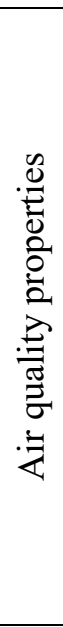 & $\begin{array}{l}\text { How does air quality, or } \\
\text { supporting systems within } \\
\text { the building correlate to } \\
\text { heritage values in the } \\
\text { analysis area? } \\
\text { Low association: air } \\
\text { quality in this scenario } \\
\text { would have low heritage } \\
\text { values unless the rooms } \\
\text { windows were operable, } \\
\text { which could be considered } \\
\text { a valuable historic } \\
\text { building feature. }\end{array}$ & $\begin{array}{l}\text { How can the space be } \\
\text { sufficiently ventilated } \\
\text { without unnecessarily } \\
\text { wasting energy or } \\
\text { invasively effecting } \\
\text { heritage fabric? } \\
\text { Sufficient ventilation: } \\
\text { Ensure the ventilation } \\
\text { system is providing } \\
\text { enough fresh air. }\end{array}$ & $\begin{array}{l}\text { What types of air quality } \\
\text { can be examined to test the } \\
\text { quality of the intervention? } \\
\text { Peak discomfort: } \\
\text { Determine the magnitude } \\
\text { and frequency of peak } \\
\text { discomfort due to poor air } \\
\text { quality. }\end{array}$ \\
\hline
\end{tabular}




\begin{tabular}{|c|c|c|c|}
\hline 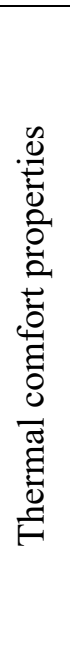 & $\begin{array}{l}\text { How does thermal } \\
\text { comfort, or supporting } \\
\text { systems within the } \\
\text { building correlate to } \\
\text { heritage values in the } \\
\text { analysis area? } \\
\text { Low association: unless } \\
\text { the space contained a } \\
\text { heating system of an } \\
\text { ornamental nature, such as } \\
\text { a decorative radiator, } \\
\text { thermal comfort does not } \\
\text { have any foreseeable } \\
\text { heritage values. }\end{array}$ & $\begin{array}{l}\text { How should heating and } \\
\text { cooling be supplied to the } \\
\text { space to minimize } \\
\text { discomfort and energy } \\
\text { consumption? } \\
\text { Appropriate system } \\
\text { type selection: examine } \\
\text { heating options to see } \\
\text { which provide better } \\
\text { overall comfort and } \\
\text { minimizes the severity of } \\
\text { in intervention } \\
\text { invasiveness. }\end{array}$ & $\begin{array}{l}\text { What types of thermal } \\
\text { comfort tests can be run to } \\
\text { assess the quality of the } \\
\text { intervention? } \\
\text { Peak discomfort: } \\
\text { determine the magnitude } \\
\text { and frequency of peak } \\
\text { thermal discomfort. }\end{array}$ \\
\hline
\end{tabular}

In this scenario, the invasiveness of the rehabilitation is to be kept to a minimum. Geometry is not flexible and other intervention options must be managed to minimise visual change but maximise performance.

\subsection{Geometric Simplification}

The scenario was broken down into two separate geometries. The wireframe model on the right seen in Figure 4.2 is used for the daylighting, energy and air model while the model on the left is three units with open doors to one another, for the acoustic raytracing model. The radiant panel geometry was specified within the boundary conditions of the energy model in order to be able to calculate the thermal comfort view factors of the panel from the occupant mannequin. The acoustic source was placed in one of the rooms and the receiver was placed in an adjacent room to represent how sound would travel from one adjacent space to another through the open doors. 


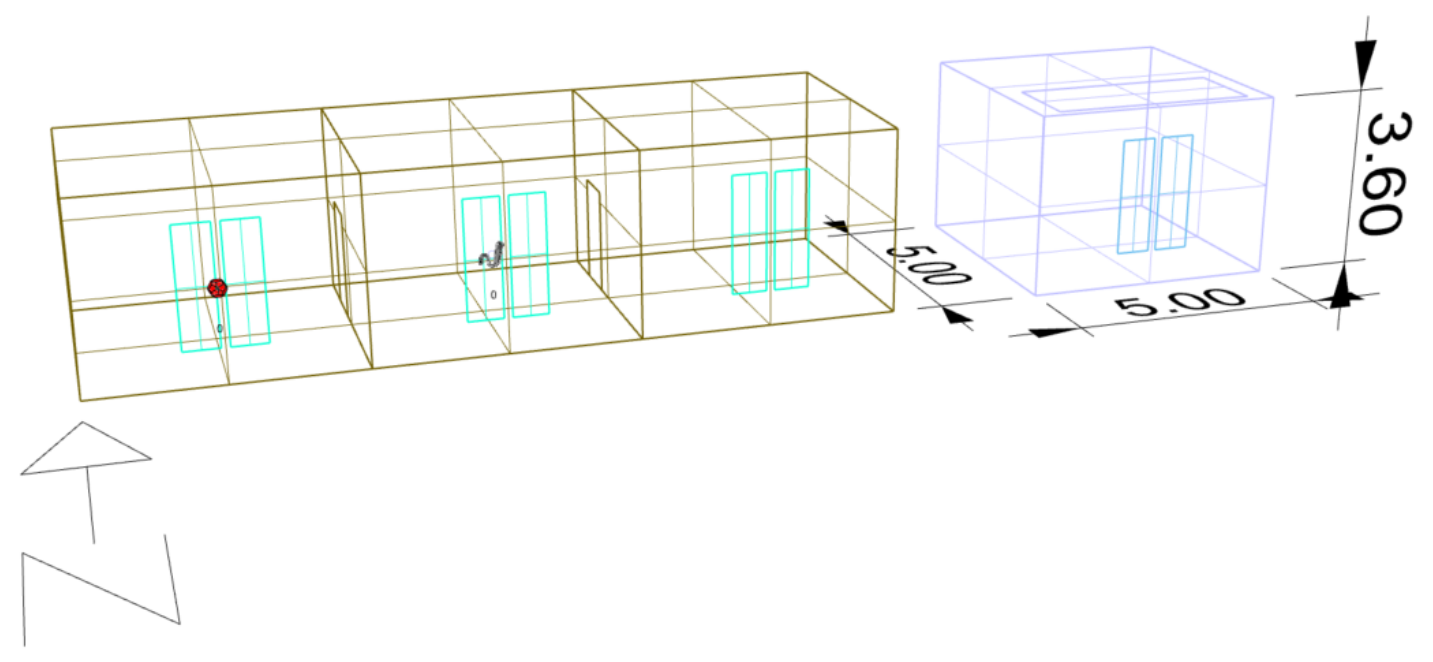

Figure 4.2 - Geometry models used for the historic office study.

\subsection{Metrics and Objectives}

Table 4.2 contains the metrics that have been recorded for the study and some of the recommended values to achieve for an office space. The table contains values or objectives that indicate acceptable conditions as per recommendations of ASHRAE, WELL, LEED and design intuition. The full list of recommended metric values and supporting sources, can be found in Table C.1 in Appendix C. Key aspects to note that are different than the courtyard case includes the lower acceptable illuminance threshold to better regulate the quality of glare within the office. The office space has a recommended STI of 0.5 and a lower recommended RT than the courtyard [88]. 
Table 4.2 - Metrics recorded for historic office case study.

\begin{tabular}{|c|c|c|}
\hline & Recorded Metric & Recommended \\
\hline \multirow{4}{*}{ 莺 } & \% IHOT & Minimize \\
\hline & Avg illuminance & \\
\hline & Min illuminance & 100 lux \\
\hline & Max illuminance & 1000 lux \\
\hline क्ठ் & $\begin{array}{l}\text { Energy usage intensity per area } \\
\text { (including heating, cooling, lighting etc.) }\end{array}$ & Minimize \\
\hline \multirow{7}{*}{ 完 } & Average $\mathrm{CO}_{2}$ concentration & \\
\hline & Minimum $\mathrm{CO}_{2}$ concentration & $350 \mathrm{ppm}$ \\
\hline & Maximum $\mathrm{CO}_{2}$ concentration & $1050 \mathrm{ppm}$ \\
\hline & Maximum PPD from $\mathrm{CO}_{2}$ concentration & $10 \%$ \\
\hline & Average PPD from OLF & \\
\hline & Lowest PPD from OLF & \\
\hline & Highest PPD from OLF & $10 \%$ \\
\hline \multirow{9}{*}{ 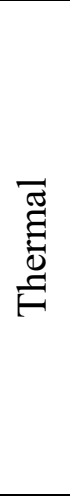 } & Hours of discomfort from highest MRT & \\
\hline & Hours of discomfort from lowest MRT & \\
\hline & Hours of discomfort from average MRT & \\
\hline & $\begin{array}{l}\text { Hours of discomfort from average MRT augmented } \\
\text { with direct solar }\end{array}$ & \\
\hline & Hours of discomfort due to asymmetry & \\
\hline & Total hours of discomfort & Minimize \\
\hline & PPD from highest MRT & $<20 \%$ \\
\hline & PPD from lowest MRT & $<20 \%$ \\
\hline & PPD from average MRT & \\
\hline \multirow{5}{*}{ 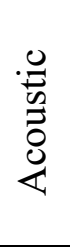 } & High attenuation & \\
\hline & Low attenuation & \\
\hline & STL of composition & \\
\hline & STI & $<0.5$ \\
\hline & RT & $1 \mathrm{~s}$ \\
\hline
\end{tabular}

\subsection{Parameter Ranges}

The parameter ranges for the model were defined as follows in Table 4.3. The HVAC system was assigned using OpenStudio templates and the default settings for each system was determined sufficient for each of the HVAC cases. 
Table 4.3 - Parameters in historic office case study.

\begin{tabular}{|c|c|c|}
\hline Parameter & Min & Max \\
\hline Infiltration rate per area & $\begin{array}{l}0.0001 \mathrm{~m}^{3} / \mathrm{s}_{\text {per }} \mathrm{m}^{2} \\
\text { facade }\end{array}$ & $\begin{array}{l}0.0006 \mathrm{~m}^{3} / \mathrm{s} \text { per } \mathrm{m}^{2} \\
\text { facade }\end{array}$ \\
\hline Lighting density per area & $3 \mathrm{~W} / \mathrm{m}^{2}$ & $15 \mathrm{~W} / \mathrm{m}^{2}$ \\
\hline Ventilation per area & $0.0002 \mathrm{~m}^{3} / \mathrm{s}$ per $\mathrm{m}^{2}$ & $0.0004 \mathrm{~m}^{3} / \mathrm{s}$ per $\mathrm{m}^{2}$ \\
\hline Ventilation per person & $0.0025 \mathrm{~m}^{3} / \mathrm{s}$ & $0.0033 \mathrm{~m}^{3} / \mathrm{s}$ \\
\hline Heating air supply temperature & $20^{\circ} \mathrm{C}$ & $38^{\circ} \mathrm{C}$ \\
\hline Cooling air supply temperature & $10^{\circ} \mathrm{C}$ & $20^{\circ} \mathrm{C}$ \\
\hline Insulation thickness & $0.01 \mathrm{~m}$ & $0.05 \mathrm{~m}$ \\
\hline Number of Panes in Windows & 1 & 3 \\
\hline Refractive index & 1.4 & 2.4 \\
\hline Glass solar transmittance & 0.1 & 0.9 \\
\hline Glass solar reflectance & 0.1 & 0.9 \\
\hline Glass visible transmittance & 0.1 & 0.9 \\
\hline Glass visible reflectance & 0.1 & 0.9 \\
\hline Glass front emissivity & 0.1 & 0.9 \\
\hline Glass back emissivity & 0.1 & 0.9 \\
\hline Air velocity over occupant & $0.25 \mathrm{~m} / \mathrm{s}$ & $0.50 \mathrm{~m} / \mathrm{s}$ \\
\hline HVAC system type & \multicolumn{2}{|c|}{$\begin{array}{l}\text { Radiant panels and DOAS, fan coil units or radian } \\
\text { floors and DOAS }\end{array}$} \\
\hline
\end{tabular}

\subsection{Model Properties}

The models were set up following the methodology discussed in Chapter 2. Certain assumptions were made to represent aspects of the model that were not subject to parametric analysis. Appendix D contains Tables D.1 through D.4 that outline the values input into the script. In this case study the occupant was assumed to be sitting and wearing average office work clothing. Walls assumed to be touching other spaces in the building were assumed to be adiabatic meaning that only the front wall of the office with the window is experiencing heat exchange from the climate. 


\subsection{Interactive Plot and Data Trend Visualization}

The optimization run produced 45474 cells of data and 858 design iterations. It took approximately 1.5 days of run time on a system with 64 GB of RAM and an Intel Xenon Gold 6154 CPU. The data was then used to produce an interactive parallel coordinate plot with select parameters and metrics as seen in Figure 4.3.

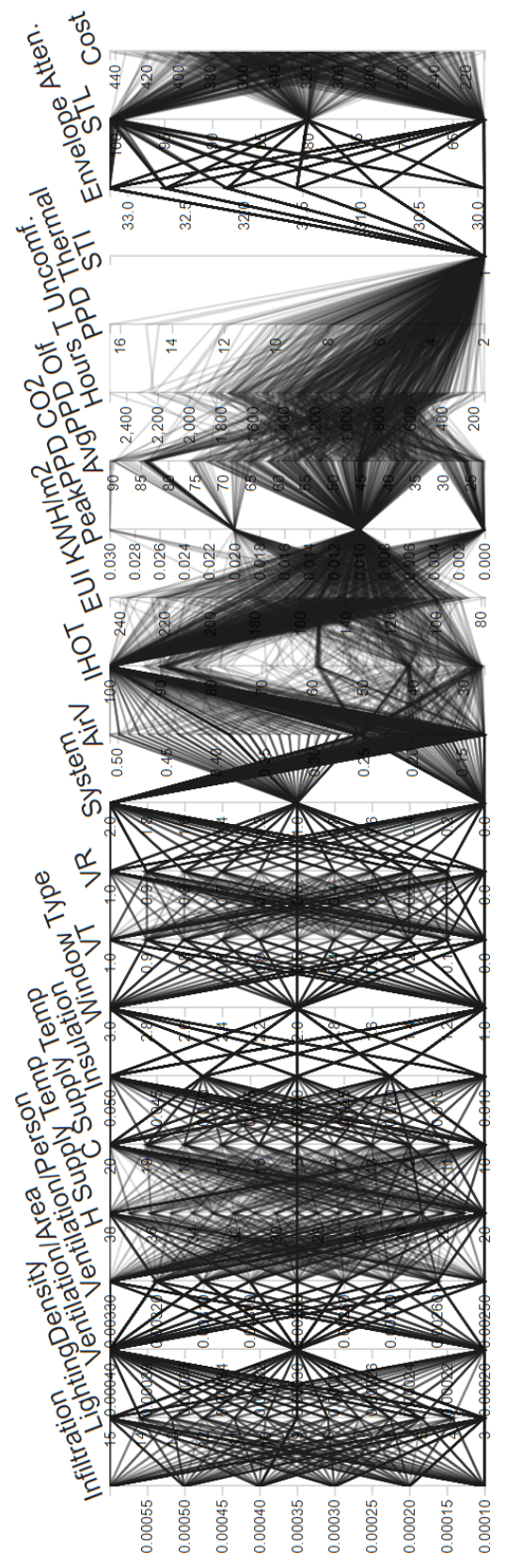


Figure 4.3 - All office case study design options.

When the plot contains all of the results at once, it is difficult to determine trends. There are some observations that can still be made without setting any filter ranges initially. Table 4.4 contains initial interpretations of the results.

Table 4.4 - Initial analysis of office case.

\begin{tabular}{|c|c|c|}
\hline Metric & Observation & Implication \\
\hline IHOT & $\begin{array}{l}\text { Loose clusters of data } \\
\text { around } 0,40,60,80 \text { and } 100 .\end{array}$ & $\begin{array}{l}\text { There are some design } \\
\text { decisions that shift the } \\
\text { performance significantly } \\
\text { while other design } \\
\text { decisions slightly change. }\end{array}$ \\
\hline EUI $\mathrm{kWh} / \mathrm{m}^{2}$ & $\begin{array}{l}\text { Data cloud with no } \\
\text { observable bins. }\end{array}$ & $\begin{array}{l}\text { Energy is affected by many } \\
\text { of the design changes. }\end{array}$ \\
\hline Peak PPD CO 2 & $\begin{array}{l}\text { Entire range is very low } \\
\text { and below a level of } \\
\text { concern. }\end{array}$ & $\begin{array}{l}\text { All design options that } \\
\text { effect carbon dioxide are } \\
\text { valid and effective. }\end{array}$ \\
\hline Average PPD OLF & $\begin{array}{l}\text { Data cloud with no } \\
\text { observable bins. }\end{array}$ & $\begin{array}{l}\text { Odours are a dominant } \\
\text { concern for air quality. } \\
\text { There may be need for } \\
\text { design options with } \\
\text { increased ventilation. }\end{array}$ \\
\hline $\begin{array}{l}\text { Total hours thermally } \\
\text { uncomfortable }\end{array}$ & $\begin{array}{l}\text { Value ranging from } 400 \text { to } \\
2,100 \text {. }\end{array}$ & $\begin{array}{l}\text { Many design options affect } \\
\text { thermal comfort. }\end{array}$ \\
\hline $\begin{array}{l}\text { PPD thermally } \\
\text { uncomfortable }\end{array}$ & $\begin{array}{l}\text { Values ranging from } 2 \text { to } \\
10 .\end{array}$ & $\begin{array}{l}\text { Most design options } \\
\text { provide an acceptable } \\
\text { thermal environment. }\end{array}$ \\
\hline STI & All values are 0.78 . & $\begin{array}{l}\text { All design options do not } \\
\text { impact or change STI } \\
\text { significantly. }\end{array}$ \\
\hline Envelope attenuation & $\begin{array}{l}\text { There are } 6 \text { clusters of } \\
\text { results and there are } 6 \\
\text { clusters of infiltration } \\
\text { options }\end{array}$ & $\begin{array}{l}\text { The range of predicted } \\
\text { envelope attenuation is } \\
\text { between } 30 \text { to } 33 \text {. }\end{array}$ \\
\hline STL & $\begin{array}{l}\text { There are three clusters of } \\
\text { STL: } 61,80 \text { and } 100 .\end{array}$ & $\begin{array}{l}\text { As there are } 3 \text { types of } \\
\text { windows, the window type } \\
\text { is most likely the dominant } \\
\text { parameter. }\end{array}$ \\
\hline
\end{tabular}


Once some performance ranges are defined it becomes more clear which design combinations are ideal. In Figure 4.4, a $0 \%$ to $50 \%$ range was defined for IHOT and the $80 \mathrm{kWh} / \mathrm{m}^{2}$ to $100 \mathrm{kWh} / \mathrm{m}^{2}$ range was defined for the EUI. The design cluster that correlates to these results typically has a high ventilation rate, low infiltration rate, minimum possible air supply temperatures, lower levels of insulation and utilizes a fan coil system. 


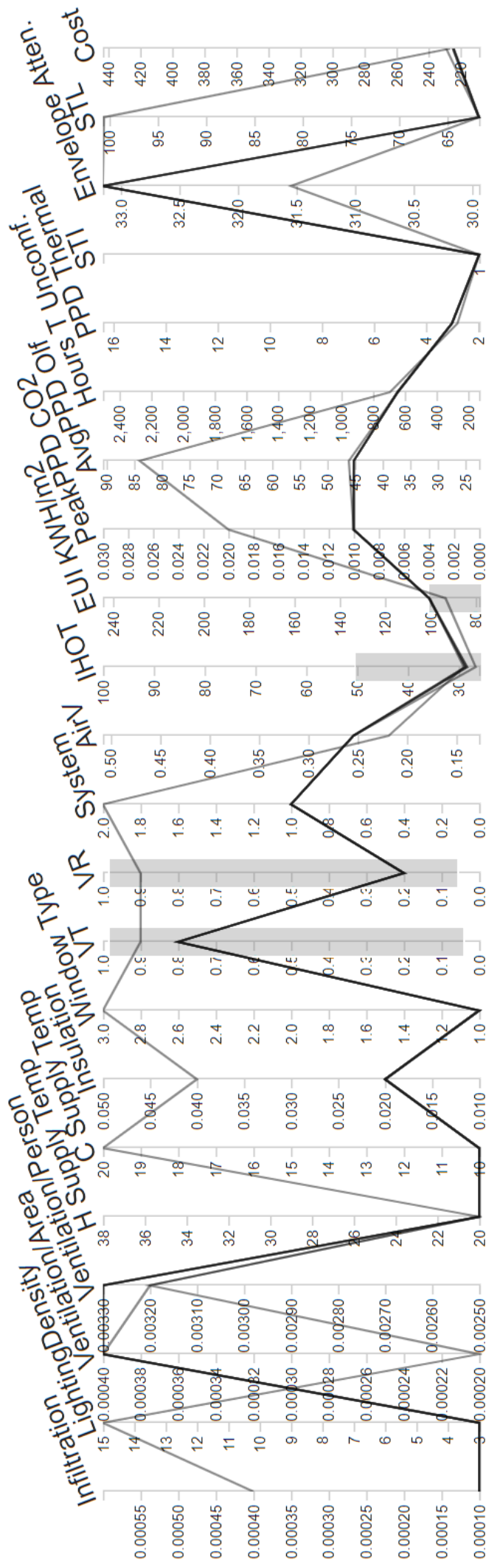

Figure 4.4 - Historic office design options cluster in ideal ranges. 
With this design cluster, there is a significant risk of discomfort due to odour even if there is enough ventilation for carbon dioxide management. This was a similar case as to the courtyard scenario. This indicates there may need to be discussions on the ability for occupants to request additional ventilation at times when the room's air is perceived as stale. Table 4.5 contains the recommended combination of parameters for the historic office case study.

Table 4.5 - Intervention recommendations for office case study.

\begin{tabular}{|l|c|}
\hline \multicolumn{1}{|c|}{ Parameter } & $\begin{array}{c}\text { Recommendation } \\
0.0001 \mathrm{~m}^{3} / \mathrm{s} \mathrm{per} \mathrm{m}^{2} \\
\text { facade }\end{array}$ \\
\hline Infiltration rate per area & $3 \mathrm{~W} / \mathrm{m}^{2}$ \\
\hline Lighting density per area & $0.0004 \mathrm{~m}^{3} / \mathrm{s} \mathrm{per} \mathrm{m}^{2}$ \\
\hline Ventilation per area & $0.0033 \mathrm{~m}^{3} / \mathrm{s}$ \\
\hline Ventilation per person & $20^{\circ} \mathrm{C}$ \\
\hline Heating air supply temperature & $10^{\circ} \mathrm{C}$ \\
\hline Cooling air supply temperature & $0.05 \mathrm{~m}$ \\
\hline Insulation thickness & 1 \\
\hline Number of panes in windows & 0.1 \\
\hline Glass solar reflectance & 0.8 \\
\hline Glass visible transmittance & 0.2 \\
\hline Glass visible reflectance & Fan coil \\
\hline HVAC system type & \\
\hline
\end{tabular}

If in the discussion phase there are concerns that a fan coil system would create the need for too many invasive penetrations on the heritage for fan coil ductwork, the parallel coordinate plot could be manipulated to show alternatives that meet similar performance levels with less need for large wall penetrations. Figure 4.5 displays a design combination with radiative panels and similar levels of performance of the fan coil option but with a higher risk of dissatisfaction from odor and thermal discomfort. This trade off in performance for system type would need to be discussed with project stakeholders in order 
to determine where compromise between rehabilitation invasiveness and performance is needed. If stakeholders were hesitant to implement a fan coil system, the other options can be presented as design alternatives.

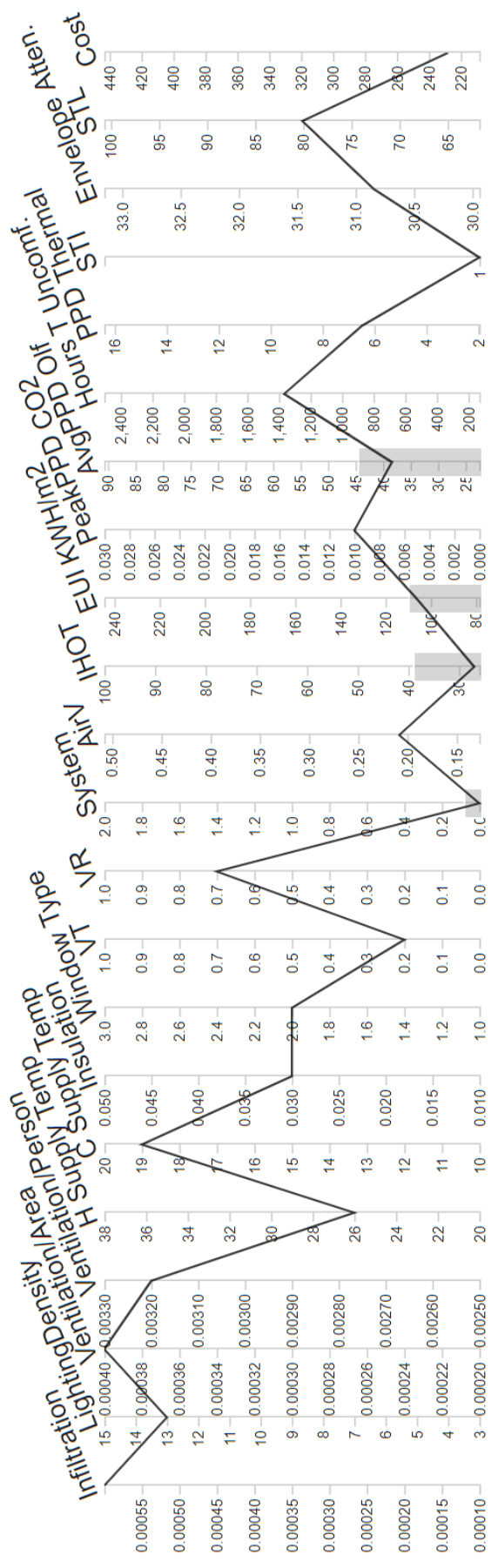

Figure 4.5 - Historic office intervention alternative design recommendations. 


\section{Chapter 5}

\section{Conclusions and Future Work}

\subsection{Conclusions}

Building performance simulation has been used as a tool to identify and better understand character defining elements and was used to examine how proposed changes impact the environmental values of a site. The objective of this thesis was to support the development of higher efficiency designs that are more comfortable for occupants and respectful to heritage values. The features of a generative design workflow, including modeling, optimization and interactive result navigation, were used to create a range of explorable design options for two case studies.

Understanding of a historic site was identified as the first steps for a simulator to take in order to better understand the architectural properties, performance expectations and relevance of simulation. Action items such as a discussion with stakeholders, an existing building assessment, a heritage sensitivity review and a flexibility checklist, were identified as structured tasks that a simulation practitioner can take to better integrate themselves into an intervention design delivery. How to define the success of a design option and the factors that are under the simulator's control are identified in project interpretation steps like the definition of relevant performance metrics and definition of parameter ranges. Guidelines for common metrics and parameter ranges were compiled. 
Relevant theory and numerical representations were collected from fundamental literature covering each of the performance categories. Supporting theory was compiled to outline how each of the performance categories were represented using numerical models to estimate real-world phenomena. By using programs that apply accepted energy balance and mass balance theory, energy models were used to estimate internal surface temperatures and average energy usage. By using programs that use raytracing theory, acoustics and daylight were estimated. Thermal comfort was modeled using fundamental theory of energy balance and perception models. The air quality was estimated using mass balance theory and occupant perception models. All the relevant framework theory was applied using existing Grasshopper tools or was coded specifically for this thesis.

With this framework, one can identify correlations between heritage values and the need to simulate certain performance metrics to address either heritage conservation or risk of discomfort. Building performance practitioners that are supporting culturally significant heritage projects can use the proposed framework to identify compromises between energy, comfort, and heritage.

\subsection{Contributions}

This thesis presented a step-by-step methodology for the generative design analysis of heritage building retrofit interventions. The presented framework is supported by theory for the estimation of energy consumption, thermal comfort, daylight, air quality and acoustics. There have been no workflows to compare to that incorporate all five pillars of building performance and there is limited literature on the application of generative design within heritage conservation. The key components of a generative design workflow, rather 
than a typical optimization or parametric workflow, were incorporated to increase novelty of the holistic performance assessment.

In order to develop this thesis, it was necessary to identify, compile and develop tools that can support the relevant theory within the methodology. A script was developed to generate design options considering all four aspects of IEQ and energy within Grasshopper.

This thesis contained two case studies to demonstrate the application of the methodology and supporting tools. The first case study was a historic courtyard scenario where different geometric additions were being considered and the framework was being used as a tool to inform which intervention geometry resulted in the highest quality conditions. The second case study scenario was an office space, where no geometric changes were being considered. In the office case, different HVAC systems where being compared for performance. In both case studies there was an identification of an overall highest performing design option, but the framework allowed the opportunity for design alternatives if any limitations or concerns arose. The performance consequence of selecting design alternatives could be quickly displayed with the parallel coordinate plot. In a realworld application this style of workflow is effective when working with stakeholders in the design development phase. 


\subsection{Recommendations for Future Work}

There are benefits for continued research into all aspects of this thesis's scope of work; however, the focus on further developing the simulation strategies for each of the performance categories would yield the most value. Annual daylight simulation must be made more accessible through improved computation time; current simulation engines are still costly in terms of computation resources required. Work is needed to streamline and optimize the simulation of performance aspects like acoustics and daylight, which utilize computationally expensive ray tracing strategies, making exercises like parametric analysis and optimizations resource intensive.

A more robust supporting theory in ways to incorporate design changes on building acoustics should also be further developed. Detailed modeling of HVAC systems and incorporating rules of thumb for aspects like in-zonal air movement would also have value in further developments.

Further research on feasible simulation practices is needed for each of the respective building performance categories within the context of heritage conservation. Details like how to properly assign historic materials to energy, acoustic and daylighting models need further research support to better reflect on site conditions. The overall combination of all performance aspects within a single scripting interface is a significant development made possible through Grasshopper and its supporting app extensions which are evolving on a weekly basis.

There is a limited range of open-source tools available to support wholistic simulation and optimization. Further work could identify how to combine the application of simulation engines aside from the ones currently available in Grasshopper to make the 
practice of wholistic analysis more available for practitioners. Tools like Dynamo for Revit will also slowly gain traction to offer the same simulation capabilities as Grasshopper and will create further opportunity for generative design methodologies in the building performance sector.

The proposed framework intended to create a balance between performance aspects and aimed to fill gaps in academia and industry practice. As technology continues to improve, data driven design will help guide decision makers to create a better performing built environment. 


\section{List of References}

[1] Canada's Historic Places, Standards and Guidelines for the Conservation of Historic Places in Canada, Second Edi. 2010.

[2] N. Soares et al., "A review on current advances in the energy and environmental performance of buildings towards a more sustainable built environment," Renew. Sustain. Energy Rev., vol. 77, no. February, pp. 845-860, 2017.

[3] Z. (John) Zhai and J. M. Previtali, "Ancient vernacular architecture: characteristics categorization and energy performance evaluation," Energy Build., vol. 42, no. 3, pp. 357-365, 2010.

[4] A. U. Uzoechi, "Microbiological Evaluation of Indoor Air Quality of State University Library," vol. 05, no. 03, pp. 525-530, 2017.

[5] D. J. Gerber, "Design Optioneering: Multi-disciplinary Design Optimization through Parameterization, Domain Integration and Automation of a Genetic Algorithm," pp. 32-39, 2011.

[6] J. E. Harding and P. Shepherd, "Meta-Parametric Design,” Des. Stud., vol. 52, pp. 73-95, 2017.

[7] X. Shi and W. Yang, "Performance-driven architectural design and optimization technique from a perspective of architects," Autom. Constr., vol. 32, pp. 125-135, 2013.

[8] D. Nagy et al., "Project Discover: An application of generative design for architectural space planning," Symp. Simul. Archit. Urban Des., no. June, pp. 5966, 2017.

[9] F. Ritter, P. Geyer, and A. Bormann, "Simulation-based Decision-making in Early Design Stages," Proc. 32nd CIB W78 Conf. 2015, 27th-29th Oct. 2015, Eindhoven, Netherlands, pp. 657-666, 2015.

[10] F. P. Chantrelle, H. Lahmidi, W. Keilholz, M. El Mankibi, and P. Michel, "Development of a multicriteria tool for optimizing the renovation of buildings," Appl. Energy, vol. 88, no. 4, pp. 1386-1394, 2011.

[11] J. Frazer, "Generative and Evolutionary Techniques for Building Envelope Design," Int. Conf. Gener. Art, vol. 2002, no. December, pp. 1-16, 2002.

[12] B. Ferreira and L. António, "Generative Design for Building Information Modeling," Proc. 33rd Educ. Res. Comput. Aided Archit. Des. Eur. Conf., vol. 1, pp. 635-644, 2015.

[13] D. J. Gerber, S.--Hsin (Eve) Lin, B. (Penny) Pan, and A. S. Solmaz, "Design Optioneering: Multi-disciplinary Design Optimization through Parameterization, Domain Integration and Automation of a Genetic Algorithm," Symp. Simul. Archit. Urban Des., no. November 2015, pp. 23-30, 2012. 
[14] T. R. Gruber and E. Al, "Generative Design Rationale: Beyond the Record and Replay Paradigm,” Des. Ration. Concepts, no. December 1991, 1993.

[15] S. C. Chase, "Generative design tools for novice designers: Issues for selection," Autom. Constr., vol. 14, no. 6, pp. 689-698, 2005.

[16] V. Buelow, A. Chaszar, P. Von Buelow, M. Turrin, and A. Arbor, "Multivariate Interactive Visualization of Data in Generative Design Multivariate Interactive Visualization of Data in Generative Design," 2016.

[17] A. Leitão, L. Santos, and J. Lopes, "Programming Languages for Generative Design: A Comparative Study," Int. J. Archit. Comput., vol. 10, no. 1, pp. 139-162, 2012.

[18] J. Berquist, A. Tessier, W. O. Brien, R. Attar, and A. Khan, "An Investigation of Generative Design for Heating, Ventilation, and Air-Conditioning," no. May, 2017.

[19] A. Athienitis and W. O’Brien, "Modeling, Design, and Optimization of Net-Zero Energy Buildings,” pp. 1-10, 2015.

[20] S. Bucking, R. Zmeureanu, and A. Athienitis, "An information driven hybrid evolutionary algorithm for optimal design of a Net Zero Energy House," Sol. Energy, vol. 96, pp. 128-139, 2013.

[21] S. Krish, "A practical generative design method," CAD Comput. Aided Des., vol. 43, no. 1, pp. 88-100, 2011.

[22] A. L. Webb, "Energy retrofits in historic and traditional buildings: A review of problems and methods," Renew. Sustain. Energy Rev., vol. 77, no. November 2016, pp. 748-759, 2017.

[23] R. Suárez, A. Alonso, and J. J. Sendra, "Intangible cultural heritage : The sound of the Romanesque cathedral of Santiago de Compostela," J. Cult. Herit., vol. 16, no. 2, pp. 239-243, 2015.

[24] U. Munarim and E. Ghisi, "Environmental feasibility of heritage buildings rehabilitation,” Renew. Sustain. Energy Rev., vol. 58, pp. 235-249, 2016.

[25] A. Maahsen-Milan and K. Fabbri, "Energy restoration and retrofitting. Rethinking restoration projects by means of a reversibility/sustainability assessment," J. Cult. Herit., vol. 14, no. 3 SUPPL, pp. e41-e44, 2013.

[26] F. Ascione, N. Bianco, R. F. De Masi, F. De'Rossi, and G. P. Vanoli, "Energy retrofit of an educational building in the ancient center of Benevento. Feasibility study of energy savings and respect of the historical value," Energy Build., vol. 95, pp. 172-183, 2015.

[27] T. Broström, P. Eriksson, L. Liu, P. Rohdin, F. Ståhl, and B. Moshfegh, "A Method to Assess the Potential for and Consequences of Energy Retrofits in Swedish Historic Buildings,” Hist. Environ. Policy Pract., vol. 5, no. 2, pp. 150-166, 2014.

[28] A. L. Pisello, A. Petrozzi, V. L. Castaldo, and F. Cotana, "On an innovative integrated technique for energy refurbishment of historical buildings: Thermal- 
energy, economic and environmental analysis of a case study," Appl. Energy, vol. 162, pp. 1313-1322, 2014.

[29] M. Sunikka-Blank and R. Galvin, "Irrational homeowners? How aesthetics and heritage values influence thermal retrofit decisions in the United Kingdom," Energy Res. Soc. Sci., vol. 11, pp. 97-108, 2016.

[30] K. Fabbri and M. Pretelli, "Heritage buildings and historic microclimate without HVAC technology: Malatestiana Library in Cesena, Italy, UNESCO Memory of the World," Energy Build., vol. 76, pp. 15-31, 2014.

[31] A. Martínez-Molina, I. Tort-Ausina, S. Cho, and J. L. Vivancos, "Energy efficiency and thermal comfort in historic buildings: A review," Renew. Sustain. Energy Rev., vol. 61, pp. 70-85, 2016.

[32] S. Al-Maiyah and H. Elkadi, "The role of daylight in preserving identities in heritage context," vol. 11, pp. 1544-1557, 2007.

[33] H. Al-Maiyah and Elkadi, "Turkish D-light: accentuating heritage values with daylight Turkish D-light : accentuating heritage values with daylight," 2015.

[34] R. Pfluger, M. Werner, and W. Feist, "Optimisation of daylight and artificial light in cultural heritage Hauptschule Hötting in Innsbruck."

[35] D. Camuffo et al., "Indoor air quality at the Correr Museum, Venice, Italy," 1999.

[36] G. Drakou, C. Zerefos, I. Ziomas, and V. Ganitis, "Studies in Conservation Numerical Simulation of Indoor Air Pollution Levels in a Church and in a Museum in Greece," vol. 3630, 2013.

[37] S. Costanzo, A. Cusumano, F. Di Maio, C. Giaconia, and G. Giaconia, "IAQ Monitoring in Heritage Buildings," no. c, pp. 942-946, 2005.

[38] U. July and L. Bd, "LEED v4 for Building design and Construction," 2017.

[39] International WELL Building Institute, "The Well Building Standard," vol. V1, no. May, 2016.

[40] Natural Resources Canada, "National Energy Code of Canada for Buildings (NECB)." 2015.

[41] US Department of Energy, "EnergyPlus TM Documentation Engineering Reference The Reference to EnergyPlus Calculations," no. c, pp. 1996-2015, 2015.

[42] V. Bazjanac, "In the Simulation of Energy performance," no. January 2001, 2014.

[43] W. O. Brien, A. Athienitis, and T. Kesik, "Thermal zoning and interzonal airflow in the design and simulation of solar houses : a sensitivity analysis," vol. 1493, 2011.

[44] J. Clarke, "Energy Simulation in Building Design, Second Edition," 2001.

[45] L. Berkeley et al., "Engineering Reference," 2018.

[46] C. Reinhart, "Daylighting Handbook II," 2018. 
[47] G. W. Larson and R. Shakespeare, Rendering with Radiance. San Francisco: Morgan Kaufman Publishers, 1998.

[48] C. F. Reinhart et al., "Dynamic Daylight Performance Metrics for Sustainable Building Design," J. Illum. Eng. Soc. North Am., vol. 2724, 2013.

[49] Illuminating Engineering Society, "IES Spatial Daylight Autonomy (sDA) and Annual Sunlight Exposure (ASE).” Illuminating Engineering Society, 2013.

[50] B. Performance, A. Conference, I. Chicago, and I. L. September, "Daylighting and Energy Simulation Workflow in Performance Simulation," pp. 382-389, 2018.

[51] J. Mardaljevic, "Useful Daylight Illuminance: A New Paradigm for Assessing Daylight in Buildings," no. March 2005, 2014.

[52] A. van der Harten, "Pachyderm Acoustical Simulation Towards Source Sound Analysis," John Wiley Sons Ltd, p. 139, 2009.

[53] A. van der Harten, "Selecting Simulation Settings," 2015. [Online]. Available: http://www.perspectivesketch.com/pachyderm/index.php/pachyderm/pachydermtutorials/10-selecting-simulation-settings.

[54] L. L. Doelle, "Environmental Acoustics Hardcover," pp. 2-5, 1972.

[55] Ş. Konca and J. H. Rindel, "Impacts of Reverberation Time , Absorption Location and Background Noise on Listening Conditions in Multi Source Environment Impacts of Reverberation Time, Absorption Location and Background Noise on Listening Conditions in Multi Source Environment Measu," no. August, 2005.

[56] K. L. Payton, "A method to determine the speech transmission index from speech waveforms A method to determine the speech transmission index from speech waveforms," no. June, 2014.

[57] B. Schwerin and K. Paliwal, "An improved speech transmission index for intelligibility prediction,” SPEECH Commun., vol. 65, pp. 9-19, 2014.

[58] M. Olechowska and A. Nowos, "Fast estimation of speech transmission index using the reverberation time," vol. 102, pp. 55-61, 2016.

[59] M. Hodgson, "Relationship between HVAC airflow rates and noise levels, and noise control in a mechanically-ventilated university building," ASHRAE Trans. 116, Issue 1), 2010.

[60] V. Iordache and T. Catalina, "Acoustic approach for building air permeability estimation," Build. Environ., vol. 57, pp. 18-27, 2012.

[61] A. London, "Methods for Determining Sound Transmission Loss in the Field," Natl. Bur. Stand., vol. 26, 1941.

[62] S. M. Levy, “Construction Calculations Manual," pp. 8-9, 2011.

[63] Indowwindows, "What is STC Rating?," 2020. [Online]. Available: https://indowwindows.com/resources/stc-rating/. 
[64] P. O. Fanger, “Thermal Comfort.” McGraw-Hill, New York, 1972.

[65] Á. Gagge and Á. Fanger, "Chapter 2 A Brief History of Thermal Comfort : From Effective Temperature to Adaptive Thermal Comfort," pp. 7-24, 2015.

[66] ASHRAE, "Chapter 9 Thermal Comfort." American Society of Heating, Refrigerating and Air-Conditioning Engineers, 2013.

[67] I. Sarbu and C. Sebarchievici, "Aspects of indoor environmental quality assessment in buildings," Energy Build., vol. 60, pp. 410-419, 2013.

[68] D. DuBois, "A formula to estimate the approximate surface area if height and weight be known." 1989.

[69] W. E. Health, L. Wa, and T. N. Onderzoek, "Affiliation : Netherlands Organization for Applied Scientific Research The actual insulation of multilayer clothing," vol. 15, no. 1, pp. 66-75, 1989.

[70] I. Standard, "Standard 7730 ISO, Moderate Thermal Environment—Determination of the PMV and PPD Indices and Specification of the Conditions for Thermal Comfort, Interna-tional Organization for Standardization,” vol. 2005, 2005.

[71] S. C. Turner et al., "ASHRAE STANDARD Thermal Environmental Conditions for Human Occupancy," vol. 2010, 2011.

[72] “Ontario Building Code 2012,” no. 1, pp. 9-10, 2014.

[73] P. Date, "UC Berkeley," 2015.

[74] "ASHRAE Chapter 11 Air contaminants." American Society of Heating, Refrigerating and Air-Conditioning Engineers.

[75] ASHRAE, "Chapter 16 Ventilation and Infiltration." American Society of Heating, Refrigerating and Air-Conditioning Engineers, 2013.

[76] I. Turiel, "Indoor Air Quality \& Human Health," pp. 2-7, 1985.

[77] ASHRAE, "ASHRAE Chapter 12 Odors." American Society of Heating, Refrigerating and Air-Conditioning Engineers, 2013.

[78] B. J. W. Lstiburek, "Insight Blame It On Star Trek : Solving IAQ Problems," no. March, pp. 1-5, 2009.

[79] V. Klimateknik, "decipol : New units for perceived air," pp. 155-157.

[80] S. Bucking, R. Zmeureanu, and A. Athienitis, "A methodology for identifying the influence of design variations on building energy performance," J. Build. Perform. Simul., vol. 7, no. 6, pp. 411-426, 2014.

[81] T. Wortmann, "Technology | Architecture + Design Model-based Optimization for Architectural Design : Optimizing Daylight and Glare in Grasshopper," vol. 1448, 2017.

[82] S. Cha and T. Jeng, "Developing Algorithmic Methodology to Vizualize \& Evaluate 
the Dynmaics of Urban Form,” vol. 2, pp. 121-130, 2019.

[83] R. Mcneel, "Glapagos on the Logic and Limitations of Generic Solvers," pp. 132$135,2012$.

[84] A. Costa and G. Nannicini, "RBFOpt: an open-source library for black-box optimization with costly function evaluations."

[85] H. Zhang, Y. Chen, C. Guo, and Z. Fu, "Application of Radial Basis Function Method for Solving Nonlinear Integral Equations," vol. 2014, 2014.

[86] S. Attia, M. Hamdy, S. Carlucci, L. Pagliano, S. Bucking, and A. Hasan, "Building performance optimization of net zero-energy buildings," Model. Des. Optim. NetZero Energy Build., pp. 175-206, 2015.

[87] J. Davies, "Parallel Coordinates," bl.ocks, 2020. [Online]. Available: https://bl.ocks.org/jasondavies/1341281.

[88] L. M. Wang and M. C. Vigeant, "Evaluations of output from room acoustic computer modeling and auralization due to different sound source directionalities," Appl. Acoust., vol. 69, no. 12, pp. 1281-1293, 2008.

[89] M. Kleindienst, Sian ; Andersen, "The Adaptation of Daylight Glare Probability to Dynamic Metrics in a Computational Setting," Lux Eur. 2009 - 11th Eur. Light. Conf. Istanbul, Turkey, Sept. 9-11, 2009, pp. 3-10, 2009.

[90] S. Vellenga, S. Persoon, and T. Höngens, "Modeling Acoustics as a Powerful Design Tool for Open Plan Offices," no. August, 2013.

[91] T. Gil, M. A. Gálvez, V. Gómez, and J. Castejón, "Environmental protection and energy savings in HVAC systems from the higrothermal and air quality standpoints," no. August, 2011. 


\section{Appendix A - Values-based Assessment}

Table A.1 - Example of values-based assessment for environmental building factors.

\begin{tabular}{|c|c|c|c|}
\hline & Heritage value association & Future use expectation & Simulation result value \\
\hline 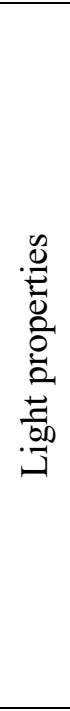 & $\begin{array}{l}\text { How does natural light within } \\
\text { the building correlate to } \\
\text { heritage values in the analysis } \\
\text { area? } \\
\quad \text { Low association } \\
\circ \quad \text { Some association } \\
\circ \quad \text { Significant } \\
\quad \text { association }\end{array}$ & $\begin{array}{l}\text { How does light need to be } \\
\text { managed for the future } \\
\text { use of the analysis area? } \\
\circ \quad \text { Work appropriate } \\
\text { lighting levels } \\
\text { required } \\
\circ \quad \text { Variable lighting } \\
\text { conditions } \\
\text { appropriate } \\
\text { No change from } \\
\text { current } \\
\text { conditions is } \\
\text { appropriate }\end{array}$ & $\begin{array}{l}\text { What types of light } \\
\text { analysis are required to test } \\
\text { quality of intervention? } \\
\circ \quad \text { Specific surface } \\
\text { illuminance } \\
\circ \text { General work } \\
\text { plane illuminance } \\
\circ \text { Annual analysis } \\
\text { required } \\
\circ \text { Hour specific } \\
\text { analysis } \\
\text { acceptable } \\
\circ \text { Glare } \\
\text { visualizations for } \\
\text { specific locations } \\
\text { required }\end{array}$ \\
\hline 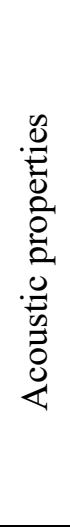 & $\begin{array}{l}\text { How does acoustics within } \\
\text { the building correlate to } \\
\text { heritage values in the analysis } \\
\text { area? } \\
\quad \text { Low association } \\
\circ \text { Some association } \\
\circ \quad \text { Significant } \\
\text { association }\end{array}$ & $\begin{array}{l}\text { How should the acoustics } \\
\text { of the space be managed } \\
\text { in the future use of the } \\
\text { analysis area? } \\
\text { O Speech privacy is } \\
\text { a concern } \\
\circ \quad \text { Speech clarity is } \\
\text { a concern } \\
\text { No change from } \\
\text { current } \\
\text { conditions is } \\
\text { appropriate }\end{array}$ & $\begin{array}{l}\text { What types of sound } \\
\text { analysis can be simulated } \\
\text { to test quality of } \\
\text { intervention? } \\
\quad \text { Privacy of sound } \\
\circ \text { Clarity of sound }\end{array}$ \\
\hline 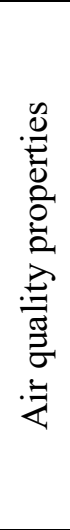 & $\begin{array}{l}\text { How does air quality, or } \\
\text { supporting systems within the } \\
\text { building correlate to heritage } \\
\text { values in the analysis area? } \\
\circ \text { Low association } \\
\circ \text { Some association } \\
\circ \quad \text { Significant } \\
\text { association }\end{array}$ & $\begin{array}{l}\text { How can the space be } \\
\text { sufficiently ventilated } \\
\text { without unnecessarily } \\
\text { wasting energy or } \\
\text { invasively effecting } \\
\text { heritage fabric? } \\
\text { ○ Ventilation rates } \\
\circ \text { Ventilation } \\
\text { schedules } \\
\text { Appropriate } \\
\text { system type } \\
\text { selection }\end{array}$ & $\begin{array}{l}\text { What types of air quality } \\
\text { can be examined to test the } \\
\text { quality of the intervention? } \\
\text { Asses worst, best } \\
\text { and average air } \\
\text { quality with } \\
\text { proposed system }\end{array}$ \\
\hline
\end{tabular}




\begin{tabular}{|c|c|c|c|}
\hline 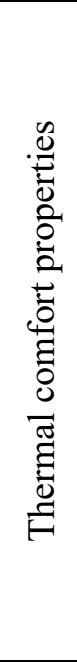 & $\begin{array}{l}\text { How does thermal comfort, or } \\
\text { supporting systems within the } \\
\text { building correlate to heritage } \\
\text { values in the analysis area? } \\
\circ \text { Low association } \\
\circ \text { Some association } \\
\circ \text { Significant } \\
\text { association }\end{array}$ & $\begin{array}{l}\text { How should heating and } \\
\text { cooling be supplied to the } \\
\text { space to minimize } \\
\text { discomfort and energy } \\
\text { consumption? } \\
\text { Appropriate } \\
\text { system type } \\
\text { selection }\end{array}$ & $\begin{array}{l}\text { What types of thermal } \\
\text { comfort tests can be run to } \\
\text { asses the quality of the } \\
\text { intervention? } \\
\text { o Define occupant } \\
\text { location or general } \\
\text { analysis grid } \\
\circ \quad \text { Asses worst, best } \\
\text { and average } \\
\text { comfort with } \\
\text { proposed system } \\
\text { Examine total } \\
\text { hours over } \\
\text { discomfort } \\
\text { threshold }\end{array}$ \\
\hline
\end{tabular}




\section{Appendix B - Flexibility Checklist Printout}

\begin{tabular}{|c|c|c|c|c|c|c|}
\hline \multicolumn{2}{|c|}{ Project Category } & \multirow[t]{2}{*}{ Rigid } & \multirow[t]{2}{*}{ Assumed } & \multirow{2}{*}{$\begin{array}{c}\text { Floating } \\
\text { point } \\
\text { parametric }\end{array}$} & \multirow{2}{*}{$\begin{array}{c}\text { Integer } \\
\text { parametric }\end{array}$} & \multirow[t]{2}{*}{ Comments } \\
\hline \multirow{9}{*}{ 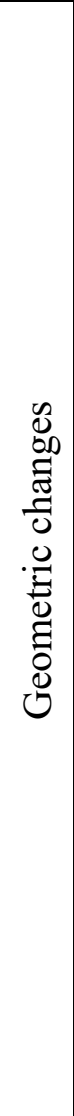 } & Site orientation & & & & & \\
\hline & $\begin{array}{l}\text { Window to wall } \\
\text { ratio or location }\end{array}$ & & & & & \\
\hline & Shading surfaces & & & & & \\
\hline & Roof surfaces & & & & & \\
\hline & Wall surfaces & & & & & \\
\hline & Floor surfaces & & & & & \\
\hline & $\begin{array}{l}\text { Inter-zonal } \\
\text { surfaces }\end{array}$ & & & & & \\
\hline & $\begin{array}{l}\text { Occupant } \\
\text { sedentary } \\
\text { location }\end{array}$ & & & & & \\
\hline & $\begin{array}{l}\text { Radiant panel } \\
\text { location }\end{array}$ & & & & & \\
\hline \multirow{5}{*}{ 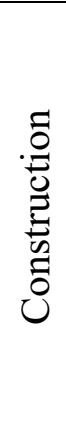 } & Roof surfaces & & & & & \\
\hline & Wall surfaces & & & & & \\
\hline & Floor surfaces & & & & & \\
\hline & $\begin{array}{l}\text { Inter-zonal } \\
\text { Surfaces }\end{array}$ & & & & & \\
\hline & Window specs & & & & & \\
\hline \multirow{4}{*}{ 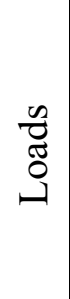 } & Equipment load & & & & & \\
\hline & Infiltration & & & & & \\
\hline & Lighting density & & & & & \\
\hline & Ventilation & & & & & \\
\hline
\end{tabular}




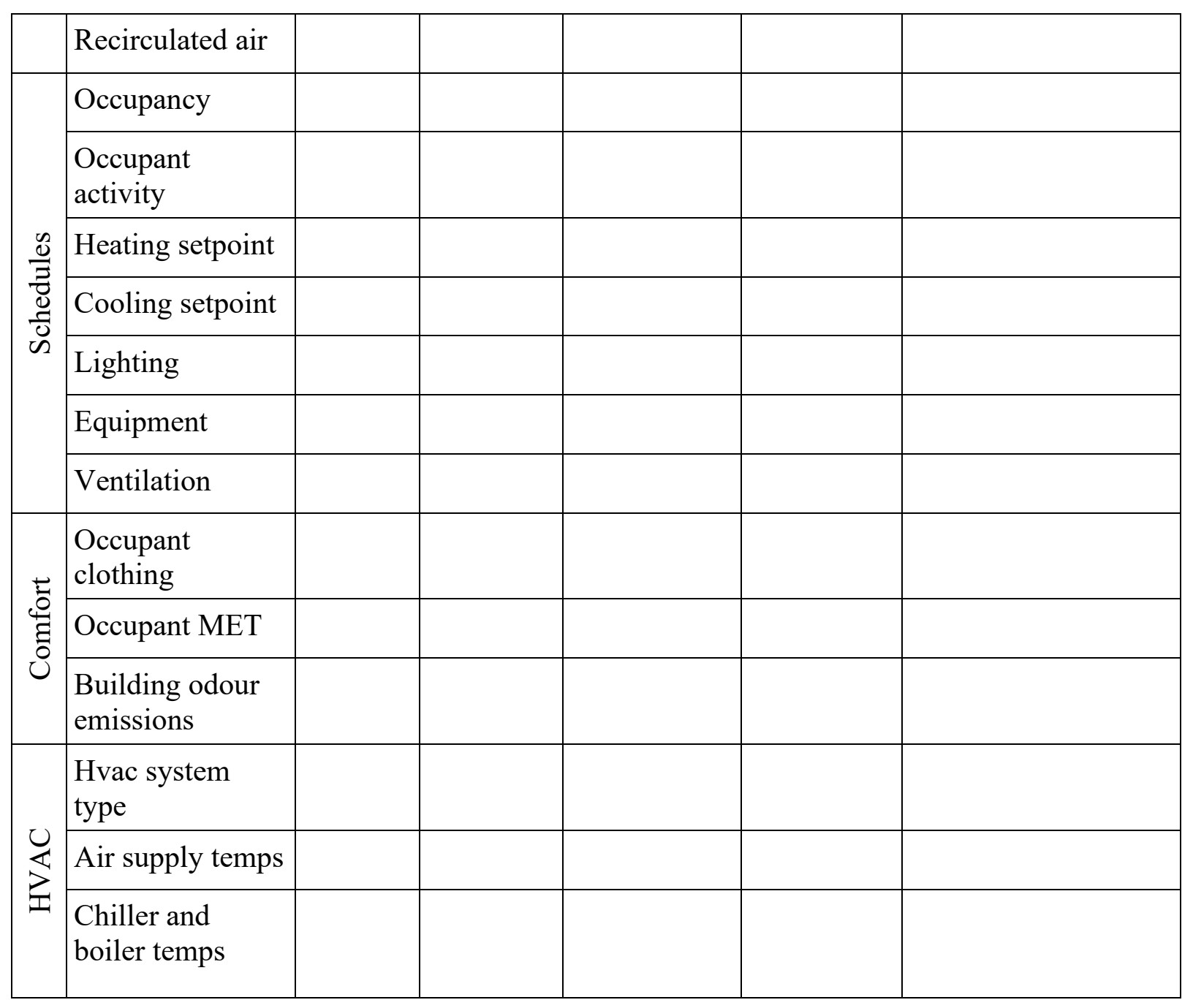




\section{Appendix $\mathrm{C}$ - Table of Metrics and Target Ranges}

Table C.1- Common performance metrics and goals.

\begin{tabular}{|l|l|l|l|}
\hline & Metric name & Goal & Explanation \\
\hline & $\begin{array}{l}\text { Ambient average light } \\
\text { intensity }\end{array}$ & No less than 215 lux at 0.76 m & $\begin{array}{l}\text { Ambient lighting systems should provide } \\
\text { enough light at the typical worksurface [39]. }\end{array}$ \\
\hline Work surface lighting intensity & Between 300 lux and 500 lux & $\begin{array}{l}\text { As a supplementary to the ambient lighting } \\
\text { systems, task lighting should provide additional } \\
\text { light on demand at the work surface [39]. }\end{array}$ \\
\hline & Window access distance & Below 12.5 m & $\begin{array}{l}\text { Sedentary occupants should ideally be able to } \\
\text { see a window from their location [39]. }\end{array}$ \\
\cline { 2 - 5 } & sDA/cDA of at least 55\% & $\begin{array}{l}\text { Value expressed as a of floor area where 300 } \\
\text { lux is experienced 50\% of occupied hours. } \\
\text { [49],[48]. }\end{array}$ \\
\hline $\begin{array}{l}\text { Spatial daylight (sDA) } \\
\text { autonomy or continuous } \\
\text { daylight autonomy (cDA) }\end{array}$ & ASEno more than 10\% & $\begin{array}{l}\text { Value expressed as \% of floor area experiencing } \\
\text { more than 1000 lux for more than 250 hours a } \\
\text { year [49]. }\end{array}$ \\
\hline Annual sunlight exposure \\
Based on a specific viewpoint [89].
\end{tabular}




\section{Appendix D - Case Study Model Properties}

Table D. 1 - Model properties for the case studies.

\begin{tabular}{|c|c|c|}
\hline Assumption & $\begin{array}{l}\text { Court Study } \\
\text { Values }\end{array}$ & $\begin{array}{l}\text { Office Study } \\
\text { Values }\end{array}$ \\
\hline People per area & $0.05 \mathrm{ppl} / \mathrm{m}^{2}$ & $0.05 \mathrm{ppl} / \mathrm{m}^{2}$ \\
\hline Equipment load & 10 Watts $/ \mathrm{m}^{2}$ & $10 \mathrm{Watts} / \mathrm{m}^{2}$ \\
\hline Occupant met rate & $1.7 \mathrm{Met}$ & 1 Met \\
\hline $\begin{array}{l}\text { Occupant Clo } \\
\text { Level }\end{array}$ & $1 \mathrm{Clo}$ & $1 \mathrm{Clo}$ \\
\hline Building Olf level & $0.1 \mathrm{olf} / \mathrm{m}^{2}$ & $0.1 \mathrm{olf} / \mathrm{m}^{2}$ \\
\hline $\begin{array}{l}\text { Constant relative } \\
\text { humidity }\end{array}$ & $40 \%$ & $40 \%$ \\
\hline Body posture & Standing & Sitting \\
\hline $\begin{array}{l}\text { PPD thermal } \\
\text { comfort threshold }\end{array}$ & $10 \%$ & $10 \%$ \\
\hline $\begin{array}{l}\text { Outside air } \\
\text { concentration }\end{array}$ & $350 \mathrm{ppm}$ & $350 \mathrm{ppm}$ \\
\hline $\begin{array}{l}\text { Lux comfort } \\
\text { threshold }\end{array}$ & $\begin{array}{l}300 \text { lux to } \\
5000 \operatorname{lux}\end{array}$ & $\begin{array}{c}300 \operatorname{lux} \text { to } 3000 \\
\operatorname{lux}\end{array}$ \\
\hline $\begin{array}{l}\text { Selected light } \\
\text { analysis hours }\end{array}$ & $\begin{array}{c}21^{\text {st }} \text { of June } \\
\text { and } \\
\text { December at } \\
9 \text { AM, 12 } \\
\text { PM, 3 PM }\end{array}$ & $\begin{array}{c}21^{\text {st }} \text { of June and } \\
\text { December at } 9 \\
\text { AM, } 12 \text { PM, } 3 \\
\text { PM }\end{array}$ \\
\hline $\begin{array}{l}\text { Number of } \\
\text { ambient light } \\
\text { bounces }\end{array}$ & 3 & 3 \\
\hline $\begin{array}{l}\text { Number of } \\
\text { acoustic rays }\end{array}$ & 5000 & 2000 \\
\hline
\end{tabular}


Table D.2 - Acoustic properties applied to all surfaces.

\begin{tabular}{|l|c|c|c|c|c|c|c|c|}
\hline & $\begin{array}{c}\mathbf{6 2 . 5} \\
\mathbf{H z}\end{array}$ & $\begin{array}{c}\mathbf{1 2 5} \\
\mathbf{H z}\end{array}$ & $\begin{array}{c}\mathbf{2 5 0} \\
\mathbf{H z}\end{array}$ & $\begin{array}{c}\mathbf{5 0 0} \\
\mathbf{H z}\end{array}$ & $\mathbf{1 ~ \mathbf { H z }}$ & $\mathbf{2} \mathbf{k H z}$ & $\mathbf{4} \mathbf{~ k H z}$ & $\mathbf{8 ~ k H z}$ \\
\hline $\begin{array}{l}\text { Wall and roof } \\
\text { surfaces } \\
\text { absorption } \\
\text { coefficients }\end{array}$ & 29 & 25 & 22 & 17 & 9 & 10 & 11 & 13 \\
\hline $\begin{array}{l}\text { Window and } \\
\text { glass surfaces } \\
\text { absorption } \\
\text { coefficients }\end{array}$ & 25 & 18 & 6 & 4 & 3 & 2 & 2 & 2 \\
\hline $\begin{array}{l}\text { Wall and roof } \\
\text { surfaces } \\
\text { scattering } \\
\text { coefficients }\end{array}$ & 25 & 25 & 25 & 25 & 25 & 25 & 25 & 25 \\
\hline $\begin{array}{l}\text { Window and } \\
\text { glass surfaces } \\
\text { scattering } \\
\text { coefficients }\end{array}$ & 15 & 15 & 15 & 15 & 15 & 15 & 15 & 15 \\
\hline
\end{tabular}

Table D.3 - Case study wall construction.

\begin{tabular}{|l|c|c|c|c|}
\hline Name & $\begin{array}{c}\text { Thickness } \\
(\mathbf{m})\end{array}$ & $\begin{array}{c}\text { Conductivity } \\
(\mathbf{W} / \mathbf{m}-\mathbf{K})\end{array}$ & $\begin{array}{c}\text { Density } \\
\left(\mathbf{k g} / \mathbf{m}^{\mathbf{3}}\right)\end{array}$ & $\begin{array}{c}\text { Specific } \\
\text { Heat } \\
(\mathbf{J} / \mathbf{k g}-\mathbf{K})\end{array}$ \\
\hline Sandstone & 0.250 & 1.83 & 2200 & 712 \\
\hline Brick & 0.266 & 0.727 & 1922 & 837 \\
\hline Polystyrene & $\mathrm{P}$ & 0.03 & 1380 & 1380 \\
\hline Plaster & 0.0119 & 0.5 & 1300 & 1000 \\
\hline
\end{tabular}

$\mathrm{P}=$ Parametric Property 
Table D.4 - Case Study Window Type Construction.

\begin{tabular}{|c|c|c|c|c|c|c|c|c|c|c|}
\hline & & $\frac{\bar{\pi}}{\stackrel{\bar{d}}{\frac{\pi}{\pi}}}$ & 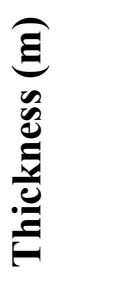 & 京 & 离 & 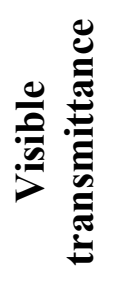 & 兽 & 兑 & 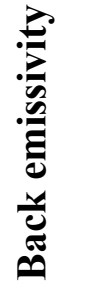 & 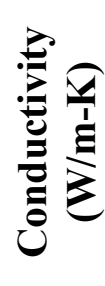 \\
\hline $\begin{array}{l}- \\
\frac{3}{8} \\
\frac{0}{3} \\
3\end{array}$ & $\begin{array}{c}\text { Layer } \\
1\end{array}$ & Glass & 0.024 & $P$ & $P$ & $P$ & $\mathrm{P}$ & $\mathrm{P}$ & $\mathrm{P}$ & 1.06 \\
\hline$\frac{7}{N}$ & $\begin{array}{c}\text { Layer } \\
1\end{array}$ & Glass & 0.006 & $\mathrm{P}$ & $\mathrm{P}$ & $\mathrm{P}$ & $\mathrm{P}$ & $\mathrm{P}$ & $\mathrm{P}$ & 1.06 \\
\hline$\frac{3}{8}$ & $\begin{array}{l}\text { Layer } \\
2\end{array}$ & $\begin{array}{l}\text { Air } \\
\text { Gap }\end{array}$ & 0.012 & N/a & N/a & N/a & $\mathrm{N} / \mathrm{a}$ & N/a & $\mathrm{N} / \mathrm{a}$ & $\mathrm{N} / \mathrm{a}$ \\
\hline 3 & $\begin{array}{c}\text { Layer } \\
3\end{array}$ & Glass & 0.024 & 0.837 & 0.075 & 0.89 & 0.081 & 0.84 & 0.84 & 1.06 \\
\hline & $\begin{array}{c}\text { Layer } \\
1\end{array}$ & Glass & 0.006 & $\mathrm{P}$ & $\mathrm{P}$ & $\mathrm{P}$ & $\mathrm{P}$ & $\mathrm{P}$ & $\mathrm{P}$ & 1.06 \\
\hline$m$ & $\begin{array}{l}\text { Layer } \\
2\end{array}$ & $\begin{array}{l}\text { Air } \\
\text { Gap } \\
\end{array}$ & 0.012 & N/a & N/a & N/a & $\mathrm{N} / \mathrm{a}$ & N/a & N/a & $\mathrm{N} / \mathrm{a}$ \\
\hline$\frac{z}{0}$ & $\begin{array}{c}\text { Layer } \\
3\end{array}$ & Glass & 0.006 & 0.837 & 0.075 & 0.89 & 0.081 & 0.84 & 0.84 & 1.06 \\
\hline 3 & $\begin{array}{c}\text { Layer } \\
4\end{array}$ & $\begin{array}{l}\text { Air } \\
\text { Gap }\end{array}$ & 0.012 & N/a & N/a & N/a & N/a & $\mathrm{N} / \mathrm{a}$ & $\mathrm{N} / \mathrm{a}$ & $\mathrm{N} / \mathrm{a}$ \\
\hline & $\begin{array}{c}\text { Layer } \\
5\end{array}$ & Glass & 0.024 & 0.837 & 0.075 & 0.89 & 0.081 & 0.84 & 0.84 & 1.06 \\
\hline
\end{tabular}

$$
\mathrm{P}=\text { Parametric Property }
$$




\title{
Appendix E - Glossary of Terms
}

\author{
Term \\ EnergyPlus \\ An open-source energy modeling engine. Its \\ development is funded by the U.S. Department of \\ Energy's (DOE) Building Technologies Office \\ (BTO). \\ Grasshopper \\ A programming interface connected to Rhino that is \\ visual in nature and behaves like an interactive flow \\ chart where data is passed between block-like \\ functions or scripts. \\ Grasshopper Component \\ A script written in Python or equivalent coding \\ language that is represented in Grasshopper as a \\ visual cube that can be connected with data strings. \\ Honeybee \\ A group of components created for Grasshopper that \\ access a series of validated simulation engines \\ including EnergyPlus, Radiance and OpenStudio. \\ Ladybug \\ Ladybug Suite \\ A set of Grasshopper tools dedicated to climate \\ simulation, thermal comfort and data visualization. \\ A set of Grasshopper libraries including Ladybug, \\ Honeybee, Dragonfly and Butterfly. All dedicated to \\ building performance simulation. \\ Opossum \\ A Grasshopper component that uses RBFOpt \\ Pachyderm \\ RADIANCE \\ RBFOpt \\ algorithms. \\ An open-source raytracing simulation script for \\ acoustic modeling \\ An open-source raytracing simulation engine used to \\ conduct daylight analysis. \\ An open-source optimization algorithm developed \\ by IBM \\ Rhino or Rhinoceros \\ A 3D modeling program commonly used by \\ architects in the design development phase. \\ Stakeholders \\ A person or group of people who are involved and \\ effected by the outcome of a project; financially, \\ physically, culturally or ethically.
}

